US Army Corps

of Engineers ${ }_{\circledast}$

Engineer Research and

Development Center

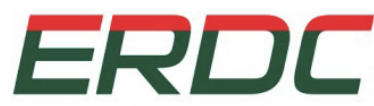

INNOVATIVE SOLUTIONS for a safer, better world

Aquatic Plant Control Research Program

\title{
Golden Algae Control: Efficacy of Hydraulic Manipulations in Coves of Lake Granbury
}

Daniel L. Roelke, Bryan W. Brooks, James P. Grover, April 2013 and Veronica M. Lundgren

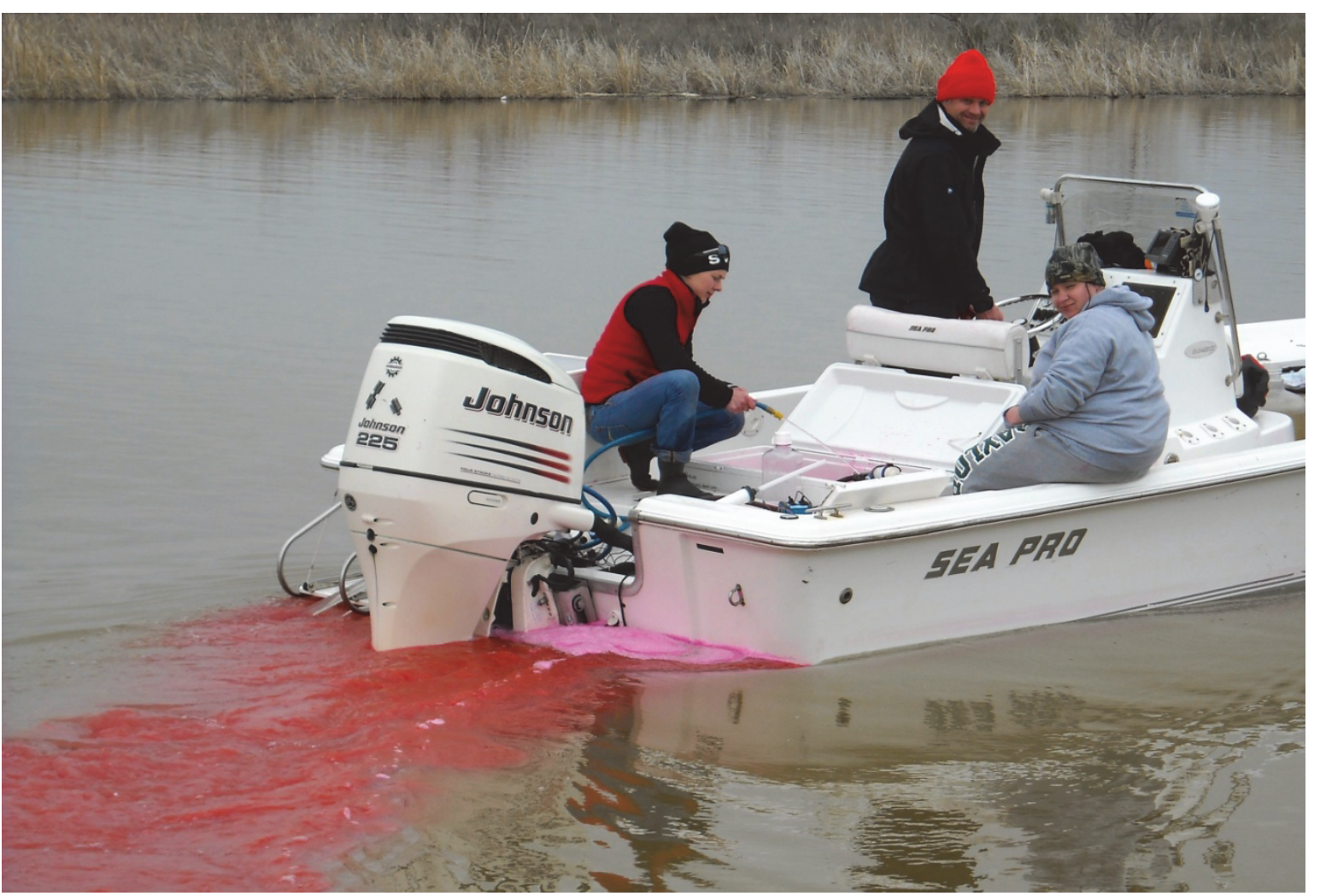


The US Army Engineer Research and Development Center (ERDC) solves the nation's toughest engineering and environmental challenges. ERDC develops innovative solutions in civil and military engineering, geospatial sciences, water resources, and environmental sciences for the Army, the Department of Defense, civilian agencies, and our nation's public good. Find out more at www.erdc.usace.army.mil.

To search for other technical reports published by ERDC, visit the ERDC online library at http://acwc.sdp.sirsi.net/client/default. 


\title{
Golden Algae Control: Efficacy of Hydraulic Manipulations in Coves of Lake Granbury
}

Daniel L. Roelke, Veronica M. Lundgren

Texas A\&M University, Texas AgriLife Research

Department of Wildlife and Fisheries Sciences

2258 TAMUS

College Station, TX 77843

Bryan W. Brooks

Baylor University

Center for Reservoir and Aquatic Systems Research

One Bear Place \#97266

Waco, TX 76798-7266

James P. Grover

University of Texas at Arlington

Department of Biology

Box 19498

Arlington, TX 76019-0001

Final report

Approved for public release; distribution is unlimited.

\author{
Prepared for U.S. Army Corps of Engineers \\ Washington, DC 20314-1000 \\ Under Work Unit 33143 \\ Monitored by U.S. Army Engineer Research and Development Center \\ 3909 Halls Ferry Road, Vicksburg, MS 39180-6199
}




\section{Abstract}

Bloom mitigation approaches employing deepwater flushing show great promise when targeting coves of Lake Granbury, USA. They may be limited, however, based on the natural water exchange rate between targeted coves and the surface waters of the open lake. This potential limitation was investigated by conducting dye-tracer studies that enabled direct measurement of water exchange rates. Historical data were also analyzed to explore the dissimilarity between coves and the open lake. Finally, a numerical model was built to estimate $P$. parvum bloom reduction levels under various deepwater flushing scenarios. Dye tracer studies involved timeseries, high-resolution spatial mapping of Rhodamine WT in three target coves. To complement spatial mapping, vertical profiling was performed at fixed-location stations throughout these coves. These combined processes allowed researchers to calculate the total amount of Rhodamine WT over time in these coves. From this information, natural water exchange rates between coves and surface waters of the open lake could be determined, and

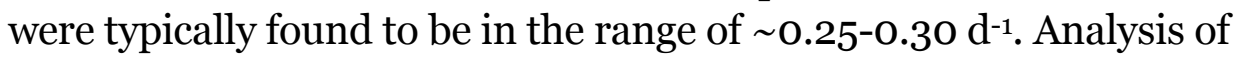
historical data utilized an extensive data set comprised of biotic and abiotic parameters from 10 coves and 10 open lake stations. The data record spanned multiple years with a once-per-month sampling frequency. Dissimilarity relationships (estimated from Euclidean distance measures) between coves and the open lake with changes in winds and inflows to the lake were examined. It was found that water exchanges with coves located lower in the lake were linked to winds and inflows. Mechanisms driving water exchanges with coves higher in the lake, however, are still not clear. Proposed management scenarios were depicted with deepwaters being pumped from the open lake to the upper regions of coves. Results suggest that $P$. parvum blooms can effectively be mitigated in cove habitats of Lake Granbury through managed deepwater hydraulic flushing. In some scenarios, blooms were reduced by $>70 \%$. The next steps in research aimed at further developing this mitigation approach should be a coupled study involving model refinement and a valuation study.

DISCLAIMER: The contents of this report are not to be used for advertising, publication, or promotional purposes. Citation of trade names does not constitute an official endorsement or approval of the use of such commercial products. All product names and trademarks cited are the property of their respective owners. The findings of this report are not to be construed as an official Department of the Army position unless so designated by other authorized documents. 


\section{Contents}

Abstract................................................................................................................................... ii

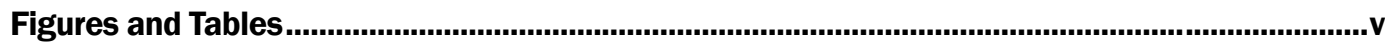

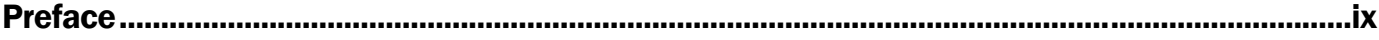

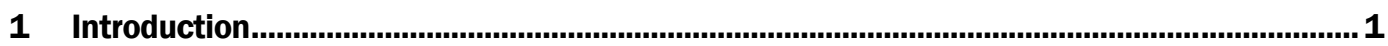

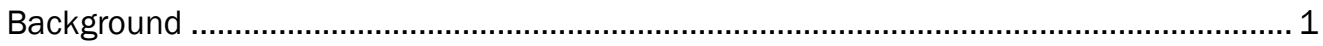

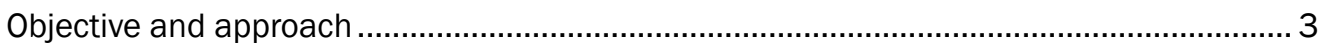

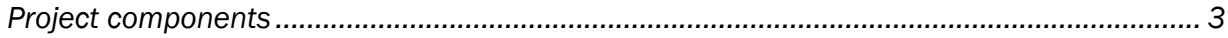

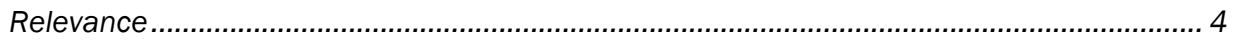

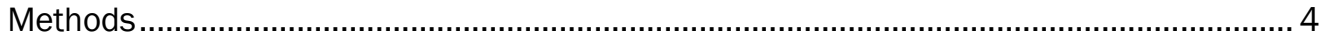

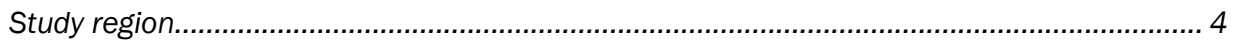

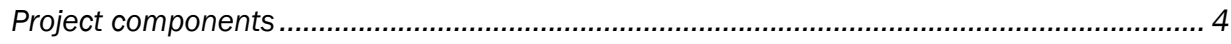

2 Technical Reporting and Discussion ...................................................................................19

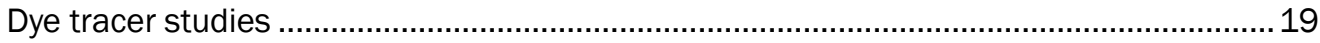

Rangers Slough (cove G, from below)........................................................................... 19

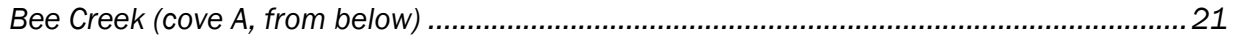

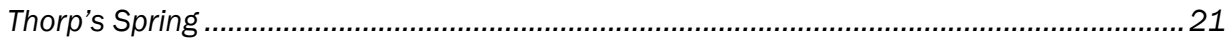

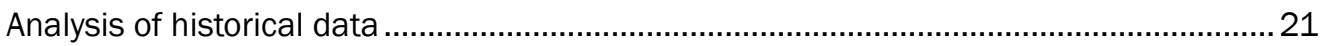

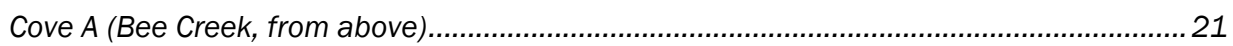

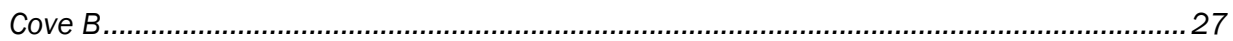

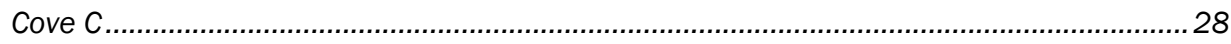

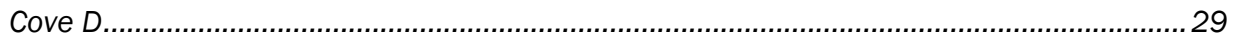

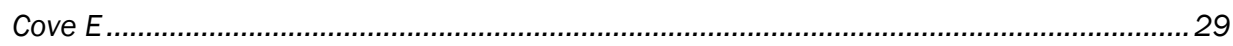

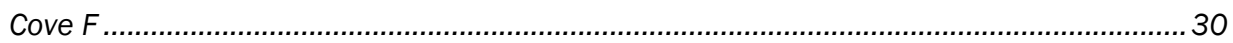

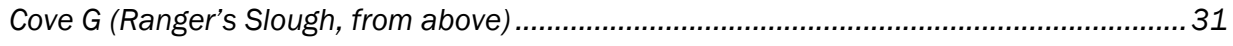

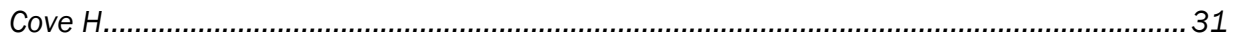

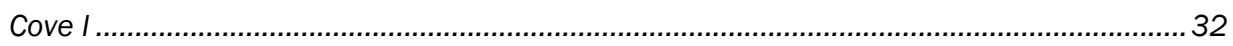

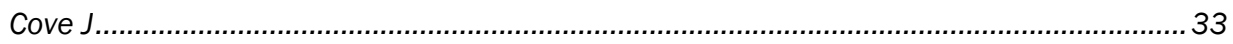

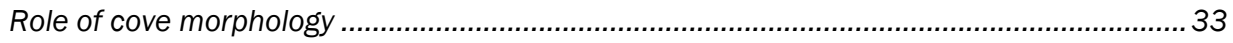

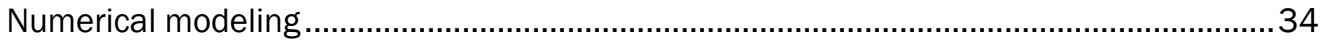

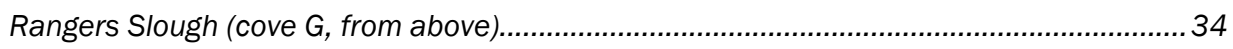

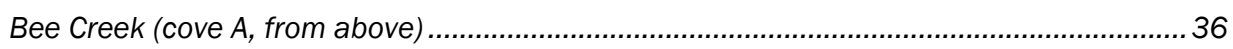

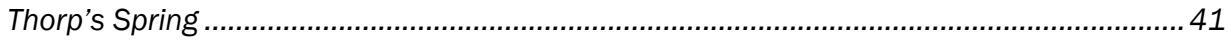

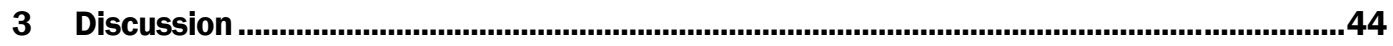

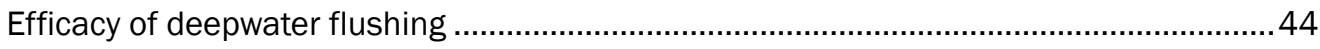

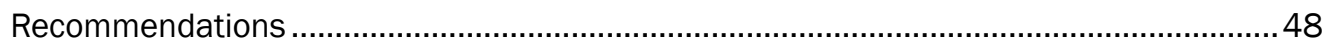

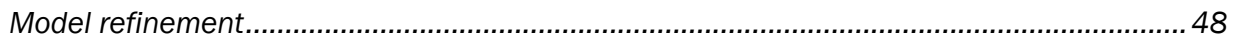

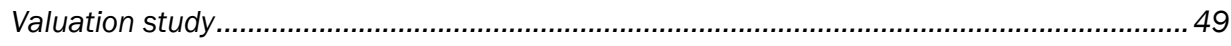

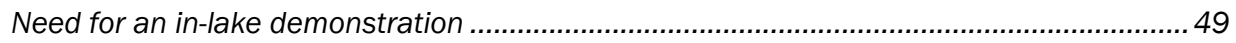




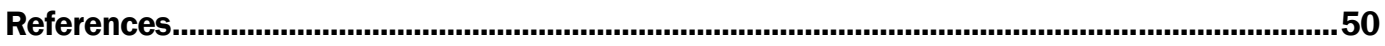

Appendix A: High-resolution Spatial Mapping of Rhodamine WT..........................................55

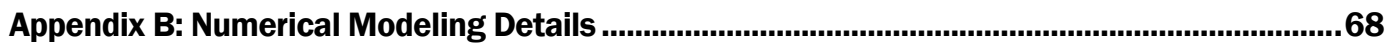

Appendix C: Dendrograms and Time-series Euclidean Distances .............................................

Report Documentation Page 


\section{Figures and Tables}

\section{Figures}

Figure 1. Lake Granbury (USA) where 5- to 7-day-long Rhodamine WT dissipation studies were conducted in three coves during February, April, and June 2012.

Figure 2. Lake Granbury (USA) where monthly monitoring was conducted from December 2007 through May 2010 at fixed location stations in the open lake (filled circles) and in adjoining coves (open squares).

Figure 3. Depth contours, cove volumes, and cove mouth cross-sectional areas for the coves of Lake Granbury (USA) from which historical data were used. 9

Figure 4. Depth contours, cove volumes, and cove mouth cross-sectional areas for the coves of Lake Granbury (USA) from which historical data were used..

Figure 5. Interactions represented by the biological reaction components of the model. Light blue arrows indicate positive, nutritional interactions and red arrows indicate negative, toxic interactions

Figure 6. Illustration of the coupled biological-physical model obtained by embedding the biological interactions represented in Figure 5 into the cove-main lake configuration.

Figure 7. Dynamics of $P$. parvum in the main lake compartment (solid line) predicted by the coupled biological-physical model with no flushing treatment imposed, after calibration to observations (solid circles)

Figure 8. Water column Rhodamine WT distribution $24 \mathrm{hr}$ after addition in Ranger's Slough, Lake Granbury (USA) during the third experiment (June 2012).

Figure 9. Total mass of Rhodamine WT in Ranger's Slough, Lake Granbury (USA) during tracer studies conducted in February (a), April (b), and June (c)...

Figure 10. Total mass of Rhodamine WT in Bee Creek, Lake Granbury (USA) during tracer studies conducted in February (a), April (b), and June (c).

Figure 11. Total mass of Rhodamine WT in Thorp's Spring, Lake Granbury (USA) during tracer studies conducted in February (a), April (b), and June (c)..

Figure 12. Biotic parameters from the historical data used in the dissimilarity analysis comparing cove $\mathrm{A}$ (solid lines) with the averages from stations 2 and 3 (dashed lines) including P. parvum (a), chlorophyll a (b), heterotrophic protozoa (c), copepod adults (d), copepod nauplii (e), cladocera (f), and rotifers (g).

Figure 13. Abiotic parameters from the historical data used in the dissimilarity analysis comparing cove A (solid lines) with the averages from stations 2 and 3 (dashed lines) including temperature (a), salinity (b), pH (c), Secchi depth (d), nitrate and nitrite summed, $\mathrm{NO}_{x}(\mathrm{e})$, ammonium, $\mathrm{NH}_{4}(\mathrm{f})$, total nitrogen, $\mathrm{TN}(\mathrm{g})$, soluble reactive phosphorus (h), and total phosphorus, TP (i).

Figure 14. Dendrograms comparing biotic (a) and abiotic (b) parameters from cove A and the averaged data from stations 2 and 3.

Figure 15. Time-series dissimilarity between biotic (a) and abiotic (b) parameters as estimated by the Euclidean distance for the comparison between cove station $A$ and open-lake stations 2 and 3 averaged. 
Figure 16. Scatter plots with linear model fits comparing the mouth cross-sectional area to volume ratio of each cove against the strength of the multivariate regression model that compared the dissimilarity between biotic (a) and abiotic (b) parameters between coves and open-lake stations with winds and inflows to the lake.

Figure 17. Illustrative time series of predicted $P$. parvum population density in Rangers Slough, with flushing treatments imposed intermittently (5 days out of 7 ), or continually (7 days out of 7 ).

Figure 18. Reduction of $P$. parvum in Rangers Slough for flushing treatment scenarios with intermittent pumping for short periods (1-3 days out of 7 ).

Figure 19. Reduction of $P$. parvum in Rangers Slough for flushing treatment scenarios with intermittent pumping for long periods (3-5 days on out of 7 ), or continual pumping ( 7 days on out of 7 )

Figure 20. Reduction of $P$. parvum in Bee Creek for flushing treatment scenarios with intermittent pumping for short periods (1-3 days out of 7 ).

Figure 21. Reduction of $P$. parvum in Bee Creek for flushing treatment scenarios with intermittent pumping for long periods (3-5 days out of 7 ), or continual pumping ( 7 days out of 7 ).

Figure 22. Reduction of $P$. parvum in Thorp's Spring for flushing treatment scenarios with intermittent pumping for short periods (1-3 days out of 7)

Figure 23. Reduction of $P$. parvum in Thorp's Spring for flushing treatment scenarios with intermittent pumping for long periods ( $3-5$ days out of 7 ), or continual pumping ( 7 days out of 7).

Figure A1. Rhodamine WT dissipation experiments were conducted in Ranger's Slough

(a), Bee Creek (b), and Thorp's Spring (c), Lake Granbury (USA).

Figure A2. Rhodamine WT distribution in Ranger's Slough during the first experiment (February) on days one (a), two (b), three (c), four (d), five (e), and six (f).

Figure A3. Rhodamine WT distribution in Ranger's Slough during the second experiment (April) on days one (a), two (b), three (c), and four (d).

Figure A4. Rhodamine WT distribution in Ranger's Slough during the second experiment (April) on days five (e), six (f) and seven (g).....

Figure A5. Rhodamine WT distribution in Ranger's Slough during the third experiment (June) on days one (a), two (b), three (c), and four (d).

Figure A6. Rhodamine WT distribution in Ranger's Slough during the third experiment (June) on days five (e), six (f), and seven (g).

Figure A7. Rhodamine WT distribution in Bee Creek during the first experiment (February) on days one (a), two (b), three (c), four (d), and five (e).

Figure A8. Rhodamine WT distribution in Bee Creek during the second experiment (April) on days one (a), two (b), three (c), four (d), five (e), six (f), and seven (f).

Figure A9. Rhodamine WT distribution in Bee Creek during the third experiment (June) on days one (a), two (b), three (c), four (d), five (e), and six (f).

Figure A10. Rhodamine WT distribution in Thorp's Spring during the first experiment (February) on days one (a), two (b), three (c), and four (d).

Figure A11. Rhodamine WT distribution in Thorp's Spring during the second experiment (April) on days one (a), two (b), three (c), four (d), and five (e).

Figure A12. Rhodamine WT distribution in Thorp's Spring during the third experiment (June) on days one (a), two (b), three (c), four (d), five (e), and six (f). 
Figure $\mathrm{C} 1$. Dendrograms comparing biotic (a) and abiotic (b) parameters from cove A and the averaged data from stations 2 and 3.

Figure C2. Time-series dissimilarity between biotic (a) and abiotic (b) parameters as estimated by the Euclidean distance for comparison of the average values for cove A and stations 2 and 3 .

Figure C3. Dendrograms comparing biotic (a) and abiotic (b) parameters from cove B and the averaged data from stations 2 and 3.

Figure C4. Time-series dissimilarity between biotic (a) and abiotic (b) parameters as estimated by the Euclidean distance for the comparison of average values for cove $B$ and stations 2 and 3 .

Figure $\mathrm{C} 5$. Dendrograms comparing biotic (a) and abiotic (b) parameters from cove $\mathrm{C}$ and the averaged data from stations 2 and 3 .

Figure C6. Time-series dissimilarity between biotic (a) and abiotic (b) parameters as estimated by the Euclidean distance for the comparison between average values for cove $C$ and stations 2 and 3 .

Figure C7. Dendrograms comparing biotic (a) and abiotic (b) parameters from cove D and the averaged data from stations 2 and 3 .

Figure C8. Time-series dissimilarity between biotic (a) and abiotic (b) parameters as estimated by the Euclidean distance for the comparison between average values for cove D and stations 2 and 3.

Figure C9. Dendrograms comparing biotic (a) and abiotic (b) parameters from cove $\mathrm{E}$ and the averaged data from stations 2 and 3.

Figure $\mathrm{C10}$. Time-series dissimilarity between biotic (a) and abiotic (b) parameters as estimated by the Euclidean distance for the comparison between average values for cove E and stations 2 and 3.

Figure $\mathrm{C} 11$. Dendrograms comparing biotic (a) and abiotic (b) parameters from cove $\mathrm{F}$ and the averaged data from stations 4 and 5 .

Figure $\mathrm{C} 12$. Time-series dissimilarity between biotic (a) and abiotic (b) parameters as estimated by the Euclidean distance for the comparison between average values for cove $\mathrm{F}$ and stations 4 and 5 .

Figure $\mathrm{C} 13$. Dendrograms comparing biotic (a) and abiotic (b) parameters from cove $\mathrm{G}$ and the averaged data from stations 4 and 5 .

Figure $\mathrm{C} 14$. Time-series dissimilarity between biotic (a) and abiotic (b) parameters as estimated by the Euclidean distance for the comparison between average values for cove $\mathrm{G}$ and stations 4 and 5 .

Figure C15. Dendrograms comparing biotic (a) and abiotic (b) parameters from cove $\mathrm{H}$ and the averaged data from stations 6 and 7 .

Figure $\mathrm{C} 16$. Time-series dissimilarity between biotic (a) and abiotic (b) parameters as estimated by the Euclidean distance for the comparison between average values for cove $\mathrm{H}$ and stations 6 and 7 ...

Figure C17. Dendrograms comparing biotic (a) and abiotic (b) parameters from cove I and the averaged data from stations 8 and 9 .

Figure $\mathrm{C} 18$. Time-series dissimilarity between biotic (a) and abiotic (b) parameters as estimated by the Euclidean distance for the comparison between average values for cove I and stations 8 and 9 .

Figure C19. Dendrograms comparing biotic (a) and abiotic (b) parameters from cove J and the data from station 10 
Figure C20. Time-series dissimilarity between biotic (a) and abiotic (b) parameters as estimated by the Euclidean distance for the comparison between cove $\mathrm{J}$ and station 10

\section{Tables}

Table 1. Volume and flow characteristics of coves simulated for the sensitivity analysis of the biological-physical mode.

Table 2. Multiple linear regression analysis of the relationship between daily water exchange rate, 24-hr wind speed and direction, and 24-hr inflow to Lake Granbury for the three Ranger's Slough experiments combined.

Table 3. Multiple linear regression analysis of the relationship between daily water exchange rate, 24-hr wind speed and direction, and 24-hr inflow to Lake Granbury for the three Bee Creek experiments combined.

Table 4. Multiple linear regression analysis of the relationship between daily water exchange rate, 24-hr wind speed and direction, and 24-hr inflow to Lake Granbury for the three Thorp's Spring experiments combined.

Table 5. The best fit multiple linear regression analysis of the relationship between the abiotic and biotic Euclidean dissimilarity, wind speed and direction, and inflow to Lake Granbury for cove A.

Table 6. Best fit multiple linear regression analysis of the relationship between the abiotic and biotic Euclidean dissimilarity, wind speed and direction, and inflow to Lake Granbury for cove $\mathrm{B}$.

Table 7. The best fit multiple linear regression analysis of the relationship between the abiotic and biotic Euclidean dissimilarity, wind speed and direction, and inflow to Lake Granbury for cove C.

Table 8. The best fit multiple linear regression analysis of the relationship between the abiotic and biotic Euclidean dissimilarity, wind speed and direction, and inflow to Lake Granbury for cove D.

Table 9. The best fit multiple linear regression analysis of the relationship between the abiotic and biotic Euclidean dissimilarity, wind speed and direction, and inflow to Lake Granbury for cove E.

Table 10. The best fit multiple linear regression analysis of the relationship between the abiotic and biotic Euclidean dissimilarity, wind speed and direction, and inflow to Lake Granbury for cove F.

Table 11. The best fit multiple linear regression analysis of the relationship between the abiotic and biotic Euclidean dissimilarity, wind speed and direction, and inflow to Lake Granbury for cove $\mathrm{G}$.

Table 12. The best fit multiple linear regression analysis of the relationship between the abiotic and biotic Euclidean dissimilarity, wind speed and direction, and inflow to Lake Granbury for cove $\mathrm{H}$.

Table 13. The best fit multiple linear regression analysis of the relationship between the abiotic and biotic Euclidean dissimilarity, wind speed and direction, and inflow to Lake Granbury for cove I.

Table 14. The best fit multiple linear regression analysis of the relationship between the abiotic and biotic Euclidean dissimilarity, wind speed and direction, and inflow to Lake Granbury for cove J.

Table B1. Notation, units, and parameter values. 


\section{Preface}

This technical report was developed to convey the results of in-lake tracer experiments, historical data analyses, and numerical modeling conducted as part of a project titled "Golden algae control: Efficacy of hydraulic manipulations in coves of Lake Granbury." This project was supported by Congress with funding through the U.S. Army Corps of Engineers, Aquatic Plant Control Research Program, Dr. Linda Nelson, Program Manager. This report was published by the U.S. Army Engineer Research and Development Center (ERDC), Vicksburg, Mississipppi.

The report was prepared by the project scientists, Drs. Daniel Roelke and Veronica Lundgren of Texas A\&M University, Bryan Brooks of Baylor University, and James Grover of the University of Texas at Arlington. The project scientists also conducted the field component of this project with assistance from graduate students (Krista Prosser and Casan Scott of Baylor University, Coridon Laws of the University of Texas at Arlington, and George Umphres of Texas A\&M University). Dr. Roelke was the principal investigator of the project.

At the time of publication of this report, ERDC Commander was COL Kevin J. Wilson. ERDC Director was Dr. Jeffery P. Holland. 


\section{Introduction}

\section{Background}

Harmful algal blooms (HABs) have increased in frequency, duration, and magnitude worldwide (Smayda 1990, Hallegraeff 1993) and produce deleterious effects ranging from fish kills to human health risks (Van Dolah et al. 2001). Unfortunately, environmental conditions leading to HABs are complex and often species-specific, making it difficult to develop a universal approach to management (Anderson and Garrison 1997, Roelke 2000, Roelke and Buyukates 2001, Maso and Garcés 2006).

The haptophyte Prymnesium parvum (golden algae) is an HAB-causing species, which occurs worldwide and is responsible for large fish kills in coastal and inland water bodies (Moestrup 1994, Edvardsen and Paasche 1998). Recent studies suggest mechanisms by which $P$. parvum might gain a selective advantage over other phytoplankton, thereby allowing bloom formation. One such mechanism is the production of toxins released into the water column where they impact fish, phytoplankton, zooplankton, and bacteria (Ulitzur and Shilo 1964, Igarashi et al. 1995, Nygaard and Tobiesen 1993, Tillmann 2003, Fistarol et al. 2003, Rosetta and McManus 2003, Barreiro et al. 2005, Baker et al. 2007, 2009). Some of the toxins apparently act as allelopathic substances that inhibit the growth of competing phytoplankton, and also act as grazer inhibitors (Fistarol et al. 2003; Sopanen et al. 2006; Roelke et al. 2007, 2010; Brooks et al. 2010).

A $P$. parvum bloom was confirmed along the Pecos River, Texas (USA) in 1985 (James and De La Cruz 1989). Subsequently, P. parvum blooms in southcentral USA have affected over 21 lakes in five river basins, killing millions of sport fish and resulting in millions of dollars in economic impact. In Texas, the majority of the P. parvum damage occurred over the last 10 years (Southard et al. 2010, Roelke et al. 2011). Nationwide, $P$. parvum is now documented in 17 states, mostly in the southern regions (Sager et al. 2008, Roelke et al. 2011), but with toxic blooms also now occurring in northern regions (Brooks et al. 2011).

Although factors controlling $P$. parvum blooms in lakes of the southcentral United States are complex and partially unknown, the research documented in this report has significantly advanced understanding of $P$. parvum 
dynamics in inland waters. However, there appears to be a link between eutrophication, salinization, and the appearance of $P$. parvum blooms. Blooms in Europe (Holdway et al. 1978, Kaartvedt et al. 1991, Amsinck et al. 2005), the Middle East (van Rijn and Shilo 1989), and Asia (Krasnotshchek and Abramowitsch 1971, Guo et al. 1996) have all occurred in aquatic systems that were eutrophic and brackish. $P$. parvum blooms in the southcentral United States have appeared only in lakes with a higher salt content (>1 psu) (Texas Parks and Wildlife Department (TPWD) 2003). Although P. parvum is present in lakes with lower salt content, no blooms have been recorded.

Over the past few years, the research team has closely examined $P$. parvum dynamics in Lake Granbury, an impoundment on the Brazos River in central Texas. The Lake Granbury fishery has experienced significant impacts by P. parvum blooms, resulting in a societal impetus for development of viable environmental management approaches in a timely fashion. Fortunately, relatively recent observations have provided information that may allow for the development of $P$. parvum mitigation options in Lake Granbury and other inland waters. These include hydraulic flushing with lake deepwaters (Hayden et al. 2012, Roelke et al. 2012a).

The research team identified that hydraulic flushing and its associated nutrient loading in Lake Granbury terminate system-wide, fish-killing $P$. parvum blooms (Roelke et al. 2010, 2011). The research team also identified that hydraulic dilution (in the absence of flushing) and its associated nutrient loading in Lake Whitney terminated a fish-killing P. parvum bloom in April 2007 (Schwierzke-Wade et al. 2011). Subsequently, it was hypothesized that targeted management of reservoir inflows and hydraulic flushing rates could mitigate $P$. parvum blooms.

A limitation to this approach, however, would be available water upstream of the impacted area. To avoid this, it was suggested that deepwaters of a lake, free of $P$. parvum cells, could be pumped to the surface to affect blooms in the same way that external inflows do. This notion was successfully tested using in-lake mesocosm experiments (Hayden et al. 2012, Roelke et al. 2012a), a project funded by the US Army Corps of Engineers (USACE) in 2010-11. Briefly, it was found that $P$. parvum cell density was reduced by $69 \%$ and ambient toxicity was completely ameliorated during the period of bloom initiation in the lake. During conditions of bloom 
maturation, population density was reduced by $53 \%$, toxicity by $57 \%$, and bloom proportions were never reached.

This deep-water pumping had minimal effect on phytoplankton and zooplankton, and little effect on water quality. Shifts towards more rapidly growing phytoplankton taxa were observed, as was enhanced abundance of copepod nauplii. In other words, while inflows using deep waters suppressed P. parvum bloom initiation and development, they were benign to other aspects of the lower food web and environment, an appealing outcome for a potential management approach (Hayden et al. 2012, Roelke et al. 2012a).

While bloom mitigation approaches employing deepwater flushing show great promise when targeting coves of a lake, they may be limited based on the natural surface water exchange rate between targeted coves and the mainstem of a lake. For example, if the natural surface water exchange rate is too great, the effects of deepwater flushing of a cove may be masked. If natural surface water exchange rates are not excessive, however, then hydraulic manipulations in selected coves might lead to creation of refugia from $P$. parvum blooms. This would greatly accelerate recovery of flora and fauna in the lake after $P$. parvum blooms subside, including economically important fisheries in the region.

\section{Objective and approach}

The narrative below describes results from a project that addressed the issue of water exchange between coves and the mainstem of a lake.The objective of this project was to identify a cove selection process in which inlake demonstrations of $P$. parvum bloom mitigation could be conducted.

\section{Project components}

The project was accomplished by:

1. Directly measuring water exchange rates between coves and natural surface waters of the open lake, and exploring relationships between water exchange, wind speed and direction, and inflow to the lake.

2. Determining seasonal differences between plankton community composition and water quality observed in coves and open lake waters based on wind speed and direction, and inflow to the lake. 
3. Determining the sensitivity of $P$. parvum bloom formation under conditions of managed deepwater flushing of coves to the rate of natural surface water exchange between coves and open waters of the lake.

\section{Relevance}

P. parvum blooms are rapidly spreading, and their proliferation is anticipated to get worse with climate change and human population growth (Roelke et al. 2011, 2012b). This research furthered understanding of a potential P. parvum mitigation strategy that would involve hydraulic manipulations of coves, e.g. deepwater hydraulic flushing. As mentioned above, this approach was successfully tested in enclosure experiments conducted within the lake (Hayden et al. 2012, Roelke et al. 2012a). An issue of uncertainty facing further development of this mitigation strategy must address uncertainty regarding the duration that cove treatments would remain effective. This duration is linked to the rate at which cove waters naturally exchange with surface waters of the open lake. With this knowledge, coves targeted for creation of refuge habitat can better be selected.

\section{Methods}

\section{Study region}

Lake Granbury is a reservoir on the Brazos River, Texas, USA, constructed in 1969. The lake has a capacity of $167 \times 10^{6} \mathrm{~m}^{3}$, a surface area of $34 \mathrm{~km}^{2}$, and an average depth of $\sim 5 \mathrm{~m}$. The shoreline follows the meandering river channel with an elongated, sinuous basin oriented northwest to southeast that is $\sim 45 \mathrm{~km}$ long and has an average width of $0.6 \mathrm{~km}$. Daily discharges from the Brazos River into the lake are measured at a location upstream from the lake (Dennis, Texas, USGS Station Number 0809080o). Wind speed and direction are routinely measured at the Granbury Regional Airport with data made available through the Local Weather Exchange Network (station KGDJ). For purposes of this research, wind data were converted into north-south and east-west vectors.

\section{Project components}

1. Directly measuring water exchange rates between coves and natural surface waters of the open lake, and exploring relationships between water exchange, wind speed and direction, and inflow to the lake. 
Studies were conducted in three coves, where the water exchange rate was measured daily over a period of 5-7 days. Each cove was investigated thrice: during the typical periods of bloom development (February); bloom decline (April); and post-bloom (June). Daily water exchange rates were monitored over a 5-7-day period because previous research employed a similar periodicity (Hayden et al. 2012, Roelke et al. 2012a).

Study coves for this project component were Ranger's Slough, Bee Creek, and Thorp's Spring (Figure 1). These coves were selected based on their restricted connection to the mainstem of the lake and their larger size. Their restricted connectivity likely increases the probability of longer hydraulic residence times, thereby increasing the probability for success of future bloom mitigation. Their larger size likely makes for more effective refuge habitat able to shelter larger populations, thereby accelerating the recovery rate of populations impacted by blooms in other areas of the lake.

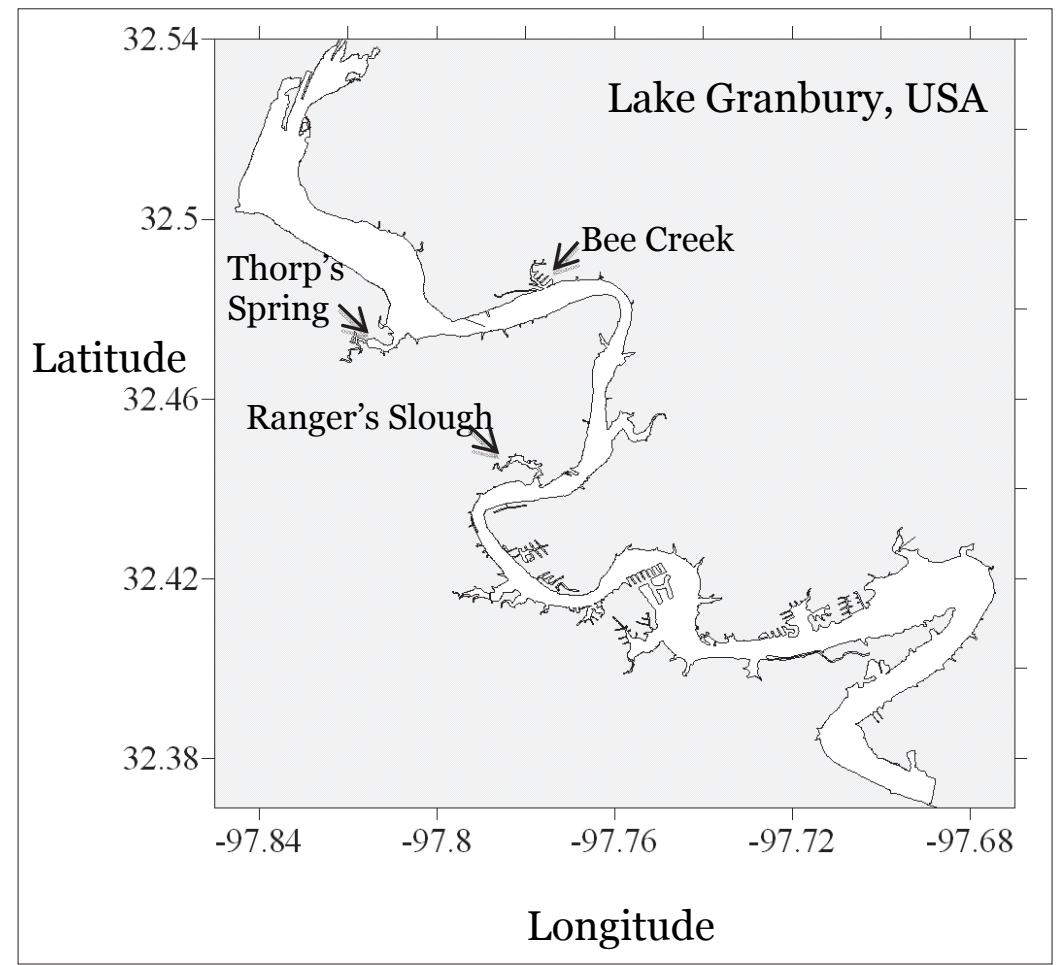

Figure 1. Lake Granbury (USA) where 5- to 7-day-long Rhodamine WT dissipation studies were conducted in three coves during February, April, and June 2012.

The horizontal and vertical dissipation of a fluorescent tracer, Rhodamine WT (Abbey Color, Inc.), was measured in order to estimate the water exchange rate. Rhodamine WT is routinely used for water tracer studies, and is benign to aquatic organisms. Because of its fluorescing 
characteristics, it was detectable by fluorometer at very low concentrations ( $0.5 \mathrm{ppb})$. The amount of Rhodamine WT needed to start each tracer experiment was determined based on the bathymetry and depth of the target coves, which enabled calculation of cove volumes (see Dataflow methods below). To start each experiment, background fluorescence was first determined followed by tracer addition. The tracer was added by slowly pumping the solution into the boat motor's outwash as the boat followed closely spaced transects through the target coves (see Figure A1). This resulted in a fairly uniform starting condition.

Horizontal Rhodamine WT distribution was estimated daily using highresolution spatial mapping technology. Dataflow, a high-speed, flowthrough measurement apparatus developed for mapping physicochemical parameters in shallow aquatic systems was used for this purpose (Madden and Day 1992). The Dataflow configuration allowed concurrent measurement of depth, multiple water quality parameters, and Rhodamine WT. Measurements were taken at 3 -second intervals from $\sim 20 \mathrm{~cm}$ below the surface. An integrated GPS was used to simultaneously record sample locations. GPS data and Dataflow information were then used to create gridded data files (Surfer v8.0). These data files were then used to create detailed contour maps showing the surface layer distribution of Rhodamine WT (Figures A2-A10).

Vertical Rhodamine WT distribution was estimated daily by vertical profiling of Rhodamine WT using data sondes equipped with filter sets designed for detection of this tracer (YSI, Inc). Multiparameter data sondes were used to collect basic water quality information (e.g., dissolved oxygen, temperature, $\mathrm{pH}$, specific conductance), which allowed for determination of chemoclines and thermoclines to support numerical modeling of coves. Fixed station locations were established throughout each cove for this purpose (see Figure A1). Another gridded data file was then generated expressing the ratio of total Rhodamine WT in the water column to the surface Rhodamine WT concentration at each of the fixed stations.

Total mass of Rhodemine WT in the target coves was determined by combining the gridded high-resolution spatial mapping of surface waters with the gridded vertical profiling data,using the gridding functions of a commercial software package (Surfer v8.o). An exponential decay function was then fit through the times series data of total Rhodamine WT (KaleidaGraph 4.0), where the exponent coefficient reflected the rate of water exchange. 
Relationships between cove-open lake water exchange, wind speed and direction, and inflow were investigated using multiple linear regression (SPSS v20.0). For this analysis, the 24-hr water exchange rate for each cove was calculated using:

$$
E=\frac{\ln \left(\frac{R d_{t+24}}{R d_{t}}\right)}{t}
$$

where

$$
\begin{aligned}
E & =\text { water exchange rate }\left(\mathrm{d}^{-1}\right) \\
R d_{t} & =\text { total mass of Rhodamine WT in the target cove }(\mathrm{kg}) \\
R d_{t+24} & =\text { total mass of Rhodamine WT } 24 \text { hrs later }(\mathrm{kg}) \\
t & =\text { time }(\mathrm{d})
\end{aligned}
$$

Wind and inflow data used in this analysis were the 24-hr averages prior to the time of sampling, with wind data split into its north-south and eastwest vectors. One multivariate linear regression was performed for each target cove, i.e. all daily estimates of water exchange rates from all three experiments were gathered into one analysis. This resulted in a total of 17, 15, and 12 observations for Rangers Slough, Bee Creek, and Thorps Spring, respectively.

Note that this approach to estimating daily water exchange assumed that photolysis and absorption of Rhodamine WT over $24 \mathrm{hr}$ were not significant. In other words, reduction in total Rhodamine WT in the coves was due to hydraulic dispersal of the dye into the open lake only. Previous studies quantifying photolysis and absorption of Rhodamine WT concluded that these mechanisms did not affect estimation of hydraulic processes (Tai and Rathbun 1988, Upstill-Goddard et al. 2001, Keefe et al. 2004, Dierberg and DeBusk 2005). Regarding photolysis, it was concluded that accounting for its effects would be necessary if experiments lasted several months to years (Suijlen and Buyse 1994), periods much longer than the 24-hr period used here.

2. Determining seasonal differences between plankton community composition and water quality observed between coves and open lake waters in Lake Granbury based on the surmised rate of natural surface water exchange. 
The study used historical data collected in Lake Granbury where concurrent measurements were taken at 10 stations located along the mainstem of the lake (labeled stations 1 through 10) and 10 stations located in connecting coves (labeled stations A through $\mathrm{J}$ ), see Figures 2 and 3. Note that cove $\mathrm{G}$ is the same as Ranger's Slough and cove A is the same as Bee Creek. Sampling occurred monthly during this previous monitoring, but not continuously, over the period of December 2007 through May 2010. Sampling was not performed during November 2008, September through December 2009, and March 2010.

For each of the historical sampling trips, parameters measured included characterizations of the plankton (total phytoplankton biomass as chlorophyll $a$, $P$. parvum population density and zooplankton community composition), nutrients (nitrate and nitrite summed, $\mathrm{NO}_{\mathrm{x}}$; ammonium, $\mathrm{NH}_{4}$; total nitrogen, TN; soluble reactive phosphorus, SRP; and total phosphorus, TP) and water quality (temperature, $\mathrm{pH}$, salinity, and Secchi depth). This historical record was generated from multiple previous projects that were funded by Texas Parks and Wildlife (Brooks, lead PI) and the Department of Energy (Roelke, lead PI).

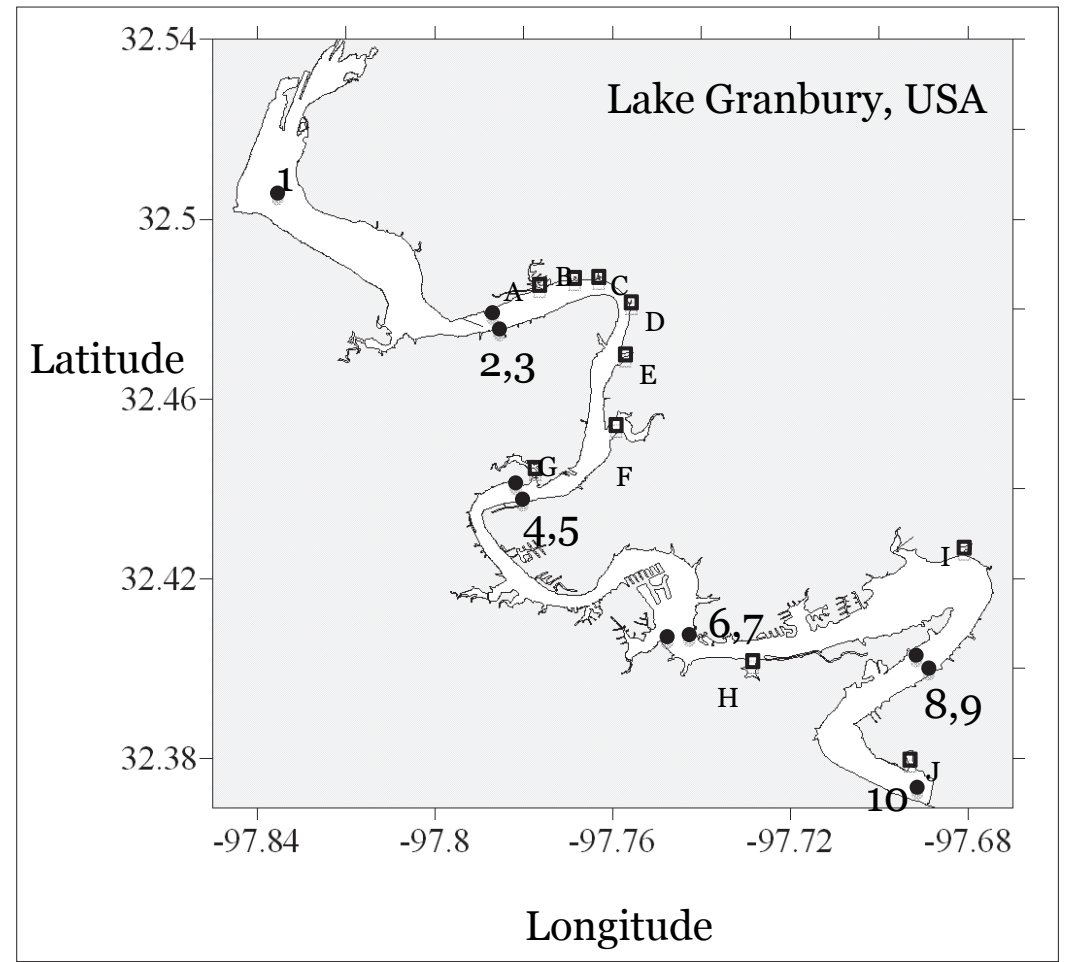

Figure 2. Lake Granbury (USA) where monthly monitoring was conducted from December 2007 through May 2010 at fixed location stations in the open lake (filled circles) and in adjoining coves (open squares). Note, station A was located within Bee Creek cove and station $G$ was located within Ranger's Slough cove. 

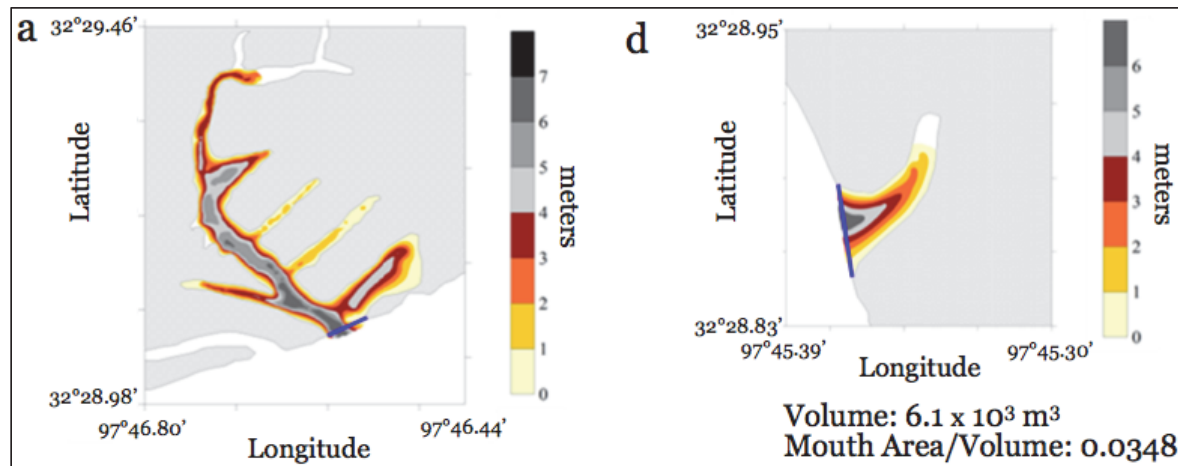

Volume: $6.1 \times 10^{3} \mathrm{~m}^{3}$

Mouth Area/Volume: 0.0348

Volume: $313 \times 10^{3} \mathrm{~m}^{3}$

Mouth Area/Volume: 0.0011
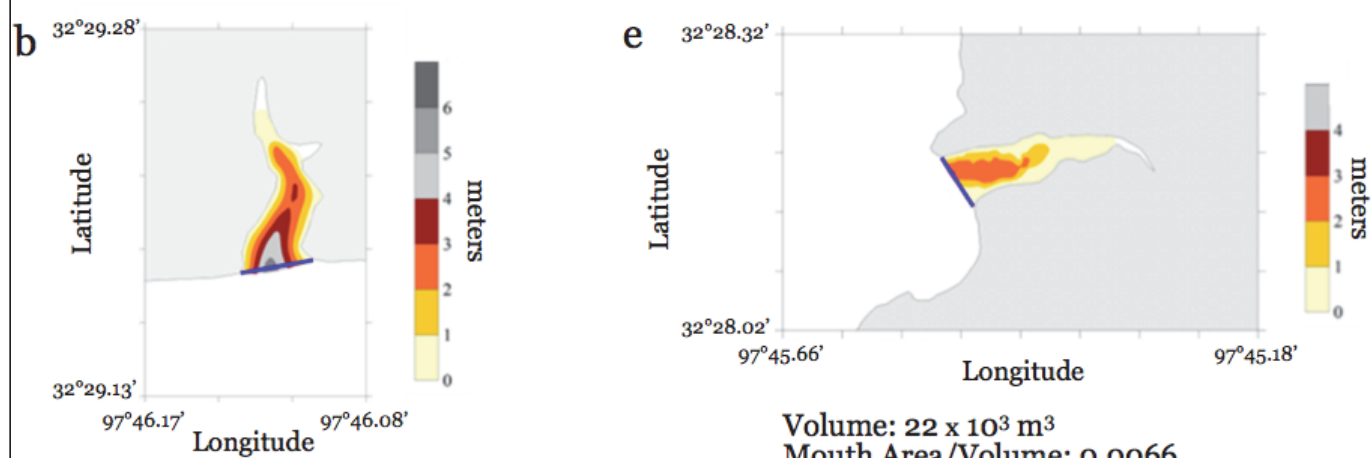

Volume: $6.3 \times 10^{3} \mathrm{~m}^{3}$

Mouth Area/Volume: 0.0226

Volume: $22 \times 10^{3} \mathrm{~m}^{3}$

Mouth Area/Volume: 0.0066

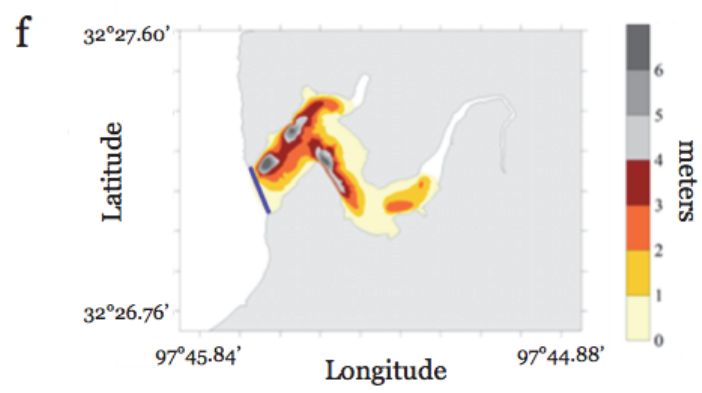

Volume: $501 \times 10^{3} \mathrm{~m}^{3}$

Mouth Area/Volume: 0.0003

Volume: $8.1 \times 10^{3} \mathrm{~m}^{3}$

Mouth Area/Volume: 0.0210

Figure 3. Depth contours, cove volumes, and cove mouth cross-sectional areas for the coves of Lake Granbury (USA) from which historical data were used. These locations correspond to sample station locations identified in Figures 1 and 2 as follows: cove $A$, also called Bee Creek (a); cove B (b); cove C (c); cove D (d); cove E (e); and cove F (f). Locations of cove mouths are identified with blue lines.

To complement this historical data, a bathymetry characterization of these coves was performed, with the exception of cove $\mathrm{H}$ (due to an orientation error). This was achieved using the Dataflow apparatus described previously. Depth data collected along the closely spaced boat transects 
through each of these coves enabled construction of depth contour maps. For the contour maps, cove volumes and cross-sectional areas of the cove mouths were determined (Surfer v8.o).

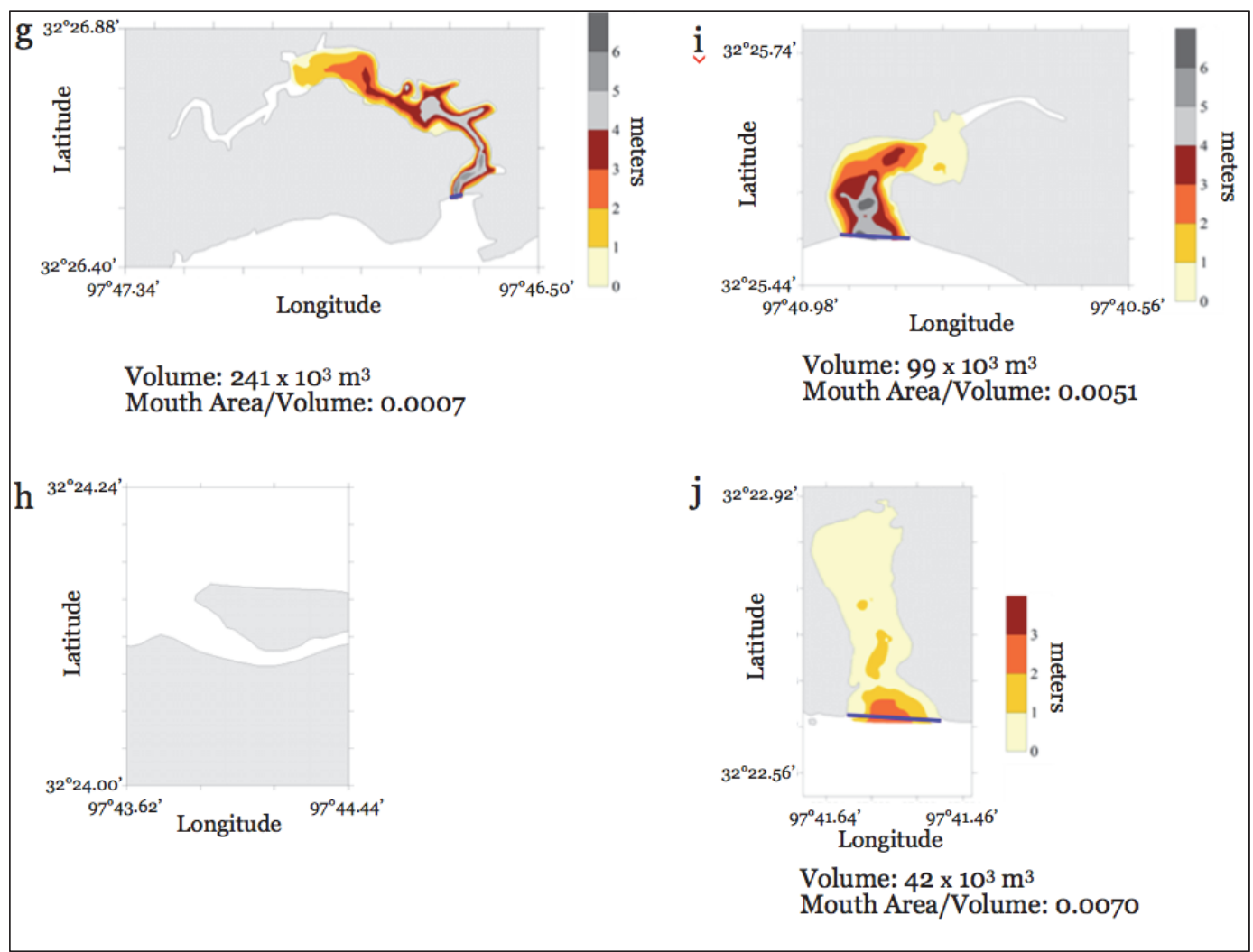

Figure 4. Depth contours, cove volumes, and cove mouth cross-sectional areas for the coves of Lake Granbury (USA) from which historical data were used. These locations correspond to sample station locations identified in Figures 1 and 2 as follows: cove G, also called Ranger's Slough (g); cove H (h); cove I (i); and cove J (j). Cove mouths are identified with blue lines.

The Euclidean distance metric was used to estimate the dissimilarity between coves and the closest station location from the mainstem of the lake. This allowed researchers to quantitatively assign a dissimilarity value between station pairs over time, where greater Euclidean distances signified greater dissimilarity. Prior to this analysis, data were transformed by z-score.

Data from cove stations A-E were paired with the averaged data from open lake stations 2 and 3 . Data from cove stations $\mathrm{F}$ and $\mathrm{G}$ were paired with the averaged data from open lake stations 4 and 5 . Data from cove station $\mathrm{H}$ were paired with the averaged data from open lake stations 6 and 7; data from cove station I were paired with the averaged data from open lake 
stations 8 and 9; and data from cove station $\mathrm{J}$ were paired with data from open lake station 10.

Hierarchical clustering was used to graphically display these dissimilarities for each cove and the nearest open lake stations (see Appendix C). This resulted in 10 cluster analyses (representing each cove-open lake station pair) focused on the biotic parameters and 10 cluster analyses focused on the abiotic parameters. Each cluster analysis had 48 observations, representing 24 observations in the cove and 24 in the open lake over the period of monitoring.

In the resulting hierarchy of clusters represented in the dendrograms, the numbers 1-24 were used to represent the time-series sampling of the cove station. That is, ' 1 ' represented the sampling in the cove during December 2007, ' 2 ' represented the sampling in the cove during January 2008, and so forth, with ' 24 ' representing the last cove sampling during May 2010. A similar notation was followed for the paired open lake samplings using the numbers 25-48.

The dissimilarity between cove-open lake stations was then compared to wind speed and direction, and inflow to the lake. This relationship was assessed using multiple linear regressions. This enabled evaluation of the relative importance of wind speed and direction, and inflow. This analysis explored all combinations of winds averaged over 24, 48, and $72 \mathrm{hr}$ prior to the time of sampling and inflows averaged over 7,15 , and 30 days. This document reports only on the wind-inflow combination for each coveopen lake station pair that explained the greatest amount of variability. Finally, scatter plots were used to compare the strength of the multivariate regression models to the cove mouth cross-sectional area to volume ratio.

3. Determining the sensitivity of $\mathrm{P}$. parvum bloom formation under conditions of managed deepwater flushing in coves of Lake Granbury to the rate of natural surface water exchange between coves and the mainstem of Lake Granbury.

The efficacy of deepwater flushing to mitigate $P$. parvum blooms in coves was assessed using numerical models that encompassed the range of water exchange rates documented in the in-lake tracer experiment studies (described above). These modeling studies also addressed a range of 
scenarios for other biological and limnological factors that affect the population dynamics of $P$. parvum.

The starting point for this modeling was a "chemostat" (or continuouslystirred tank reactor) model of the population dynamics of $P$. parvum and varying numbers of competing algae. This model permitted forcing of population dynamics by known relationships of $P$. parvum growth rate to temperature, salinity, and nutrient concentration (Baker et al. 2007, 2009). This model was previously applied to population dynamics of $P$. parvum in Lake Granbury, and results of that research are documented in Grover et al. (2010). Since that document was published, modeling has been improved by adding representations of toxin production by $P$. parvum and zooplankton grazing on algae (Grover et al. 2011, 2012).

For this study, the updated model was embedded in the "cove-main lake" setting developed by Grover et al. (2011). This modeling context coupled two chemostat models, one representing the mainstem of a large lake and the other a cove, and allowed for setting flows in both segments and exchanges between them, to represent observed rates. Therefore the model used is a coupled biological-physical model focused on evaluating bloom dynamics within coves.

The biological component of the model included several interactions and reactions known or suspected to be important to the bloom dynamics of $P$. parvum (Figure 5). Two nutrients, nitrate and phosphate, are consumed by P. parvum and other algae, and support their growth. The other algae, representing cyanobacteria, produce a dissolved toxin that partially inhibits the growth of $P$. parvum (Roelke et al. 2010). Both types of algae are consumed by a small-bodied zooplankton population. Consumption of the other algae supports the growth of the zooplankton, as does consumption of $P$. parvum, but the dissolved toxin produced by $P$. parvum also inhibits zooplankton ingestion and growth. The relationship between zooplankton and $P$. parvum therefore ranges from positive to negative depending on the amount of toxin produced. Toxin production by $P$. parvum is most rapid when its population growth rate is reduced by suboptimal temperature or salinity (Baker et al. 2007), or by nutrient limitation (Johansson and Granéli 1999, Skingel et al. 2010). Growth rates of $P$. parvum and other populations depend on temperature, salinity, and hydraulic flow, which are provided as input to the model from observational data. The mathematical equations, functions, and parameters representing these relationships are presented in detail in Appendix B. 


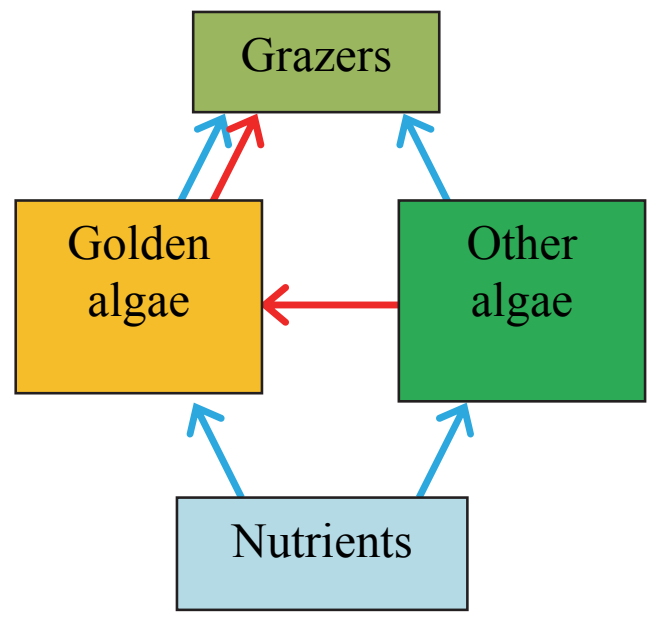

Figure 5. Interactions represented by the biological reaction components of the model. Light blue arrows indicate positive, nutritional interactions and red arrows indicate negative, toxic interactions.

Equations representing the reaction rates for the constituents of the biological model were embedded in a physical model representing covemain lake configuration (Figure 6). In this system, a cove of small volume is coupled to the main body of the reservoir by an exchange flow that mixes constituents between these compartments. Throughflow also enters and leaves the main lake; a much smaller throughflow enters the cove and exits into the main lake. The biological model is implemented in both the cove and the main lake, with reaction rates that depend on the conditions within each respective compartment. An additional pumped flow is imposed in the model to represent hypothetical bloom treatments that enhance the small, natural throughflow of the cove with additional flushing. In practice, the source water for this flushing would be deep water from the main lake, free of $P$. parvum, which tends to concentrate in the upper waters of the lake.

The physical component of the model is a set of ordinary differential equations representing the flows illustrated (Figure 6) and their transport of the biological constituents. The physical parameters quantifying such transport include two that are dimensionless ratios: $\phi$ is the ratio of cove volume to total system volume (cove plus main lake), and $\psi$ is the ratio of flow through the cove to total flow through the system. Both of these ratios are small (much less than 0.01) because coves are small in relation to the main lake. For simplicity, these ratios are set as equal. While this is not likely to be strictly true, both numbers are very small, and as long as this is the case, differences in these parameters have negligible influence on the predictions of the model. Moreover, the detailed hydrological information necessary to estimate $\psi$ is not available. 


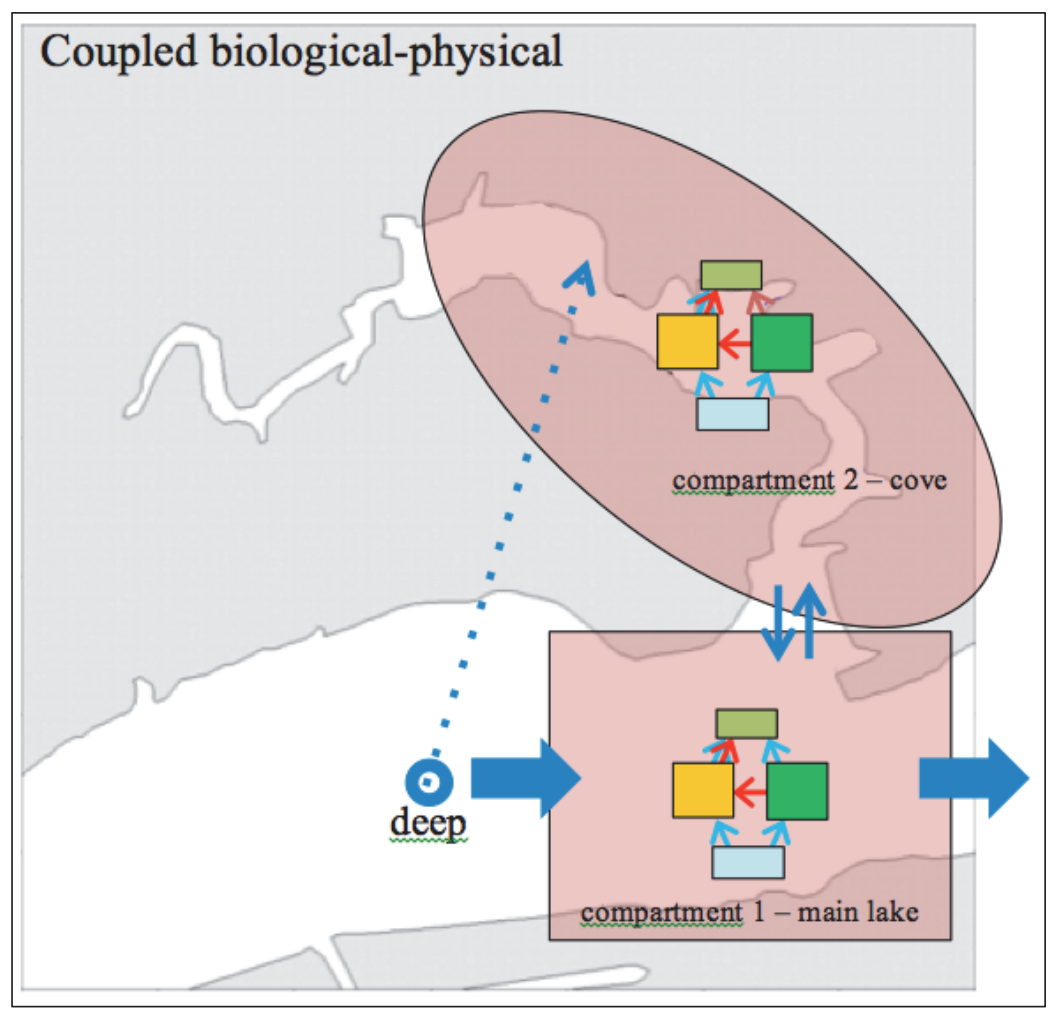

Figure 6. Illustration of the coupled biological-physical model obtained by embedding the biological interactions represented in Figure 5 into the cove-main lake configuration. Large, dark blue arrows indicate flow through the main lake, and smaller dark blue arrows indicate exchange between the cove and the main lake compartments. The dotted dark blue arrow indicates the flow that is imposed by pumping deep water from the main lake to the headwaters of the cove.

The flow through the total system (cove plus main lake) is parameterized by a dilution rate $D$, based on the total volume and total throughflow of the system. Daily estimates of $D$ are obtained from hydrological data on Brazos River flow (Grover et al. 2010).

An additional parameter $E$ represents the exchange rate between the cove and the main lake. Estimation of this parameter was the goal of the tracer experiments done in this study, and based on these results, a plausible range of values for $E$ was explored in modeling. Although $E$ varies with time, within the model runs reported here, its value was held constant through time.

Finally, a parameter $F$ represents the additional flushing through the cove imposed by hypothetical bloom treatments.

The equations of the physical component of the model are: 


$$
\begin{gathered}
\frac{d X_{1}}{d t}=\frac{(1-\phi) D}{1-\psi} X_{1}^{i n}-\frac{D+E}{1-\psi} X_{1}+\frac{\phi D+E+F}{1-\psi} X_{2}+\text { reactions } \\
\frac{d X_{2}}{d t}=\frac{\phi D}{\psi} X_{2}^{i n}+\frac{E}{\psi} X_{1}-\frac{\phi D+E+F}{\psi} X_{2}+\text { reactions }
\end{gathered}
$$

Here, the variables $X_{1}$ and $X_{2}$ are the concentrations of a constituent in the main lake (compartment 1) and the cove (compartment 2), respectively.

The first term in each equation quantifies the inflow of a constituent into the headwaters of the main lake and the cove, respectively. For the main lake and the cove, it is assumed phosphate and nitrate enter both compartments at equal concentrations (i.e. $X_{1}^{i n}=X_{2}^{i n}$ ) and values for these inputs are obtained from observations during $P$. parvum monitoring studies (Grover et al. 2010, 2012). Equal input concentrations are assumed because fine-scaled data are not available to estimate input concentrations separately for coves.

It is assumed that small amounts of zooplankton, $P$. parvum, and other algae are input into the main lake compartment (i.e. $X_{1}^{\text {in }}=$ a small number) but not into the cove (i.e. $X_{2}^{i n}=0$ ). This small input was imposed for technical reasons, to avoid extinction of any species during long-term model simulations (Grover et al. 2010, 2012).

Inputs are assumed to be zero for both the toxin produced by cyanobacteria and the toxin produced by $P$. parvum (i.e. $X_{1}^{i n}=X_{2}^{i n}=0$ ). It was also assumed that the deep water used for flushing has zero nutrient concentrations. This is unlikely to be true, but because the model does not completely budget the fate of the nutrients made available from deep water, during long model runs an unrealistic accumulation occurs. Thus, for essentially technical reasons, the nutrient content of deep water was neglected in modeling reported here.

Prior to exploring hypothetical bloom treatments based on enhanced flushing of coves, the model was calibrated against observational data with the flushing parameter $F$ set to zero. The calibration procedure was similar to that used for the one-compartment lake model that provided the basis for the biological component described above (Grover et al. 2012). Calibration focused on a one-year time period beginning 1 August 2006. Extensive 
observations of $P$. parvum populations and other lake characteristics are available for this time period. Daily values of temperature, salinity, light, nutrient input, and dilution rate were used to run the model for several (3-5) annual cycles, producing one-year seasonal cycles of the predicted population density of $P$. parvum, which were compared to observations.

The results were graphically indistinguishable for a range of parameters representing the volumes and exchange rates of coves as measured in this study. The predicted annual cycle of $P$. parvum density matched that predicted by the predecessor model (Grover et al. 2012), and thus displays the same high correspondence to observations during the calibration year (Figure 7). Without flushing treatments, the dynamics of $P$. parvum in coves are predicted to be virtually identical to the main lake, for the range of exchange rates found in the tracer study. That is, the exchange rates are high enough to predict strong coupling of cove conditions to those in the main lake.

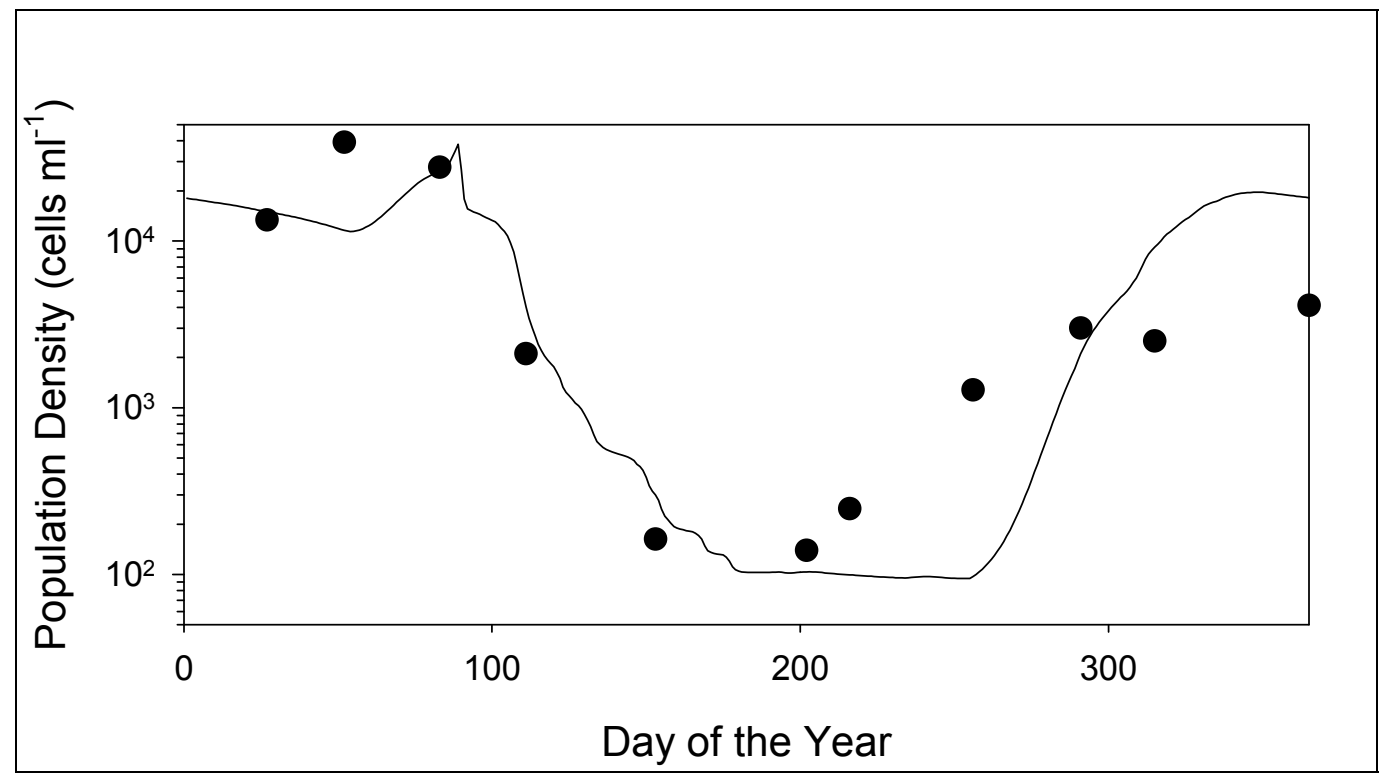

Figure 7. Dynamics of $P$. parvum in the main lake compartment (solid line) predicted by the coupled biological-physical model with no flushing treatment imposed, after calibration to observations (solid circles).

With the calibrated model, the cove-specific efficacy of mitigating blooms with flushing treatments was evaluated through sensitivity analyses along a gradient of water exchange rates between coves and the mainstem of the lake, where the gradient explored spans the level of water exchange plausible, based on the tracer studies reported here. 
Model runs for sensitivity analysis were constructed as follows. For a given cove, the model was run with no flushing treatment for four years using daily values of temperature, salinity, light, nutrient input, and dilution rate as forcing data. This was a sufficient amount of time to achieve the annual cycle illustrated (Figure 7). On 1 January of the fifth year of the model run, when $P$. parvum density exceeded $10^{4}$ cells $/ \mathrm{ml}$, flushing treatments began. That is, treatments were assumed to begin after establishment of a large $P$. parvum bloom. Treatments continued for the next 200 days, which covers the early part of the year when P. parvum blooms have historically occurred in Lake Granbury and other Texas reservoirs (Roelke et al. 2011).

The design of the sensitivity analysis was based on plausible scenarios for flushing treatments during the 200-day treatment period. The flows imposed were based on deploying one, two, or three of the highest-capacity solar-powered pumps available (SolarBee model SB100ooHW v18, 14.4-million gallons/day (mgd) capacity). Pumps were simulated as operating on five different schedules: operating 1, 2, 3, 5, or 7 days per week. For the coves that were studied in the tracer experiment, deploying this number of pumps produces flushing that equals or exceeds the flushing rates found to be effective in reducing $P$. parvum blooms in enclosure experiments (Hayden et al. 2012) Intermittent pumping was explored in addition to continual pumping (operating 7 days per week) because enclosure experiments imposed flushing treatments intermittently. Therefore a total of 15 bloom treatment scenarios were explored for each cove, over a gradient of cove exchange rates $(E)$ ranging from 0.05 to $1.0 \mathrm{~d}^{-1}$, going both above and below the exchange rates observed in tracer experiments.

The sensitivity analysis used the three coves in which tracer experiments were conducted. Cove volumes measured during the morphometric survey prior to the first tracer experiment were used to assign the volume ratio parameter $\phi$ (Table 1). Although cove volumes, and hence, values of $\phi$ can be expected to vary over time as lake levels change, this variation was neglected because the resulting changes in $\phi$ have virtually no impact on model predictions. The flow ratio parameter $\psi$ was set equal to $\phi$ as explained above. The flushing parameter $F$ was calculated from the pump capacity (14.4 mgd per pump) in relation to cove volume. 
Table 1. Volume and flow characteristics of coves simulated for the sensitivity analysis of the biological-physical mode.

\begin{tabular}{|l|l|l|l|l|l|}
\hline \multirow{2}{*}{ Cove } & \multirow{2}{*}{} & & \multicolumn{3}{|c|}{ Flushing $\left(F, \mathrm{~d}^{-1}\right)$ based on number of } \\
pumps
\end{tabular}




\section{Technical Reporting and Discussion}

\section{Dye tracer studies}

The slow Rhodamine WT addition method adopted in this study resulted in a fairly uniform dye distribution throughout the target coves. A representative example is shown from the third experiment in Ranger's Slough

(Figure 8) where $24 \mathrm{hr}$ after dye addition, concentrations of Rhodamine WT were in the range of $1300-1600(\mu \mathrm{g})$ throughout most of the cove. The daily horizontal dissipation of dye was easily followed in all three coves during the experiments using Dataflow technology (see figures in Appendix A). Similarly, the daily vertical dissipation of dye was easily followed from the vertical profiling data. Combined, this information enabled determination of the daily dissipation of Rhodamine WT from the coves, thereby enabling estimation of water exchange rates between cove and open lake waters.

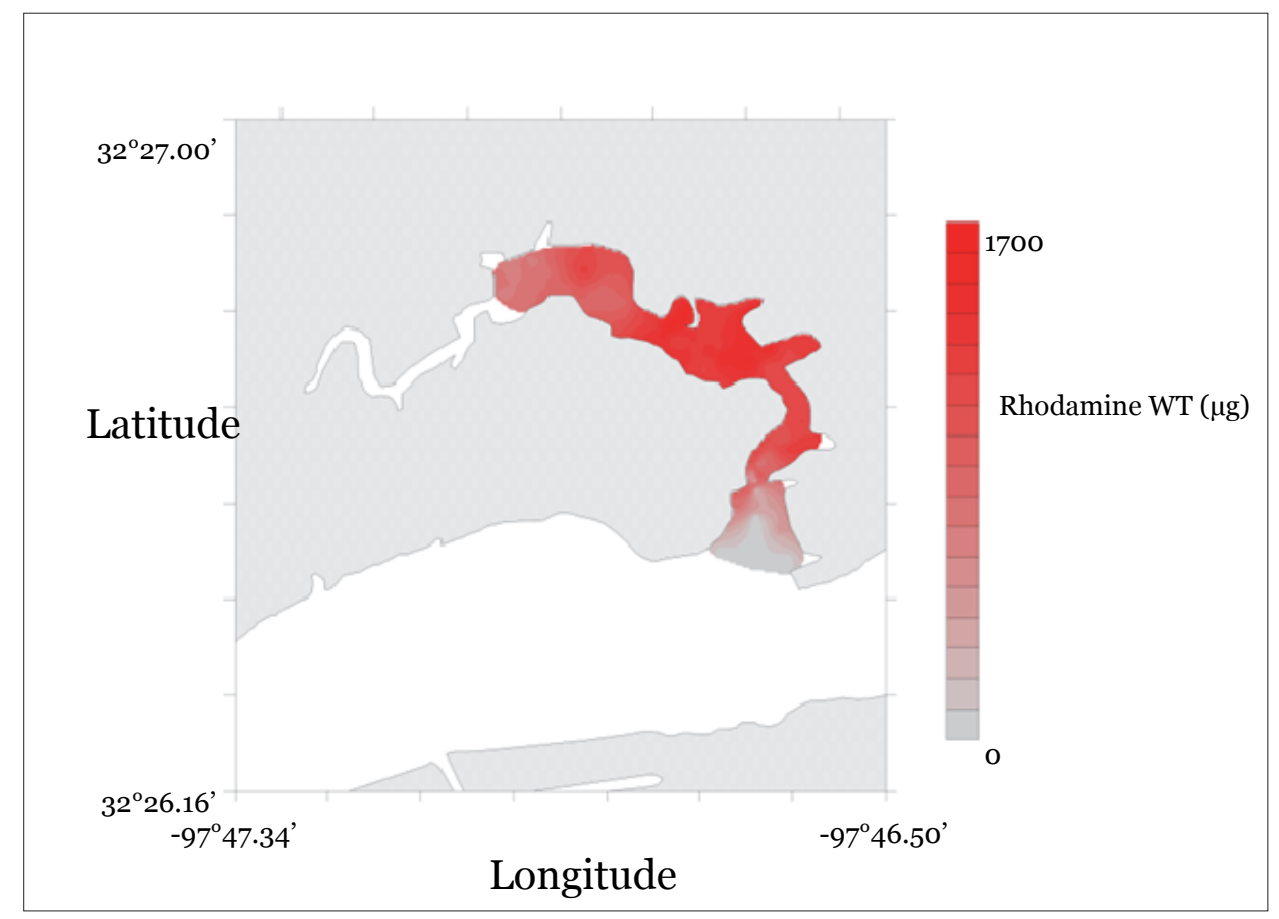

Figure 8. Water column Rhodamine WT distribution $24 \mathrm{hr}$ after addition in Ranger's Slough, Lake Granbury (USA) during the third experiment (June 2012).

\section{Rangers Slough (cove G, from below)}

Natural surface water exchange rates during the three experiments were very similar in Ranger's Slough, with the exponent coefficient ranging 
between 0.20 and $0.25 \mathrm{~d}^{-1}$ (Figure 9). Daily variation in the water exchange rate was not well explained by $24-\mathrm{hr}$ winds and lake inflows. The regression model showed insignificant $p$-values for these independent variables, and insignificant $p$-values and low variance are explained in the overall model (Table 2).

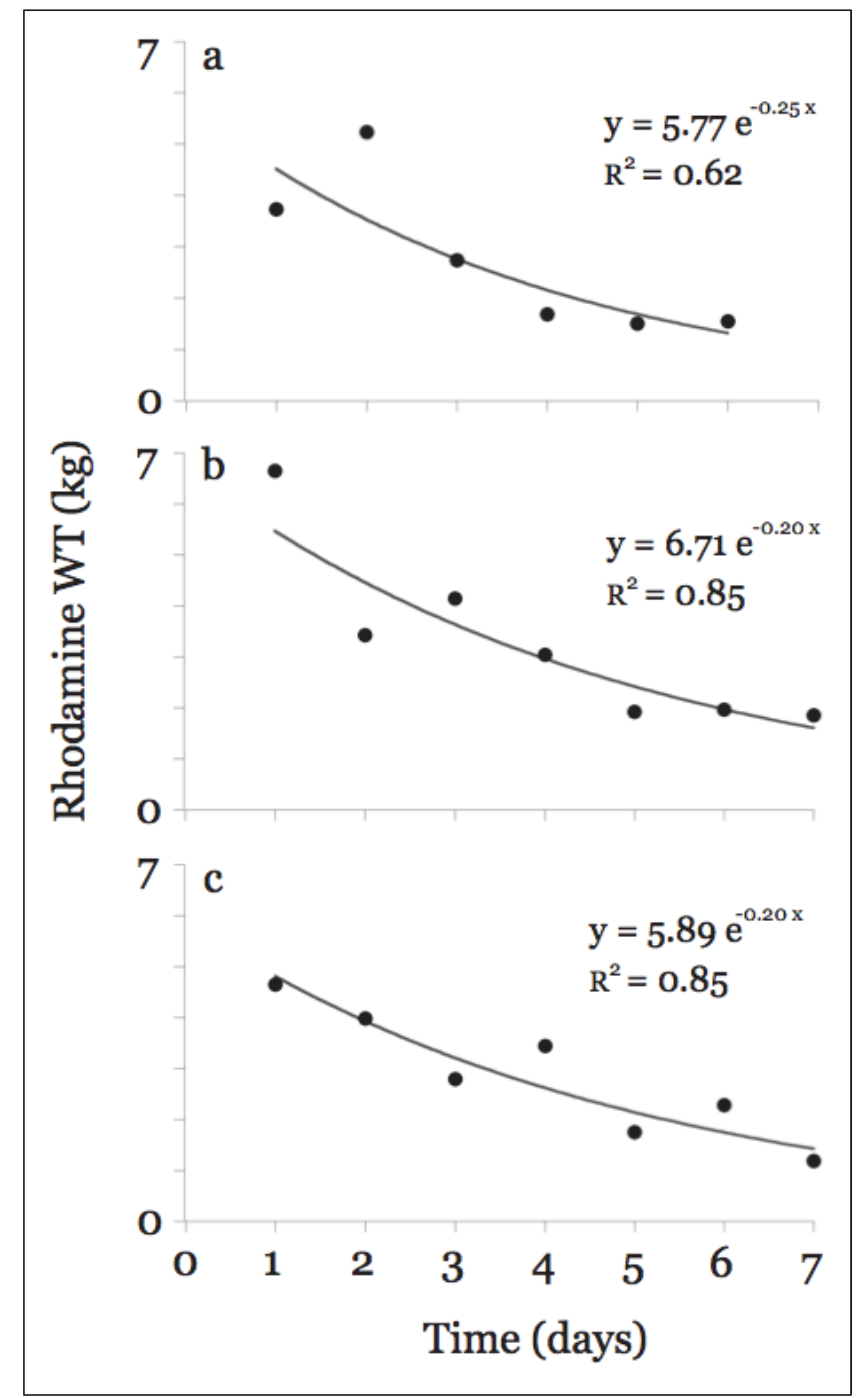

Figure 9. Total mass of Rhodamine WT in Ranger's Slough, Lake Granbury (USA) during tracer studies conducted in February (a), April (b), and June (c). Here, time-zero marks the timing of Rhodamine WT addition immediately after measurement of background fluorescence. 
Table 2. Multiple linear regression analysis of the relationship between daily water exchange rate, 24-hr wind speed and direction, and 24-hr inflow to Lake Granbury for the three Ranger's Slough experiments combined.

\begin{tabular}{|l|l|l|l|l|l|}
\hline Cove & $\begin{array}{l}\text { Predictor } \\
\text { Variables }\end{array}$ & $\begin{array}{l}\text { Significance } \\
\text { of Model }\end{array}$ & $\begin{array}{l}\text { Adjusted } \\
\text { R square }\end{array}$ & $\begin{array}{l}\text { Standardized } \\
\text { Coefficients }\end{array}$ & $\begin{array}{l}\text { Significance } \\
\text { of Predictor } \\
\text { Variables }\end{array}$ \\
\hline Ranger's Slough & NS_24 & 0.805 & -0.144 & 0.207 & 0.698 \\
\hline & EW_24 & & & -0.098 & 0.864 \\
\hline & Inflow_24 & & & -0.086 & 0.791 \\
\hline
\end{tabular}

\section{Bee Creek (cove A, from below)}

In Bee Creek, exponent coefficients were again similar during the three experiments, ranging between 0.24 ando.30 $\mathrm{d}^{-1}$ (Figure 3). Again, daily variation in the water exchange rate was not well explained by 24 -hr winds and lake inflows. The regression model showed insignificant $p$-values for winds and inflow variables, and insignificant $p$-values and low variance were explained in the overall model (Table 3 ).

\section{Thorp's Spring}

Natural surface water exchange rates were much more variable during the three experiments in Thorp's Spring, with the exponent coefficient ranging between 0.06 and $0.59 \mathrm{~d}^{-1}$ (Figure 11). The low rate of water exchange during the third experiment might have been an artifact of a passing storm that occurred on day 5 of this tracer study. The storm re-suspended sediments that likely elevated the background fluorescence level, resulting in an overestimation of Rhodamine WT late in the experiment.

Consistent with the other two coves, daily variation in the water exchange rate could not be explained by $24-\mathrm{hr}$ winds and lake inflows. The regression model showed insignificant $p$-values for these independent variables, and lack of an explanation for insignificant $p$-values and low variance in the overall model (Table 4).

\section{Analysis of historical data}

\section{Cove A (Bee Creek, from above)}

Historical data were used to analyze the dissimilarity measure between cove station $A$ and the average of open lake stations 2 and 3. From the biotic parameters (Figure 12) it can be seen that trends in biomass over 


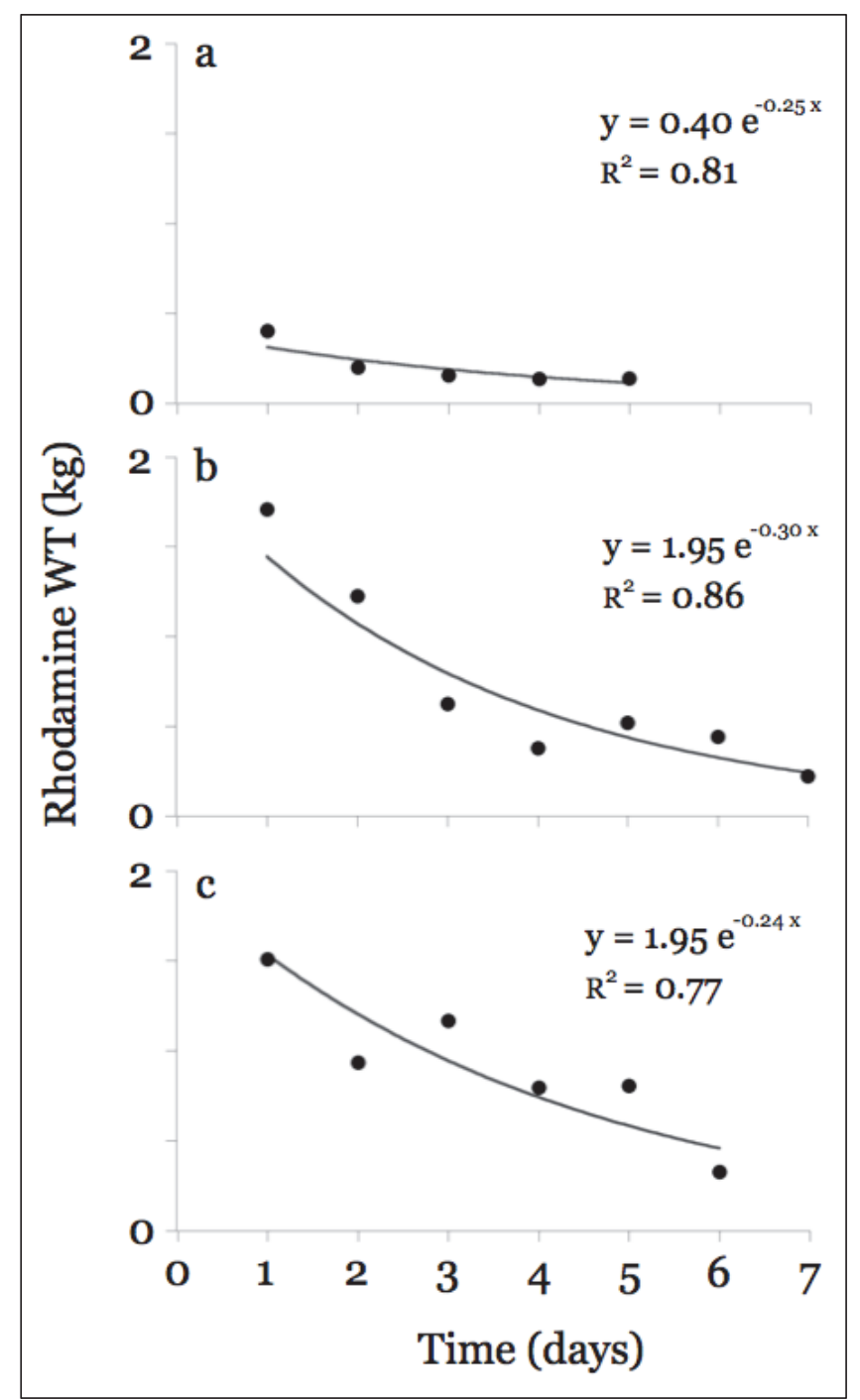

Figure 10. Total mass of Rhodamine WT in Bee Creek, Lake Granbury (USA) during tracer studies conducted in February (a), April (b), and June (c). Here, time-zero marks the timing of Rhodamine WT addition immediately after measurement of background fluorescence.

Table 3. Multiple linear regression analysis of the relationship between daily water exchange rate, 24-hr wind speed and direction, and 24-hr inflow to Lake Granbury for the three Bee Creek experiments combined.

\begin{tabular}{|l|l|l|l|l|l|}
\hline Cove & $\begin{array}{l}\text { Predictor } \\
\text { Variables }\end{array}$ & $\begin{array}{l}\text { Significance } \\
\text { of Model }\end{array}$ & $\begin{array}{l}\text { Adjusted } \\
\text { R square }\end{array}$ & $\begin{array}{l}\text { Standardized } \\
\text { Coefficients }\end{array}$ & $\begin{array}{l}\text { Significance } \\
\text { of Predictor } \\
\text { Variables }\end{array}$ \\
\hline Bee Creek & NS_24 & 0.597 & -0.080 & 0.661 & 0.191 \\
\hline & EW_24 & & & 0.555 & 0.283 \\
\hline & Inflow_24 & & & 0.035 & 0.917 \\
\hline
\end{tabular}




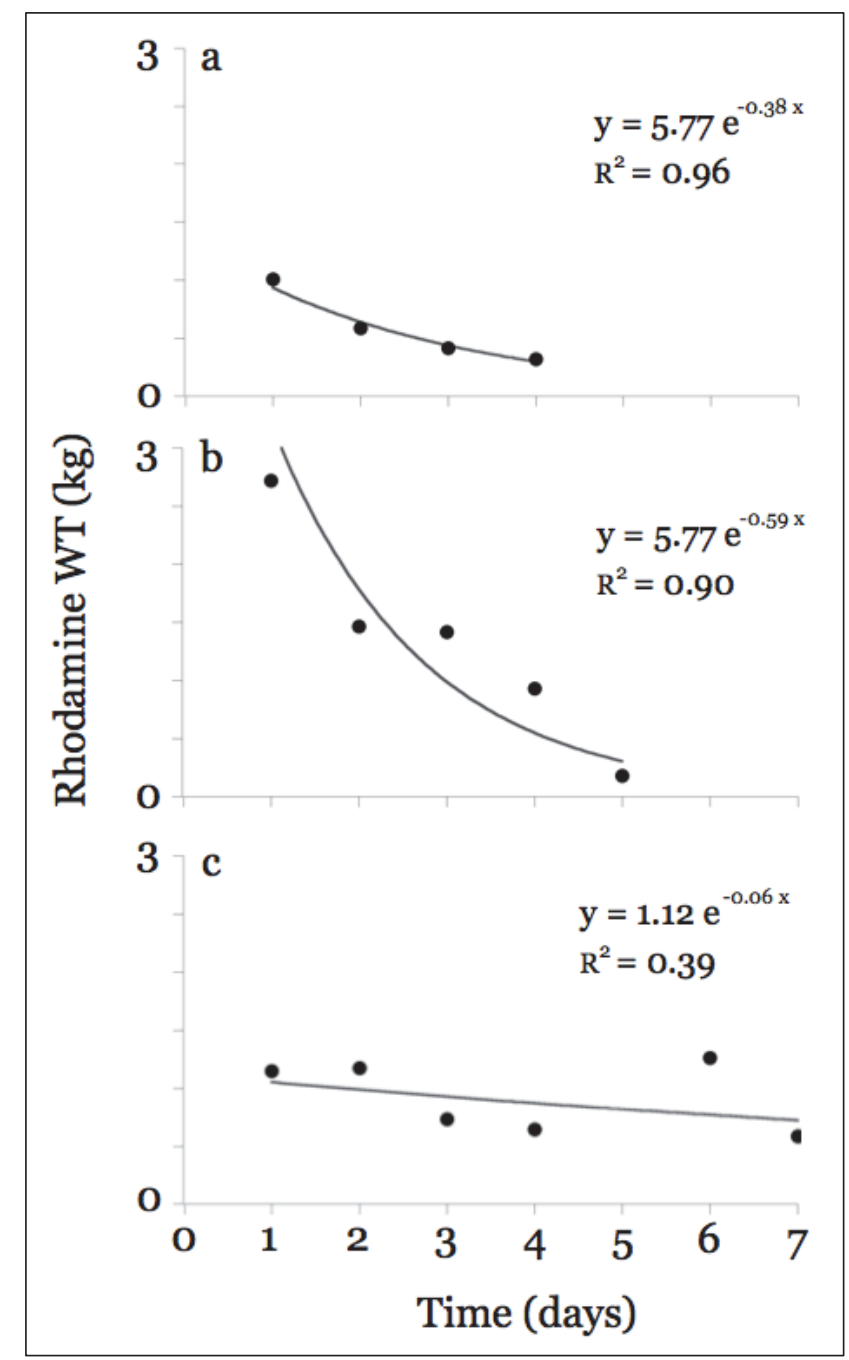

Figure 11. Total mass of Rhodamine WT in Thorp's Spring, Lake Granbury (USA) during tracer studies conducted in February (a), April (b), and June (c). Here time-zero marks the timing of Rhodamine WT addition immediately after measurement of background fluorescence.

Table 4. Multiple linear regression analysis of the relationship between daily water exchange rate, 24-hr wind speed and direction, and 24-hr inflow to Lake Granbury for the three Thorp's Spring experiments combined.

\begin{tabular}{|l|l|l|l|l|l|}
\hline Cove & $\begin{array}{l}\text { Predictor } \\
\text { Variables }\end{array}$ & $\begin{array}{l}\text { Significance } \\
\text { of Model }\end{array}$ & $\begin{array}{l}\text { Adjusted } \\
\text { R square }\end{array}$ & $\begin{array}{l}\text { Standardized } \\
\text { Coefficients }\end{array}$ & $\begin{array}{l}\text { Significance } \\
\text { of Predictor } \\
\text { Variables }\end{array}$ \\
\hline Thorp's Spring & NS_24 & 0.671 & -0.145 & 0.762 & 0.270 \\
\hline & EW_24 & & & 0.825 & 0.251 \\
\hline & Inflow_24 & & & 0.183 & 0.613 \\
\hline
\end{tabular}




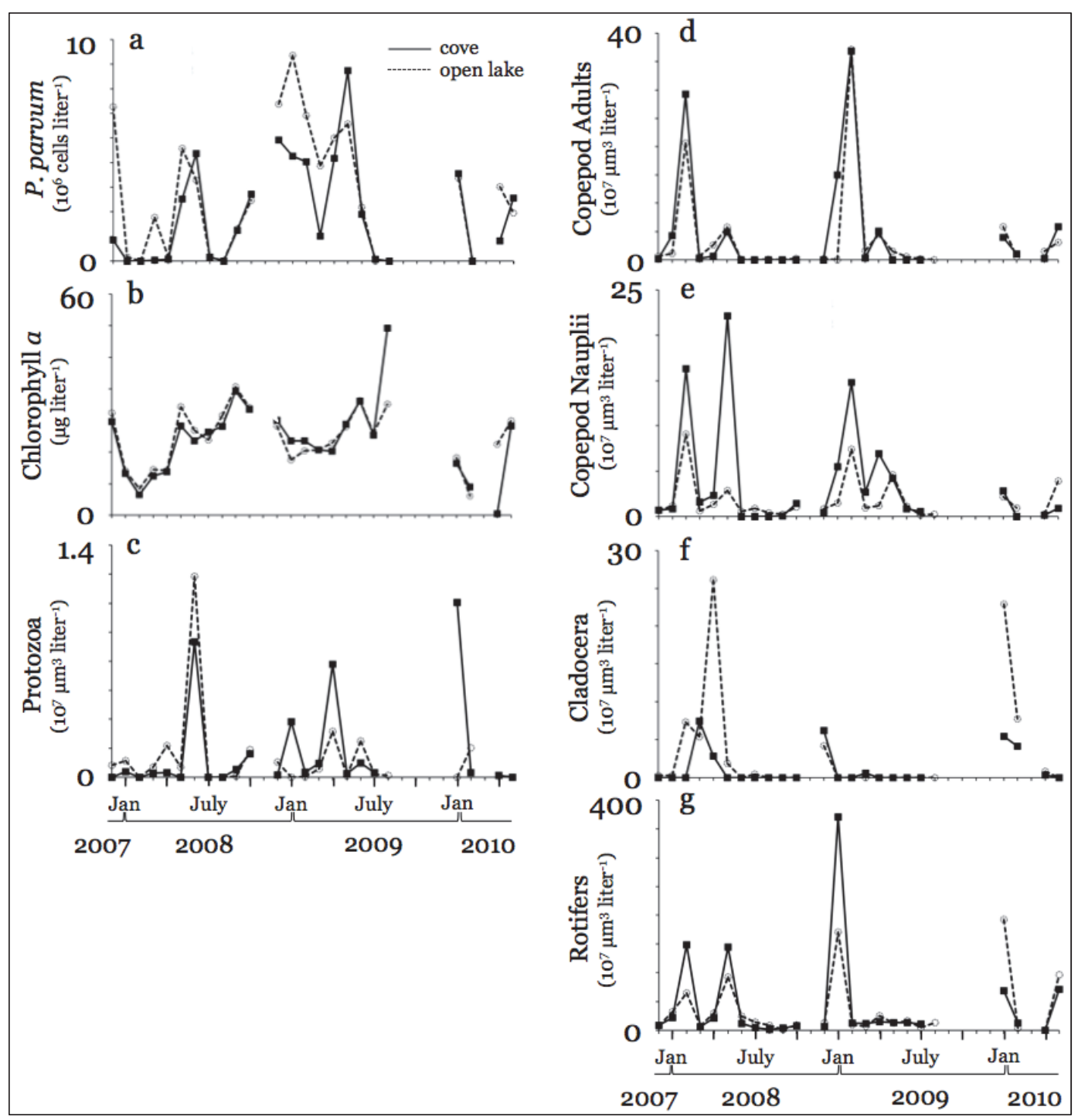

Figure 12. Biotic parameters from the historical data used in the dissimilarity analysis comparing cove A (solid lines) with the averages from stations 2 and 3 (dashed lines) including P. parvum (a), chlorophyll a (b), heterotrophic protozoa (c), copepod adults (d), copepod nauplii (e), cladocera (f), and rotifers (g).

time were similar regarding the timing in peaks, with one-month offsets sometimes occurring. Greater variability was observed in the magnitude of peak biomass for this cove-open lake station pair. Abiotic parameters (Figure 13) showed less variability for this cove-open lake station pair, where the timing and magnitude of peaks were similar.

As stated previously, much of this historical data was generated from projects that were funded by Texas Parks and Wildlife (Brooks, lead PI) and the Department of Energy (Roelke, lead PI) and has been reported previously. These data have been included in this section only to familiarize the reader with the scope of data analysis being performed here. 


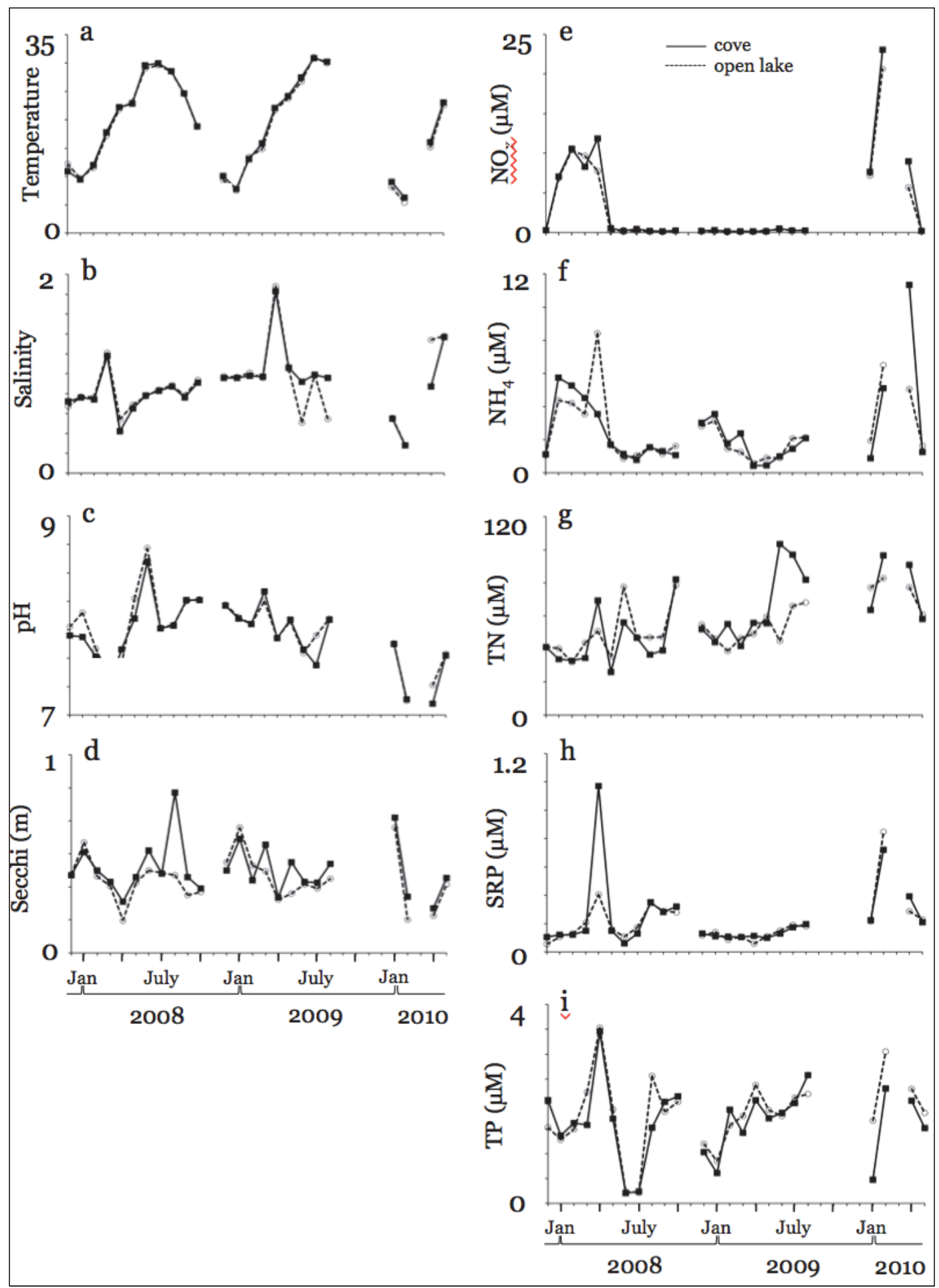

Figure 13. Abiotic parameters from the historical data used in the dissimilarity analysis comparing cove A (solid lines) with the averages from stations 2 and 3 (dashed lines) including temperature (a), salinity (b), $\mathrm{pH}(\mathrm{c})$, Secchi depth (d), nitrate and nitrite summed, $\mathrm{NO}_{x}(\mathrm{e})$, ammonium, $\mathrm{NH}_{4}(\mathrm{f})$, total nitrogen, $\mathrm{TN}(\mathrm{g})$, soluble reactive phosphorus (h), and total phosphorus, TP (i). 
Dendrograms based on the biotic and abiotic parameters showed hierarchal clustering where the dissimilarity between cove and open lake station pairs could be evaluated (Figure 14). For example, the dissimilarity between biotic parameters of the cove and open lake during December 2007 was 2 scaled as the Euclidean distance (graphically displayed from the level of clustering between observations ' 1 ' and ' 25 '). The dissimilarity between the cove and open lake changed over time, and did not show consistent seasonal patterns (Figure 15).

To compare cove station A with averaged data from open-lake stations 2 and 3, the change in dissimilarity (for both biotic and abiotic parameters) over the monitoring period, a sufficient explanation was not provided by the multiple linear regression models. None of the wind and inflow variables correlated with dissimilarity, contributing to weak overall models (Table 5).

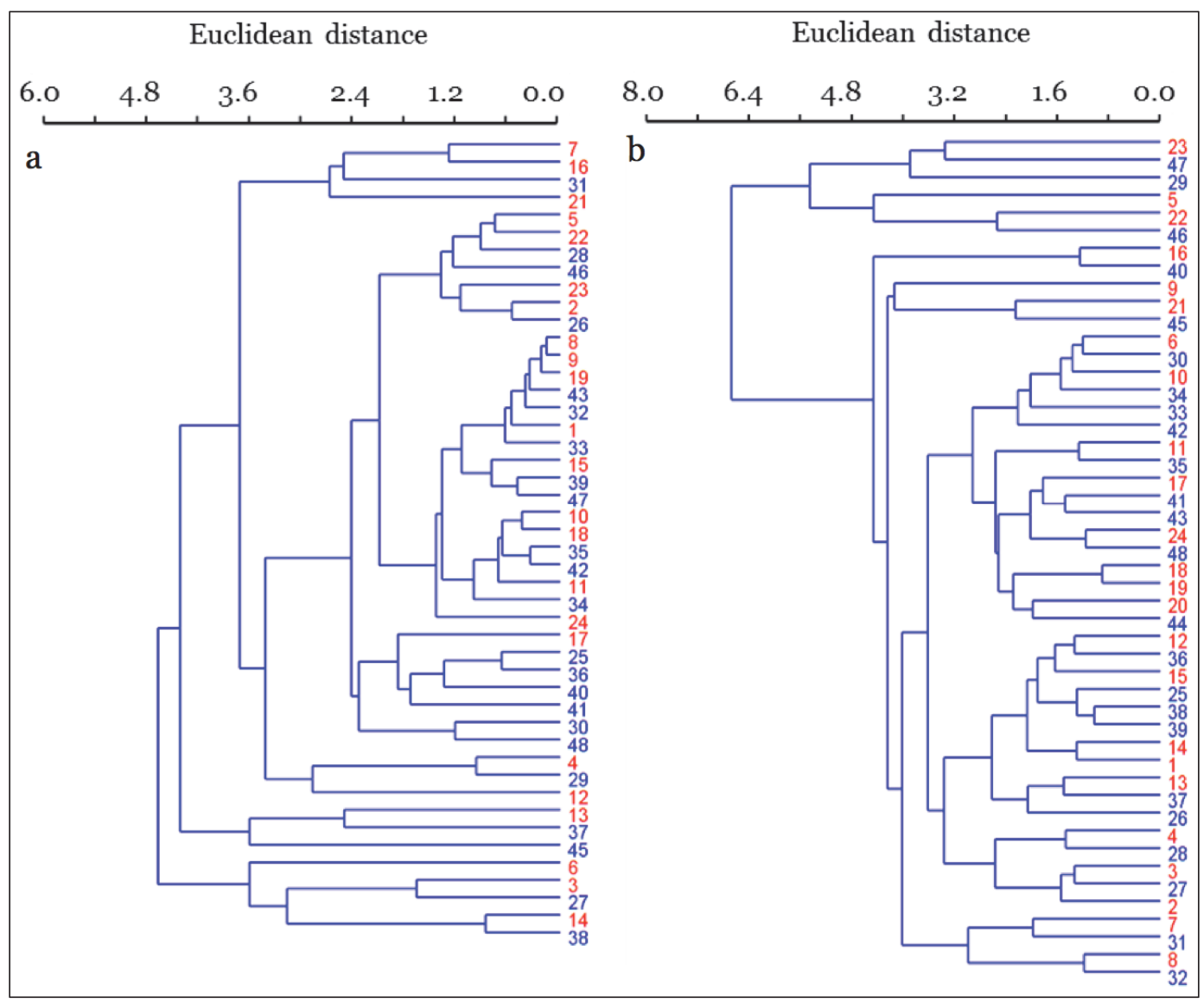

Figure 14. Dendrograms comparing biotic (a) and abiotic (b) parameters from cove $A$ and the averaged data from stations 2 and 3 . Here, red numbers reflect observations from the cove and blue numbers reflect observation averages from the open lake. The numbers are paired based on sampling month and year. For example, $[1,25]$ represents the first cove and open lake sampling during December 2007; [2,26] represents the second cove and open lake sampling during January 2008; and so forth, with $[24,48]$ representing the final cove and open lake sampling during May 2010. 


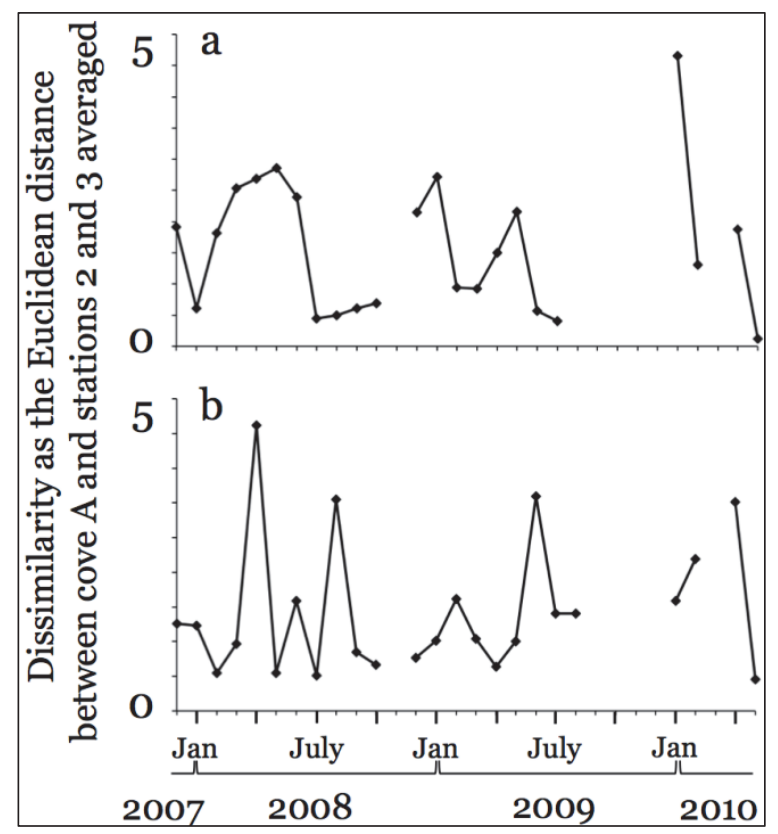

Figure 15. Time-series dissimilarity between biotic (a) and abiotic (b) parameters as estimated by the Euclidean distance for the comparison between cove station $A$ and open-lake stations 2 and 3 averaged.

Table 5. The best fit multiple linear regression analysis of the relationship between the abiotic and biotic Euclidean dissimilarity, wind speed and direction, and inflow to Lake Granbury for cove A.

\begin{tabular}{|l|l|l|l|l|l|}
\hline \multirow{4}{*}{ Cove A } & $\begin{array}{l}\text { Predictor } \\
\text { Variables }\end{array}$ & $\begin{array}{l}\text { Significance } \\
\text { of Model }\end{array}$ & $\begin{array}{l}\text { Adjusted } \\
\text { R square }\end{array}$ & $\begin{array}{l}\text { Standardized } \\
\text { Coefficients }\end{array}$ & $\begin{array}{l}\text { Significance } \\
\text { of Predictor } \\
\text { Variables }\end{array}$ \\
\hline \multirow{4}{*}{ Abiotic } & NS_48 & 0.204 & 0.081 & -0.041 & 0.897 \\
\cline { 2 - 6 } & EW_48 & & & -0.207 & 0.513 \\
\cline { 2 - 6 } & Inflow_15 & & & 0.429 & 0.045 \\
\hline \multirow{3}{*}{ Biotic } & NS_24 & 0.672 & -0.070 & -0.159 & 0.572 \\
\cline { 2 - 6 } & EW_24 & & & -0.253 & 0.357 \\
\cline { 2 - 6 } & Inflow_15 & & & 0.170 & 0.480 \\
\hline
\end{tabular}

\section{Cove B}

When data for cove station B were compared with averaged data from open-lake stations 2 and 3, none of the wind and inflow variables correlated well with dissimilarity for either biotic or abiotic parameters, and the multivariate regression models were weak (Table 6).

Dendrograms and time-series dissimilarity graphs corresponding to this cove-open lake pair are provided in Appendix C. 
Table 6. Best fit multiple linear regression analysis of the relationship between the abiotic and biotic Euclidean dissimilarity, wind speed and direction, and inflow to Lake Granbury for cove B.

\begin{tabular}{|l|l|l|l|l|l|}
\hline \multirow{2}{*}{ Cove B } & $\begin{array}{l}\text { Predictor } \\
\text { Variables }\end{array}$ & $\begin{array}{l}\text { Significance } \\
\text { of Model }\end{array}$ & $\begin{array}{l}\text { Adjusted } \\
\text { R square }\end{array}$ & $\begin{array}{l}\text { Standardized } \\
\text { Coefficients }\end{array}$ & $\begin{array}{l}\text { Significance } \\
\text { of Predictor } \\
\text { Variables }\end{array}$ \\
\hline \multirow{4}{*}{ Abiotic } & NS_48 & 0.191 & 0.098 & -0.169 & 0.615 \\
\cline { 2 - 6 } & EW_48 & & & -0.430 & 0.209 \\
\cline { 2 - 6 } & Inflow_15 & & & 0.389 & 0.079 \\
\hline \multirow{3}{*}{ Biotic } & NS_72 & 0.571 & -0.047 & 0.471 & 0.200 \\
\cline { 2 - 6 } & EW_72 & & & 0.239 & 0.494 \\
\cline { 2 - 6 } & Inflow_15 & & & 0.166 & 0.493 \\
\hline
\end{tabular}

\section{Cove C}

For the biotic parameters, winds along the east-west vector correlated with dissimilarity between cove station $\mathrm{C}$ and averaged data from open-lake stations 2 and 3 . This resulted in a stronger multivariate regression model, although the $p$-value still exceeded 0.05 (Table 7).

Table 7. Best fit multiple linear regression analysis of the relationship between the abiotic and biotic Euclidean dissimilarity, wind speed and direction, and inflow to Lake Granbury for cove C.

\begin{tabular}{|l|l|l|l|l|l|}
\hline \multirow{4}{*}{ Cove C } & $\begin{array}{l}\text { Predictor } \\
\text { Variables }\end{array}$ & $\begin{array}{l}\text { Significance } \\
\text { of Model }\end{array}$ & $\begin{array}{l}\text { Adjusted } \\
\text { R square }\end{array}$ & $\begin{array}{l}\text { Standardized } \\
\text { Coefficients }\end{array}$ & $\begin{array}{l}\text { Significance } \\
\text { of Predictor } \\
\text { Variables }\end{array}$ \\
\hline \multirow{4}{*}{ Abiotic } & NS_72 & 0.258 & 0.059 & 0.067 & 0.827 \\
\cline { 2 - 6 } & EW_72 & & & -0.436 & 0.221 \\
\cline { 2 - 6 } & Inflow_30 & & & -0.280 & 0.277 \\
\hline \multirow{3}{*}{ Biotic } & NS_24 & 0.071 & 0.193 & 0.328 & 0.232 \\
\cline { 2 - 6 } & EW_24 & & & 0.633 & 0.020 \\
\cline { 2 - 6 } & Inflow_30 & & & 0.154 & 0.474 \\
\hline
\end{tabular}

None of the wind and inflow variables correlated well with dissimilarity when considering the abiotic parameters, and the multivariate regression model was weak.

Dendrograms and time-series dissimilarity graphs corresponding to this cove-open lake pair are provided in Appendix C. 


\section{Cove D}

Winds along the north-south vector correlated with dissimilarity between cove station D and averaged data from open-lake stations 2 and 3 when considering biotic parameters. This resulted in a stronger multivariate regression model, but again with a $p$-value still exceeding 0.05 (Table 8).

Table 8. The best fit multiple linear regression analysis of the relationship between the abiotic and biotic Euclidean dissimilarity, wind speed and direction, and inflow to Lake Granbury for cove D.

\begin{tabular}{|l|l|l|l|l|l|}
\hline \multirow{4}{*}{ Cove D } & $\begin{array}{l}\text { Predictor } \\
\text { Variables }\end{array}$ & $\begin{array}{l}\text { Significance } \\
\text { of Model }\end{array}$ & $\begin{array}{l}\text { Adjusted } \\
\text { R square }\end{array}$ & $\begin{array}{l}\text { Standardized } \\
\text { Coefficients }\end{array}$ & $\begin{array}{l}\text { Significance } \\
\text { of Predictor } \\
\text { Variables }\end{array}$ \\
\hline \multirow{4}{*}{ Abiotic } & NS_72 & $<0.000$ & 0.609 & 0.492 & 0.017 \\
\cline { 2 - 6 } & EW_72 & & & 0.306 & 0.159 \\
\cline { 2 - 6 } & Inflow_30 & & & 0.799 & $<0.000$ \\
\hline \multirow{3}{*}{ Biotic } & NS_48 & 0.150 & 0.113 & 0.702 & 0.035 \\
\cline { 2 - 6 } & EW_48 & & & 0.409 & 0.195 \\
\cline { 2 - 6 } & Inflow_15 & & & 0.220 & 0.287 \\
\hline
\end{tabular}

Winds along the north-south vector and inflows to the lake correlated with dissimilarity when considering abiotic parameters. In addition, the multivariate regression model was strong, with a $p$-value less than 0.05 and $\sim 61 \%$ of the variance explained.

Dendrograms and time-series dissimilarity graphs corresponding to this cove-open lake pair are provided in Appendix C.

\section{Cove E}

For the biotic parameters, inflows to the lake correlated with dissimilarity between cove station $\mathrm{E}$ and averaged data from open-lake stations 2 and 3 . This resulted in a stronger multivariate regression model, although with a $p$-value still exceeding 0.05 (Table 9).

None of the wind and inflow variables correlated well with dissimilarity when considering the abiotic parameters (although north-south winds were close), and the multivariate regression model was insignificant.

Dendrograms and time-series dissimilarity graphs corresponding to this cove-open lake pair are provided in Appendix C. 
Table 9. The best fit multiple linear regression analysis of the relationship between the abiotic and biotic Euclidean dissimilarity, wind speed and direction, and inflow to Lake Granbury for cove $\mathrm{E}$.

\begin{tabular}{|l|l|l|l|l|l|}
\hline \multirow{4}{*}{ Cove E } & $\begin{array}{l}\text { Predictor } \\
\text { Variables }\end{array}$ & $\begin{array}{l}\text { Significance } \\
\text { of Model }\end{array}$ & $\begin{array}{l}\text { Adjusted } \\
\text { R square }\end{array}$ & $\begin{array}{l}\text { Standardized } \\
\text { Coefficients }\end{array}$ & $\begin{array}{l}\text { Significance } \\
\text { of Predictor } \\
\text { Variables }\end{array}$ \\
\hline \multirow{4}{*}{ Abiotic } & NS_72 & 0.167 & 0.102 & 0.455 & 0.076 \\
\cline { 2 - 6 } & EW_72 & & & 0.121 & 0.624 \\
\cline { 2 - 6 } & Inflow_15 & & & 0.319 & 0.133 \\
\hline \multirow{3}{*}{ Biotic } & NS_72 & 0.066 & 0.199 & 0.355 & 0.140 \\
\cline { 2 - 6 } & EW_72 & & & 0.287 & 0.274 \\
\cline { 2 - 6 } & Inflow_30 & & & 0.494 & 0.040 \\
\hline
\end{tabular}

\section{Cove F}

North-south and east-west wind vectors, as well as inflows to the lake, correlated with dissimilarity between cove station $\mathrm{F}$ and averaged data from open-lake stations 4 and 5 when considering biotic parameters. A strong multivariate regression model resulted, with $p$-value less than 0.05 . However, this model only accounted for $\sim 36 \%$ of the total variability in dissimilarity (Table 10).

Table 10. The best fit multiple linear regression analysis of the relationship between the abiotic and biotic Euclidean dissimilarity, wind speed and direction, and inflow to Lake Granbury for cove F.

\begin{tabular}{|l|l|l|l|l|l|}
\hline \multirow{4}{*}{ Cove F } & $\begin{array}{l}\text { Predictor } \\
\text { Variables }\end{array}$ & $\begin{array}{l}\text { Significance } \\
\text { of Model }\end{array}$ & $\begin{array}{l}\text { Adjusted } \\
\text { R square }\end{array}$ & $\begin{array}{l}\text { Standardized } \\
\text { Coefficients }\end{array}$ & $\begin{array}{l}\text { Significance } \\
\text { of Predictor } \\
\text { Variables }\end{array}$ \\
\hline \multirow{4}{*}{ Abiotic } & NS_72 & 0.137 & 0.128 & -0.295 & 0.328 \\
\cline { 2 - 6 } & EW_72 & & & -0.712 & 0.031 \\
\cline { 2 - 6 } & Inflow_15 & & & -0.195 & 0.382 \\
\hline \multirow{3}{*}{ Biotic } & NS_72 & 0.009 & 0.361 & 2.798 & 0.011 \\
\cline { 2 - 6 } & EW_72 & & & 2.113 & 0.048 \\
\cline { 2 - 6 } & Inflow_30 & & & 2.600 & 0.018 \\
\hline
\end{tabular}

For the abiotic parameters, the east-west wind vector correlated with dissimilarity. This resulted in a stronger multivariate regression model, but with a $p$-value still exceeding 0.05 .

Dendrograms and time-series dissimilarity graphs corresponding to this cove-open lake pair are provided in Appendix C. 


\section{Cove G (Ranger's Slough, from above)}

The north-south wind vector and inflows to the lake correlated with dissimilarity between cove station $\mathrm{G}$ and averaged data from open-lake stations 4 and 5 when considering biotic parameters. A strong multivariate regression model resulted, with a $p$-value less than 0.05 . This model accounted for $\sim 38 \%$ of the total variability in dissimilarity (Table 11 ).

Table 11. The best fit multiple linear regression analysis of the relationship between the abiotic and biotic Euclidean dissimilarity, wind speed and direction, and inflow to Lake Granbury for cove G.

\begin{tabular}{|l|l|l|l|l|l|}
\hline \multirow{4}{*}{ Cove G } & $\begin{array}{l}\text { Predictor } \\
\text { Variables }\end{array}$ & $\begin{array}{l}\text { Significance } \\
\text { of Model }\end{array}$ & $\begin{array}{l}\text { Adjusted } \\
\text { R square }\end{array}$ & $\begin{array}{l}\text { Standardized } \\
\text { Coefficients }\end{array}$ & $\begin{array}{l}\text { Significance } \\
\text { of Predictor } \\
\text { Variables }\end{array}$ \\
\hline \multirow{4}{*}{ Abiotic } & NS_48 & 0.447 & -0.010 & 0.239 & 0.485 \\
\cline { 2 - 6 } & EW_48 & & & 0.433 & 0.214 \\
\cline { 2 - 6 } & Inflow_7 & & & 0.246 & 0.271 \\
\hline \multirow{3}{*}{ Biotic } & NS_72 & 0.009 & 0.380 & 0.673 & 0.011 \\
\cline { 2 - 6 } & EW_72 & & & 0.430 & 0.101 \\
\cline { 2 - 6 } & Inflow_15 & & & 0.452 & 0.027 \\
\hline
\end{tabular}

None of the wind and inflow variables correlated well with dissimilarity, when the abiotic parameters and the multivariate regression model were considered to be insignificant.

Dendrograms and time-series dissimilarity graphs corresponding to this cove-open lake pair are provided in Appendix C.

\section{Cove H}

The east-west wind vector and inflows to the lake correlated with dissimilarity between cove station $\mathrm{H}$ and averaged data from open-lake stations 6 and 7 when considering biotic parameters. A strong multivariate regression model resulted, with a $p$-value less than 0.05. This model accounted for $\sim 58 \%$ of the total variability in dissimilarity (Table 12).

None of the wind and inflow variables correlated well with dissimilarity when considering the abiotic parameters (although inflows to the lake were close), and the multivariate regression model was insignificant. 
Table 12. The best fit multiple linear regression analysis of the relationship between the abiotic and biotic Euclidean dissimilarity, wind speed and direction, and inflow to Lake Granbury for cove H.

\begin{tabular}{|l|l|l|l|l|l|}
\hline \multirow{4}{*}{ Cove H } & $\begin{array}{l}\text { Predictor } \\
\text { Variables }\end{array}$ & $\begin{array}{l}\text { Significance } \\
\text { of Model }\end{array}$ & $\begin{array}{l}\text { Adjusted } \\
\text { R square }\end{array}$ & $\begin{array}{l}\text { Standardized } \\
\text { Coefficients }\end{array}$ & $\begin{array}{l}\text { Significance } \\
\text { of Predictor } \\
\text { Variables }\end{array}$ \\
\hline \multirow{4}{*}{ Abiotic } & NS_48 & 0.198 & 0.089 & 0.228 & 0.482 \\
\cline { 2 - 6 } & EW_48 & & & 0.507 & 0.137 \\
\cline { 2 - 6 } & Inflow_15 & & & 0.419 & 0.068 \\
\hline \multirow{3}{*}{ Biotic } & NS_24 & $<0.001$ & 0.576 & 0.208 & 0.287 \\
\cline { 2 - 6 } & EW_24 & & & 0.488 & 0.018 \\
\cline { 2 - 6 } & Inflow_15 & & & 0.765 & 0.000 \\
\hline
\end{tabular}

Dendrograms and time-series dissimilarity graphs corresponding to this cove-open lake pair are provided in Appendix C.

\section{Cove I}

When considering biotic parameters, inflows to the lake correlated with dissimilarity between cove station I and averaged data from open-lake stations 8 and 9. A strong multivariate regression model resulted, with a $p$-value less than 0.05 . This model accounted for $\sim 62 \%$ of the total variability in dissimilarity (Table 13).

Table 13. The best fit multiple linear regression analysis of the relationship between the abiotic and biotic Euclidean dissimilarity, wind speed and direction, and inflow to Lake Granbury for cove I.

\begin{tabular}{|l|l|l|l|l|l|}
\hline \multirow{4}{*}{ Cove I } & $\begin{array}{l}\text { Predictor } \\
\text { Variables }\end{array}$ & $\begin{array}{l}\text { Significance } \\
\text { of Model }\end{array}$ & $\begin{array}{l}\text { Adjusted } \\
\text { R square }\end{array}$ & $\begin{array}{l}\text { Standardized } \\
\text { Coefficients }\end{array}$ & $\begin{array}{l}\text { Significance } \\
\text { of Predictor } \\
\text { Variables }\end{array}$ \\
\hline \multirow{4}{*}{ Abiotic } & NS_24 & 0.840 & -0.104 & -0.099 & 0.754 \\
\cline { 2 - 6 } & EW_24 & & & -0.125 & 0.697 \\
\cline { 2 - 6 } & Inflow_15 & & & 0.201 & 0.383 \\
\hline \multirow{3}{*}{ Biotic } & NS_24 & $<0.000$ & 0.619 & 0.066 & 0.739 \\
\cline { 2 - 6 } & EW_24 & & & 0.297 & 0.146 \\
\cline { 2 - 6 } & Inflow_15 & & & 0.827 & $<0.000$ \\
\hline
\end{tabular}

None of the wind and inflow variables correlated well with dissimilarity when the abiotic parameters and the multivariate regression model were considered to be insignificant. 
Dendrograms and time-series dissimilarity graphs corresponding to this cove-open lake pair are provided in Appendix C.

\section{Cove J}

The east-west wind vector and inflows to the lake correlated with dissimilarity between cove station $J$ and data from open-lake station 10 when considering biotic parameters. A strong multivariate regression model resulted, with a $p$-value less than 0.05 . This model accounted for $\sim 41 \%$ of the total variability in dissimilarity (Table 14 ).

Table 14. The best fit multiple linear regression analysis of the relationship between the abiotic and biotic Euclidean dissimilarity, wind speed and direction, and inflow to Lake Granbury for cove J.

\begin{tabular}{|l|l|l|l|l|l|}
\hline \multirow{4}{*}{ Cove J } & $\begin{array}{l}\text { Predictor } \\
\text { Variables }\end{array}$ & $\begin{array}{l}\text { Significance } \\
\text { of Model }\end{array}$ & $\begin{array}{l}\text { Adjusted } \\
\text { R square }\end{array}$ & $\begin{array}{l}\text { Standardized } \\
\text { Coefficients }\end{array}$ & $\begin{array}{l}\text { Significance } \\
\text { of Predictor } \\
\text { Variables }\end{array}$ \\
\hline \multirow{4}{*}{ Abiotic } & NS_72 & 0.768 & -0.102 & -0.124 & 0.770 \\
\cline { 2 - 6 } & EW_72 & & & -0.272 & 0.514 \\
\cline { 2 - 6 } & Inflow_7 & & & 0.151 & 0.552 \\
\hline \multirow{3}{*}{ Biotic } & NS_24 & 0.008 & 0.406 & 0.635 & 0.023 \\
\cline { 2 - 6 } & EW_24 & & & 0.672 & 0.018 \\
\cline { 2 - 6 } & Inflow_15 & & & 0.557 & 0.006 \\
\hline
\end{tabular}

None of the wind and inflow variables correlated well with dissimilarity when the abiotic parameters and the multivariate regression model were considered to be insignificant.

Dendrograms and time-series dissimilarity graphs corresponding to this cove-open lake pair are provided in Appendix C.

\section{Role of cove morphology}

When comparing the strength of the multivariate regression models against the morphology of coves, correlations were poor for both biotic and abiotic parameters (Figure 16). Here, cove morphology is only depicted by the cove mouth cross-sectional area to volume ratio. In addition, the orientation of coves on the landscape is not considered here. 


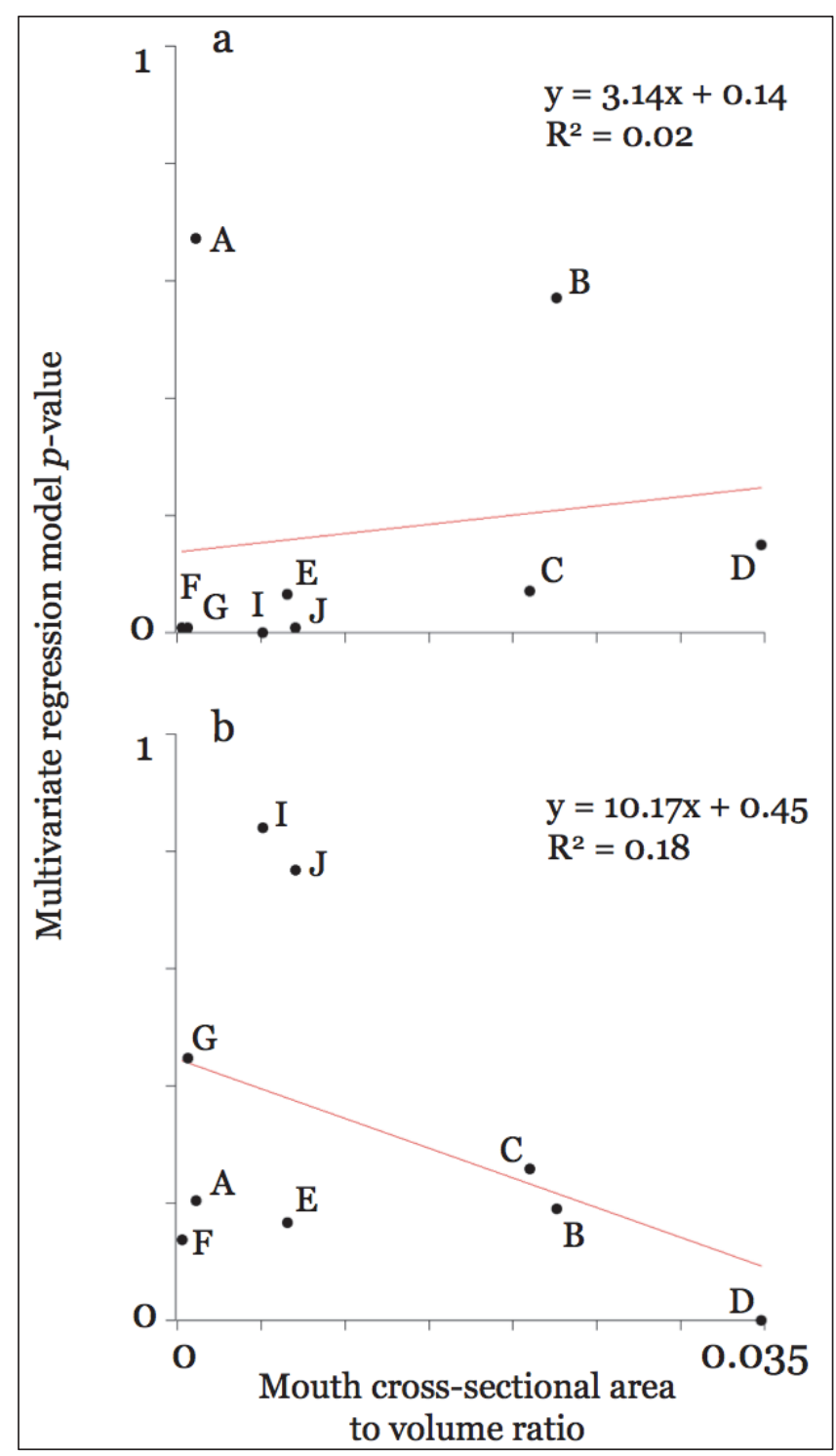

Figure 16. Scatter plots with linear model fits comparing the mouth cross-sectional area to volume ratio of each cove against the strength of the multivariate regression model that compared the dissimilarity between biotic (a) and abiotic (b) parameters between coves and open-lake stations with winds and inflows to the lake.

\section{Numerical modeling}

\section{Rangers Slough (cove G, from above)}

As described previously, hypothetical flushing treatments were simulated for a range of cove exchange rates encompassing those measured in the tracer experiments, for each of three coves. A coupled biological-physical model was used, treating the cove and the main lake as two compartments coupled by hydraulic exchange. For each scenario and each exchange rate 
assigned, the model was run for four years before initiating simulated treatments on January 1 of the fifth year. The 200 days of flushing treatment simulated thereafter followed a characteristic pattern, illustrated here for a simulation based on Rangers Slough, with three pumps deployed, and operated for either 5 or 7 days each week (Figure 17). For this illustration, the lowest measured exchange rate $\left(0.2 \mathrm{~d}^{-1}\right)$ was adopted.

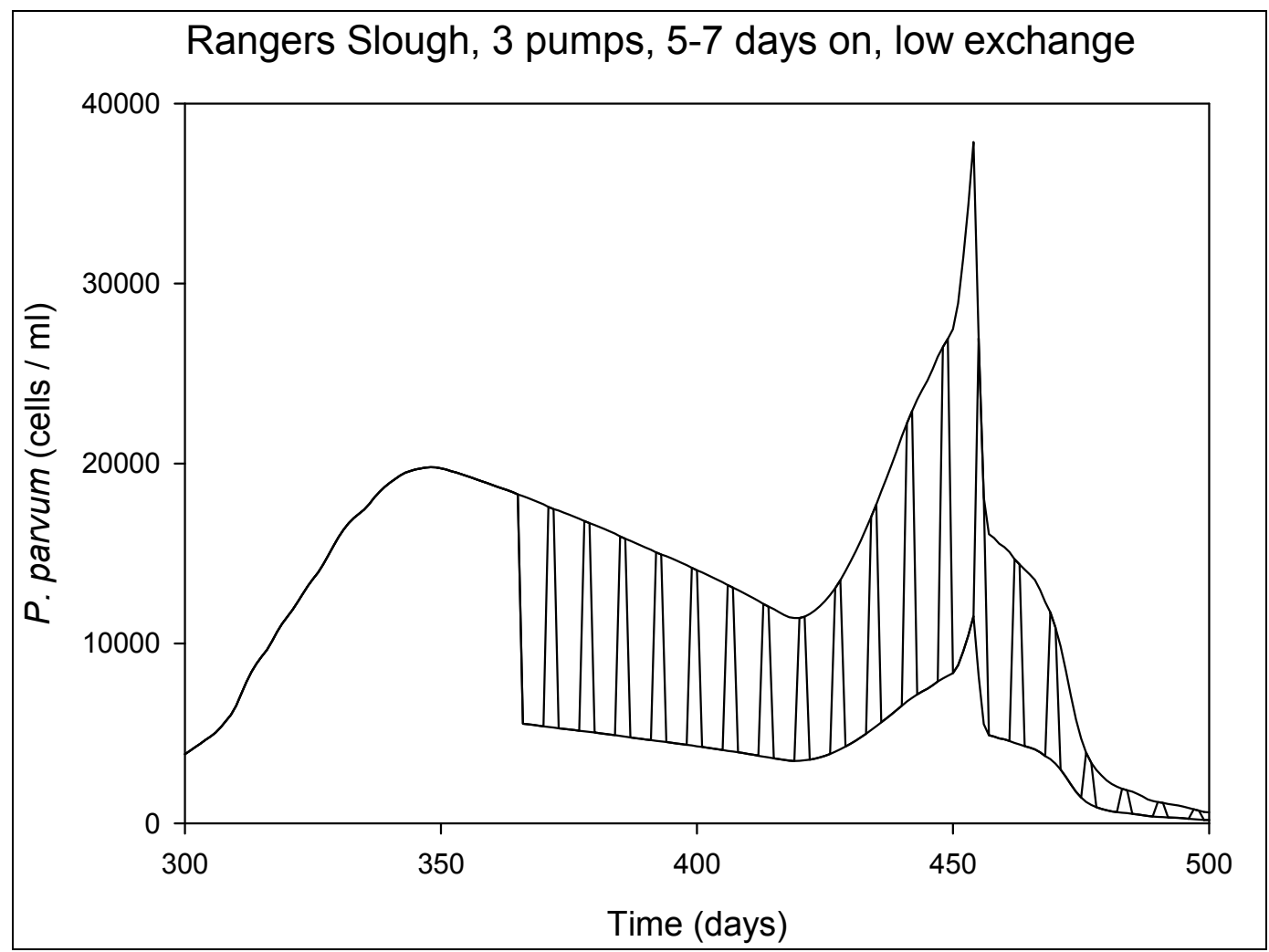

Figure 17. Illustrative time series of predicted $P$. parvum population density in Rangers Slough, with flushing treatments imposed intermittently (5 days out of 7 ), or continually ( 7 days out of 7 ).

In Figure 17, three time series of predicted $P$. parvum densities are displayed. The upper line is the predicted population density in the main lake. The other two lines display predicted population densities in the cove. Time is measured in days from the start of the fourth year of the run, and all three lines coincide until day 365 , the start of the fifth year, when flushing treatments are imposed. After the lines diverge, the lower line is the predicted population density with continual flushing of the cove (7 days of pumping per week). The intermediate line, bouncing from high to low, is the predicted population density with intermittent flushing of the cove ( 5 days of pumping per week). The model predicts that when pumps are on, the population density of $P$. parvum is rapidly reduced to a lower 
value. However, with intermittent pumping, population density recovers quickly during the two days that pumps are off and is close to that in the main lake.

These results indicate that continual flushing is predicted to reduce the density of $P$. parvum. However, intermittent flushing is rapidly overcome by exchange between the cove and main lake, such that $P$. parvum is reduced when pumping is on, but rapidly rises when it is off. These large fluctuations are driven by the force of exchange with the much larger main lake, and arise even when a relatively modest exchange rate is assumed. To make long-term comparisons among treatment scenarios using different numbers of pumps and schedules of intermittent (or continual) operation, $P$. parvum density over the 200 days of simulated flushing treatment was averaged, and the percent reduction below the main lake level was calculated for each model run and displayed in relation to the exchange rate (Figures 18 and 19).

The predicted reduction of $P$. parvum is sensitive to the treatment scenario adopted, and to the value of the exchange rate (Figures 18 and 19). For any scenario, the reduction is predicted to decrease as the exchange rate increases. This is expected, because with a larger exchange rate, pumping must overcome more rapid transport of $P$. parvum from the main lake. For the observed range of exchange rates in Rangers Slough, 0.20 to $0.25 \mathrm{~d}-1$, reduction in $P$. parvum relative to the main lake ranges from about $5 \%$ for the least effective treatments, up to about $70 \%$ for the most effective. Increasing the number of pumps or the number of days that they run always produces a greater reduction of $P$. parvum. For scenarios using 1,2 , or 3 pumps, continual pumping is always more effective, and reduces $P$. parvum density by $40-70 \%$ at the range of exchange rates observed in Rangers Slough.

\section{Bee Creek (cove A, from above)}

The results of modeling various bloom treatment scenarios for Bee Creek are similar to those described previously for Rangers Slough. The predicted reduction of $P$. parvum is again sensitive to the treatment scenario adopted, and to the value of the exchange rate (Figures 20 and 21). For any scenario, the reduction is predicted to decrease as the exchange rate increases. For the observed range of exchange rates in Bee Creek, 0.24 to $0.30 \mathrm{~d}^{-1}$, reduction in $P$. parvum relative to the main lake ranges from about $8 \%$ for the least effective treatments, up to about $80 \%$ for the most effective. 


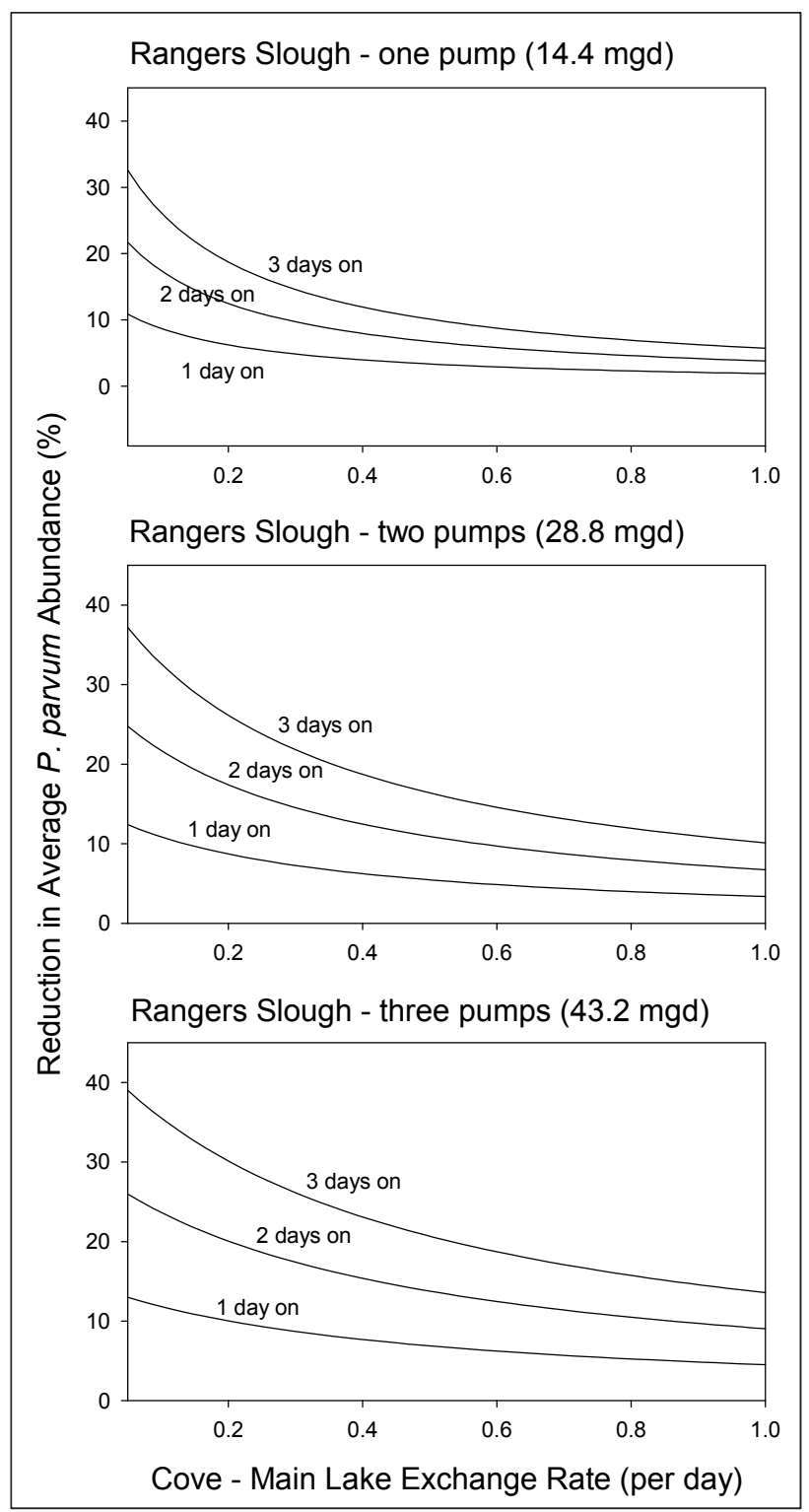

Figure 18. Reduction of $P$. parvum in Rangers Slough for flushing treatment scenarios with intermittent pumping for short periods (1-3 days out of 7 ). 


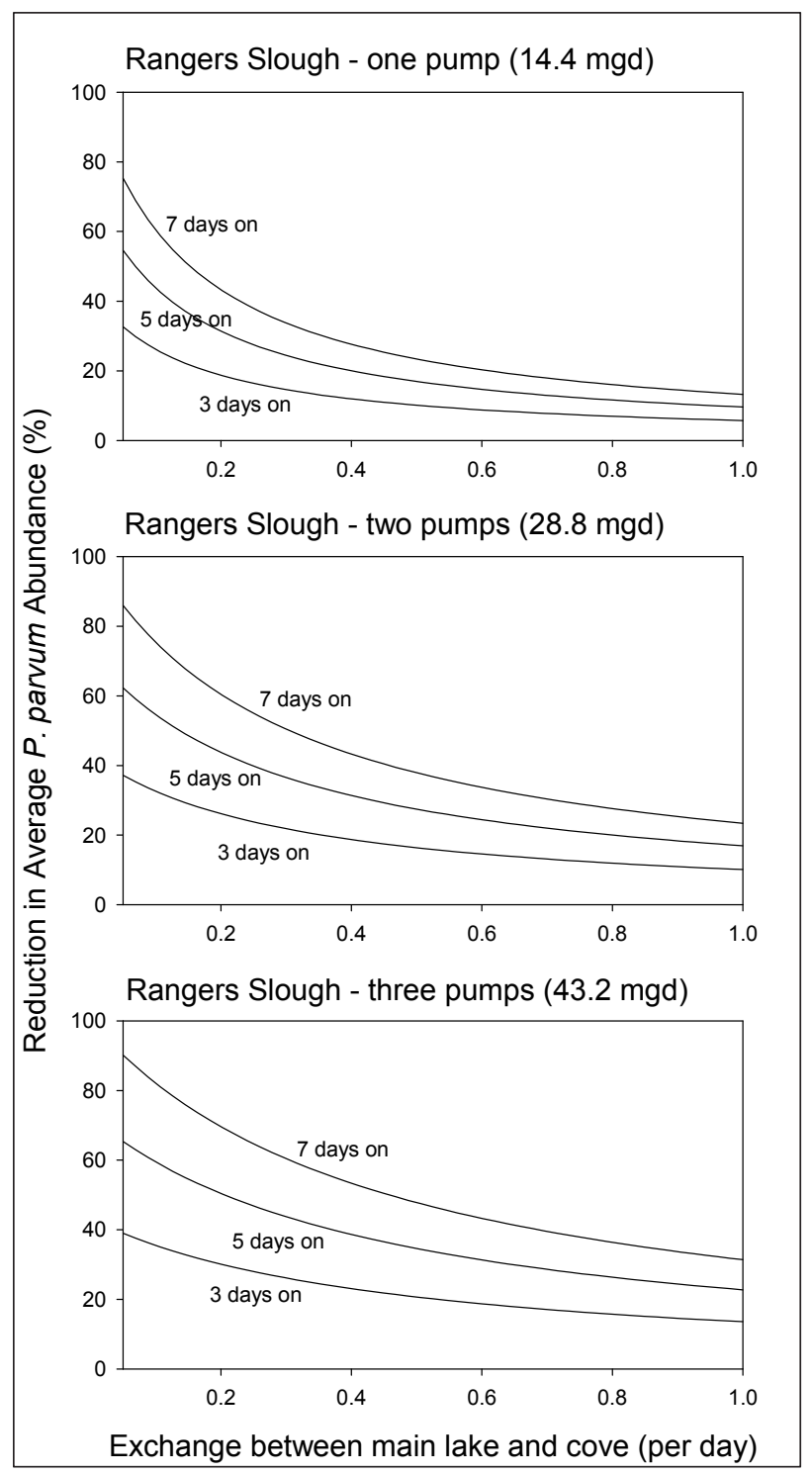

Figure 19. Reduction of $P$. parvum in Rangers Slough for flushing treatment scenarios with intermittent pumping for long periods ( $3-5$ days on out of 7 ), or continual pumping ( 7 days on out of 7 ). 


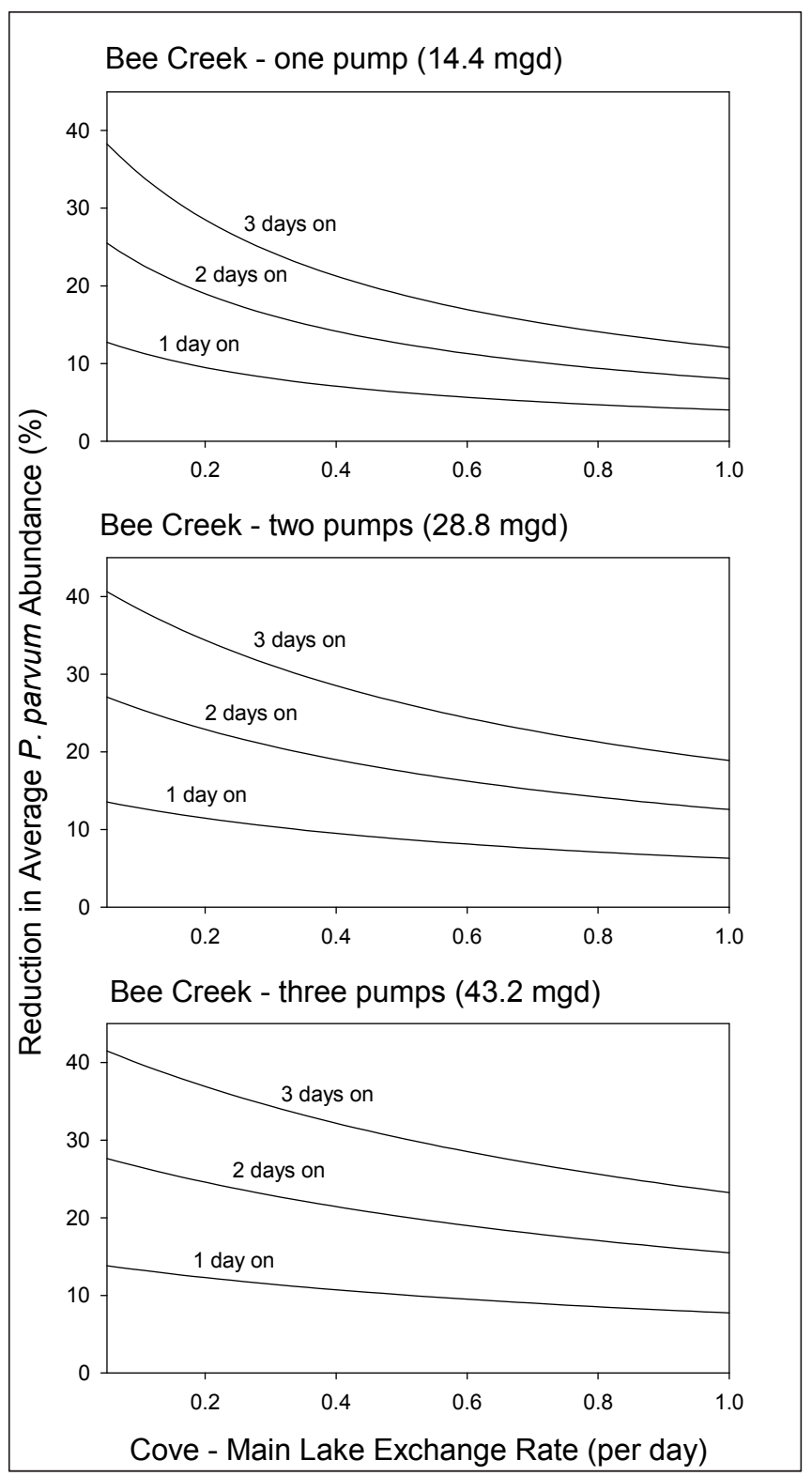

Figure 20. Reduction of $P$. parvum in Bee Creek for flushing treatment scenarios with intermittent pumping for short periods (1-3 days out of 7 ). 


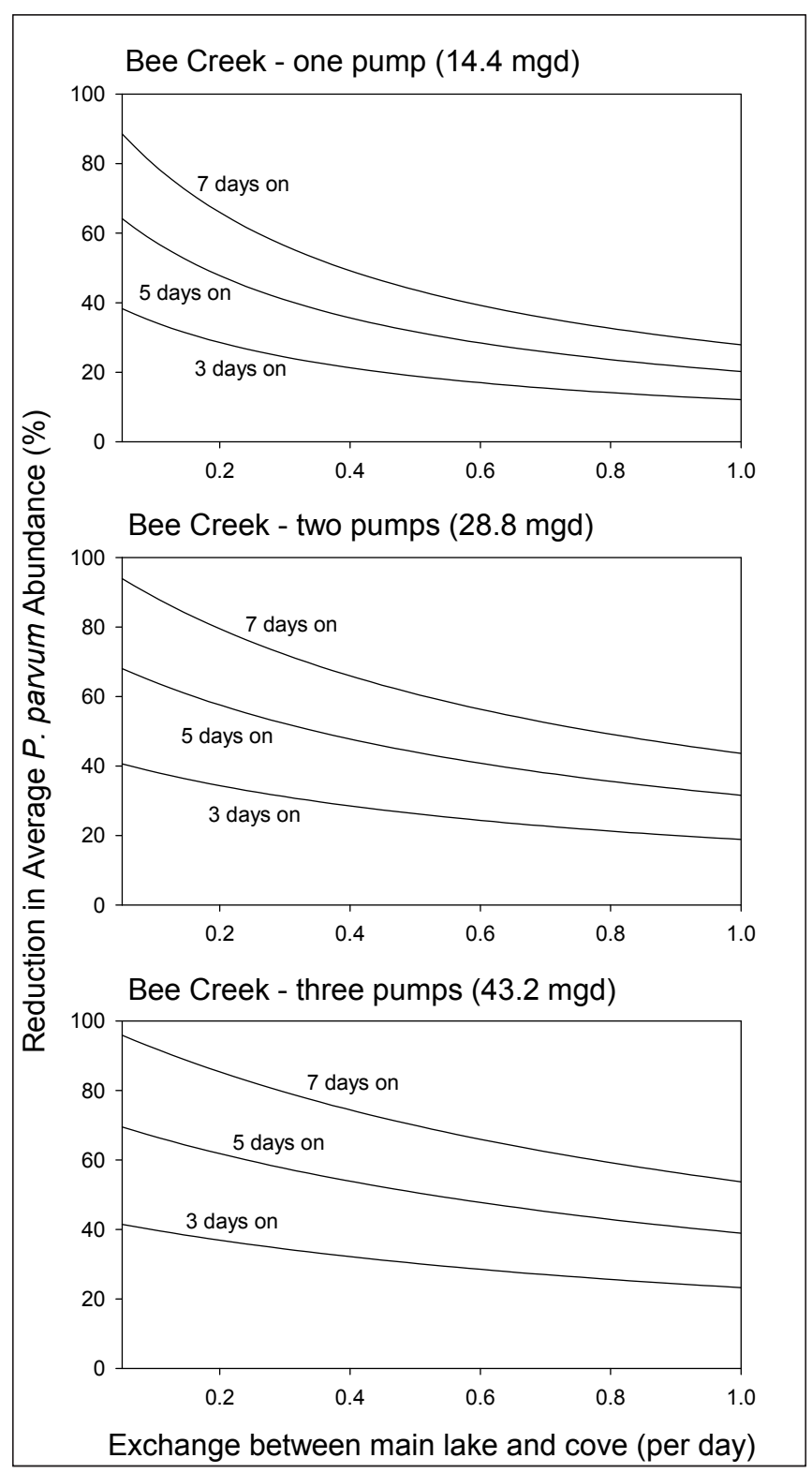

Figure 21. Reduction of $P$. parvum in Bee Creek for flushing treatment scenarios with intermittent pumping for long periods ( $3-5$ days out of 7 ), or continual pumping (7 days out of 7 ).

Increasing the number of pumps or the number of days that they run always produces a greater reduction of $P$. parvum. For scenarios using 1, 2, or 3 pumps, continual pumping is always more effective, and reduces $P$. parvum density by $60-80 \%$ at the range of exchange rates observed in Bee Creek. 


\section{Thorp's Spring}

The results of modeling various bloom treatment scenarios for Thorp's Spring are similar to those described previously for Rangers Slough and Bee Creek. The predicted reduction of $P$. parvum is again sensitive to the treatment scenario adopted, and to the value of the exchange rate (Figures 22 and 23). For any scenario, the reduction is predicted to decrease as the exchange rate increases. For the observed range of exchange rates in Thorp's Spring, 0.38 to $0.59 \mathrm{~d}^{-1}$ (excluding a low value of $0.06 \mathrm{~d}^{-1}$ whose measurement is suspect), reduction in $P$. parvum relative to the main lake ranges from about $5 \%$ for the least effective treatments, up to about $65 \%$ for the most effective. Increasing the number of pumps or the number of days that they run always produces a greater reduction of $P$. parvum. For scenarios using 1, 2, or 3 pumps, continual pumping is always more effective, and reduces $P$. parvum density by 30-65\% at the range of exchange rates observed in Thorp's Spring. 


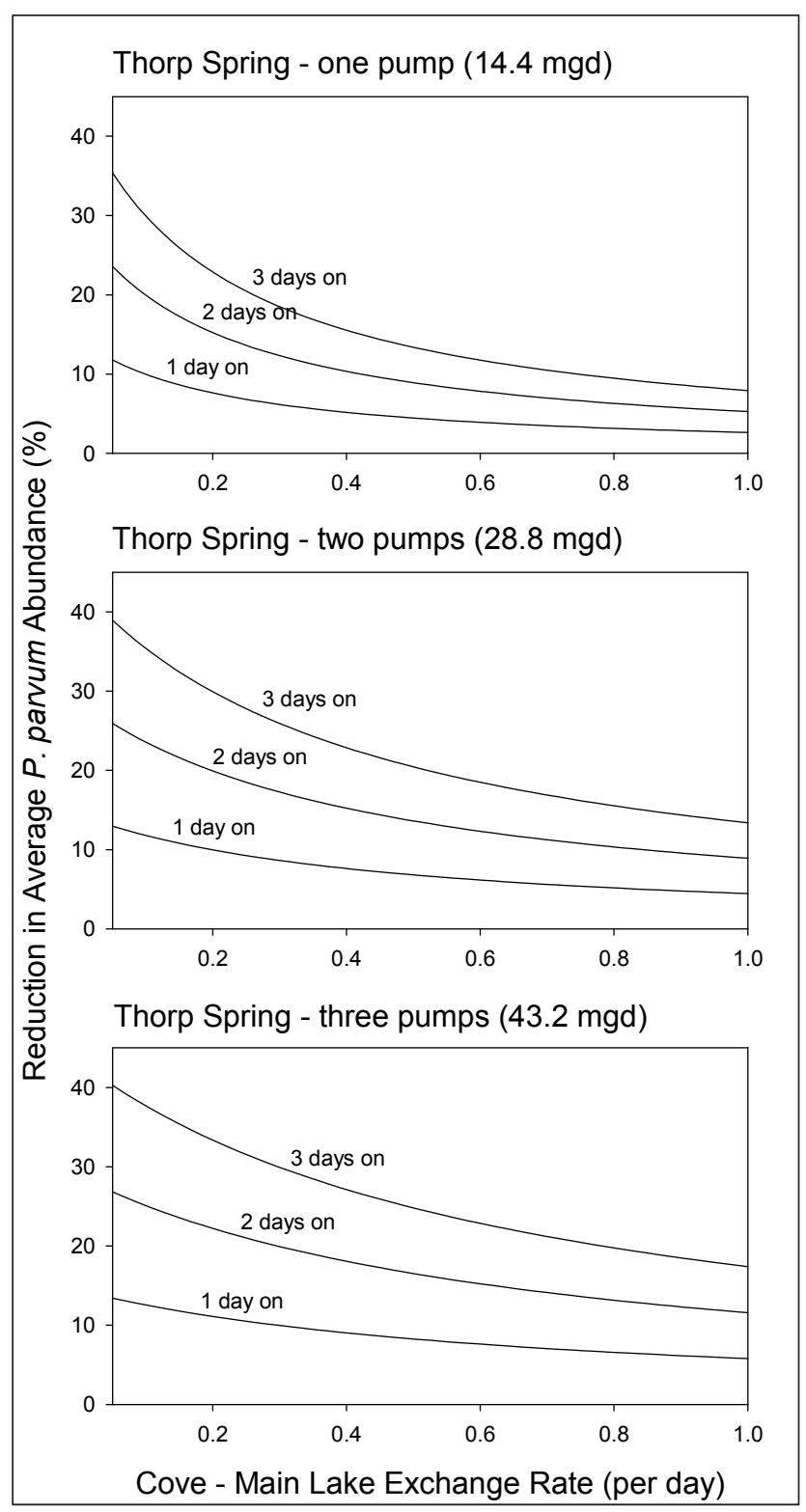

Figure 22. Reduction of $P$. parvum in Thorp's Spring for flushing treatment scenarios with intermittent pumping for short periods (1-3 days out of 7 ). 


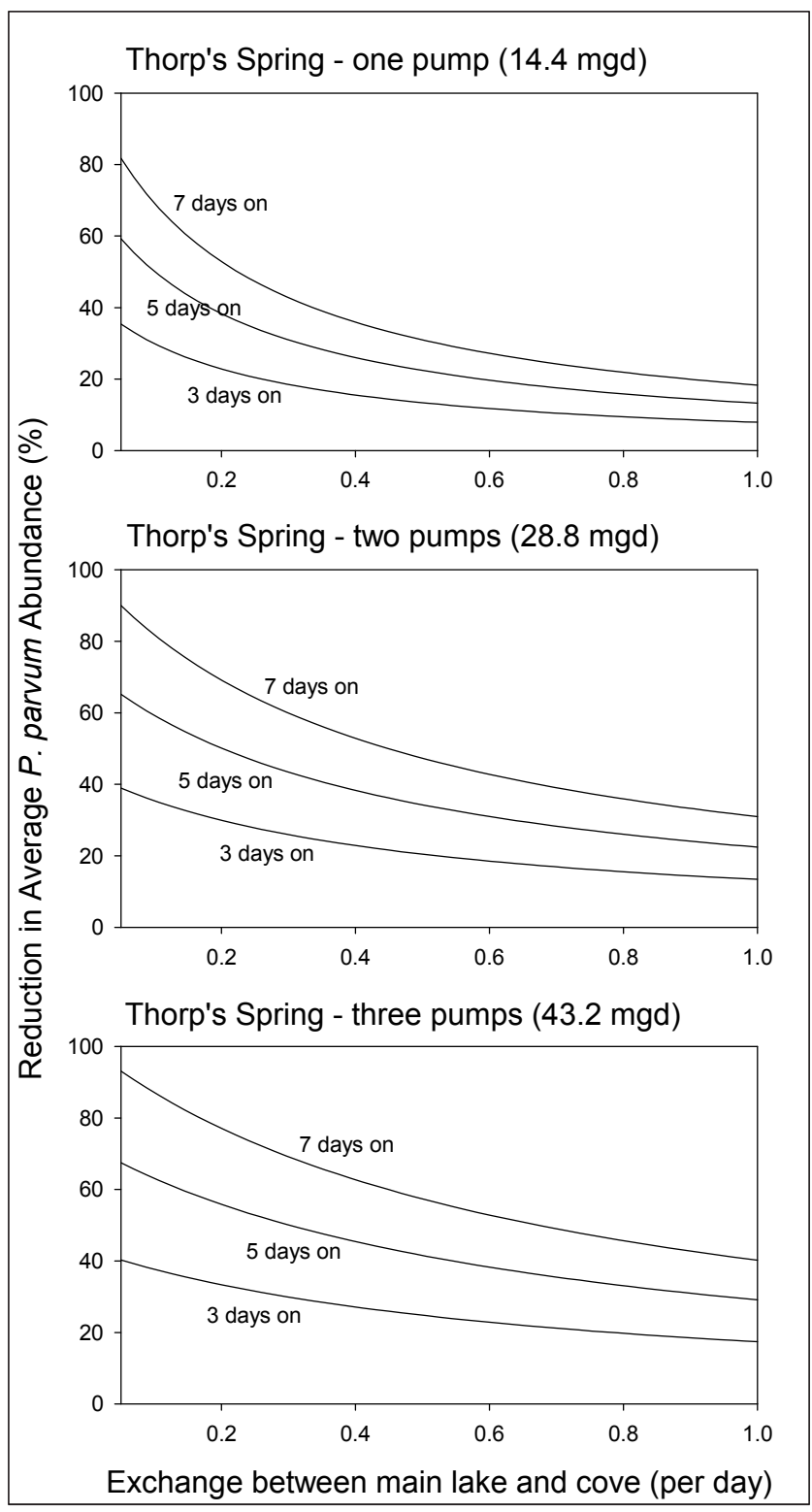

Figure 23. Reduction of $P$. parvum in Thorp's Spring for flushing treatment scenarios with intermittent pumping for long periods (3-5 days out of 7 ), or continual pumping ( 7 days out of 7 ). 


\section{Discussion}

\section{Efficacy of deepwater flushing}

Natural water exchange rates between coves and surface waters of the open lake were high. For Ranger's Slough and Bee Creek, two coves with a lower cove mouth cross-sectional area to volume ratio, water exchange rates were $\sim 0.25 \mathrm{~d}^{-1}$. For Thorp's Spring, exchange rates were more variable. But the one low exchange rate observed for this cove coincided with a lateexperiment wind event that suspended sediments. These sediments likely interfered with on-board fluorometer measurements. In turn, this likely resulted in an overestimation of Rhodamine WT late in the dye tracer experiment, thereby masking the true dissipation rate. If that observation is discounted, then water exchange rates for Thorp's Spring were higher than the other two coves. This finding would be consistent with having a larger cove mouth cross-sectional area to volume ratio for Thorp's Spring (0.0014) compared to Ranger's Slough (0.0007) and Bee Creek (0.0011).

Given water exchange rates of $\sim 0.25 \mathrm{~d}^{-1}$ and higher, it is not surprising that plankton dynamics and water quality changes in the coves of Lake Granbury were similar to those of the open lake in the historical record (Roelke, Brooks, and Grover, unpublished data). Homogenization effects in regards to community composition occur in systems where immigration rates are high (Leibold and Norberg 2004, Leibold et al. 2004). They occur because spatial heterogeneity in the system is lost. In other words, the system behaves as a single closed entity driven by processes acting at the system scale, which overwhelm local-scale processes. This generalized system response to high immigration has been observed in many other ecosystem types that include sea floor communities, alpine vegetation, and island fauna (Thrush et al. 2006, Britton et al. 2009, Masseti 2009). In Lake Granbury, it is likely that spatial heterogeneity is reduced due to high water exchange rates between coves and the surface waters of the open lake. The resulting high immigration of plankton likely leads to similar seasonal patterns observed between coves and the open lake.

In addition to homogenization effects arising at these high water exchange rates, it is likely that the presence of $P$. parvum influences plankton community composition and the seasonal plankton trajectory. This alga directly affects many competing phytoplankton through allelopathy, many 
zooplankton predators through toxicity, and preys on heterotrophic bacteria and some small protozoa (Ulitzur and Shilo 1964, Igarashi et al. 1995, Nygaard and Tobiesen 1993, Tillmann 2003, Fistarol et al. 2003, Rosetta and McManus 2003, Barreiro et al. 2005, Baker et al. 2007, 2009). Some of these interactions were observed at sub-lethal levels, and some effects were taxon-specific (Roelke et al. 2007, 2012b; Brooks et al. 2010, Remmel et al. 2011). So it is likely that $P$. parvum influences plankton compositional states, reducing the probability of differing community compositions, even during non-bloom periods. In this sense, $P$. parvum would be serving in the role of an ecosystem-engineering organism (sensu Jones et al. 1994).

Interestingly, water exchange rates between coves and surface waters of the open lake were not well predicted by the 24-hr averaged wind speed and direction, or inflow to the lake. It may be that dissipation of turbulence important to cove-open lake water exchanges occurs over longer periods. Alternatively, it may be that biotic and abiotic attributes of plankton environments are sensitive to processes occurring over periods less than $24 \mathrm{hr}$, such as grazing and excretion events by zooplankton and planktivorus fish. An experimental design involving several more dyetracer experiments timed throughout the year during periods of higher and lower winds and inflows would be needed to explore this directly. Currently, these data do not exist for Lake Granbury. Indirect evidence, however, showed that winds and inflows over longer periods influenced water exchanges between some coves and the open lake in the analysis of historical data (discussed below).

As mentioned previously, plankton dynamics and water quality changes in the coves of Lake Granbury were similar to those of the open lake. But they were not identical. The timing and magnitude of biomass and chemical concentration peaks varied with temporal offsets of $\sim 1-2$ months and peak magnitudes differed several-fold at times. Dissimilarity analysis focuses on these types of differences.

Temporal changes in dissimilarity measures were dynamic, with some coves showing greater variability than others. For example, cove A (Bee Creek) showed a gradual increase in dissimilarity with the open lake in 2008 while cove G (Ranger's Slough) showed erratic changes in dissimilarity during this same period. Intuitively, and in reference to biotic parameters, one can envision dissimilarity increasing over time after local communities become isolated, a notion stemming from Island Biogeography Theory (MacArthur 
and Wilson 1967). In plankton systems, where reproduction and competitive exclusion occur over short periods, it is anticipated that dissimilarity between communities might arise quickly, even at aggregated taxonomic levels (Cottenie et al. 2003, Xu et al. 2012). With the onset of immigration that would arise when waters begin to mix again, dissimilarity can decrease. This phenomenon was suggested to happen very quickly in plankton systems, and at very low levels of immigration (Roelke and Eldridge 2008, 2010). Dissimilarity would all but disappear with water exchanges between the cove and surface waters of the open lake, leading to a homogenized system state.

It is expected that water exchanges will be driven primarily by winds and inflows to a lake. As such, it is anticipated that dissimilarity between coves and the open lake should also closely follow winds and inflows. For the shorter periods investigated here $(24,48$, and $72 \mathrm{hr})$, this was only observed for some coves, however. For example, coves F, G, H, I, and J, all coves lower in the lake, showed a significant relationship in the multivariate regression models of biotic parameters. These models were strongly driven by inflows to the lake. Coves closer to the head of the lake did not show a significant relationship in the multivariate regression models.

It may be that inflows to the lake follow a laminar pattern of flow initially, i.e., when in "upstream" areas of the lake, but eventually yield to a more turbulent flow regime in "downstream" areas of the lake. Under such a scenario, lateral water exchanges with adjacent coves would be enhanced lower in the lake, and those coves would be more vulnerable to homogenization effects. The multivariate models that use the biotic data fit this explanation. The models using abiotic data, however, did not show this same trend. This is not surprising, however, in that abiotic parameters would not show sensitivity to mixing on par with the expected sensitivity of biotic parameters to immigration.

Winds also showed significant relationships in the multivariate regression models of biotic and abiotic parameters. But no consistent spatial trend emerged. For example, winds blowing in the direction of a cove mouth sometimes were significant in the multivariate regression models, as in cove G (Ranger's Slough). Surprisingly, this was the exception, not the norm. In addition, winds were commonly significant in the multivariate regression models when they were blowing perpendicular to the orientation of the cove's mouth. It is possible Ekman transport might have developed in such 
cases, driving a water exchange between cove and lake surface waters perpendicular to the direction of winds. Exploration of this circulation mechanism is beyond the scope of this study, however.

Dissimilarity in the coves situated higher in the lake (coves A-D) was not well explained in the multivariate regression models, and the coves highest in the lake (coves A and B) never correlated with winds or inflows. Furthermore, the strength of the multivariate regression models was poorly related to the measure of cove morphometry, i.e., cove mouth cross-sectional area to cove volume ratio.

Other factors likely influenced water exchange between coves and the open lake. These include morphometry of the open lake adjacent to coves and the lake's variable fetch. In regards to open lake morphometry, sills have developed over the life span of this reservoir and may impede water movement towards some coves. Sills may be more likely to form laterally to the mainstem of the lake closer to the point of river inflow. In that area, current deceleration begins as the system widens and deepens, allowing sediment deposition. In regards to fetch, Lake Granbury is sinuous. This results in coves with the same landscape orientation having varied relationships with winds. For example, cove I would be more susceptible to wind-driven mixing with southerly winds relative to cove $\mathrm{C}$ because of the open expanse of lake stretching southward from cove I and the narrow section of open lake in front of cove C. It does not seem likely that differences in water density would have an effect, as water temperatures were very similar between the coves and open lake, even when considering deeper waters, at this time of year.

While the results of this study shed only some light on the mechanisms driving water exchange between coves and surface waters of the open lake, they conclusively show that measured rates of water exchange are high and that the coves of Lake Granbury vary in their morphometry. Consequently, it follows that mitigating $P$. parvum blooms in coves through deepwater flushing will require different levels of pumping.

The model enables determination of pumping volumes and the duration pumps need to be turned on to achieve varied levels of bloom reduction. For example, at the $0.25 \mathrm{~d}^{-1}$ water exchange rate and assuming a target $50 \%$ reduction in $P$. parvum bloom, the model estimates that $\sim 29 \mathrm{mgd}$ of deepwater flushing (two pumps) for 5 days per week would be required in 
Ranger's Slough. Pumping at the lower rate of $\sim 15 \mathrm{mgd}$ (one pump) would not attain the targeted 50\% bloom reduction. For Bee Creek, a 50\% bloom reduction could be achieved by pumping $\sim 29 \mathrm{mgd}$ for 4 days per week, or by pumping $\sim 15 \mathrm{mgd}$ for 5 days per week. For Thorp's Spring, a $50 \%$ bloom reduction could be achieved by pumping $\sim 29 \mathrm{mgd}$ for 5 days per week or by continuously pumping at $\sim 15 \mathrm{mgd}$.

The measured exchange rates between coves and the open lake are large enough so that main lake and cove conditions are coupled in the absence of pumping, with homogenization effects masking the influence of localized processes. Modeling suggests that the coupling is not so strong that it cannot be overcome by deepwater pumping to reduce $P$. parvum. The model also suggests that pumping scenarios with higher and more continual flows will be the most effective.

\section{Recommendations}

Results of this study suggest that $P$. parvum blooms can effectively be mitigated in cove habitats of Lake Granbury through managed deep-water hydraulic flushing. The acting mechanisms that enable this approach to be effective are the hydraulic displacement of $P$. parvum populations from cove waters and the ecological disruption of bloom development that occurs with nutrient loading associated with flushing events. The next steps in research aimed at further developing this mitigation approach should be a coupled study involving model refinement and a valuation study.

\section{Model refinement}

Model predictions probably underestimate the flushing magnitude and duration of flow needed to mitigate $P$. parvum blooms. They assume the coves to be well-mixed entities. They are not. A model capturing the longitudinal aspects of coves, perhaps employing a one-dimensional framework, would better represent cove hydrology. Within a one-dimensional framework for the coves, the required amount of deep-water flushing from the open lake would be less than the estimates reported here. When a cove is flushed, its upper waters are likely cleared of $P$. parvum to a high degree, even if the mouth of the cove retains higher populations.

In addition, the open lake should be modeled with greater detail. While the open waters are not stratified in regards to temperature at this time of year, chemoclines are still likely to exist. Exchanging water between the 
open lake and coves at the volumes suggested here might have an effect on water chemistry of the open lake and possibly influence water quality "downstream." For this purpose, off-the-shelf models like CE-QUAL-W2 might be used.

\section{Valuation study}

The costs of infrastructure, pump operation, and maintenance need to be determined. The cost of pipe may be high, as it will have to contain waters being transported from deeper waters of the open lake to the head regions of coves. Lower pumping levels will lead to smaller diameter pipe requirements, and smaller pumps with lower energy consumption, thereby lowering total costs. This underscores the importance of model refinement. A valuation study would then compare these costs to what will be gained by implementing this mitigation strategy. Here, gains include an accelerated recovery rate of fisheries lake-wide, renewal of recreational use of the lake, and boosted commerce associated with increased visitors to the region. On these latter points, recovery rate of fisheries lake-wide and renewal of recreational use of the lake following successful $P$. parvum mitigation in coves has yet to be studied.

\section{Need for an in-lake demonstration}

The structure and parameterization of the numerical model is based on a decade of research focused on P. parvum in Texas waters. Even so, there are many uncertainties regarding ecological and foodweb interactions prior to and during blooms. For example, there appear to be grazers that are resistant to $P$. parvum toxins, and there appear to be bacterial and/or viral pathogens that affect $P$. parvum. Neither of these were depicted in the modeling due to lack of information, and either may be important as a bloom-influencing factor. Continued research is needed to focus on issues such as these, as it will improve the model predictions. But all models are ultimately limited in that they can never capture all the complexities of a natural ecosystem. As such, models can only predict what might happen. Consequently, an in-lake demonstration is needed for situations where ecosystem complexities, even if unknown, are influencing the system. Such a demonstration, guided by results from a more refined model and valuation study, is needed to advance the notion of $P$. parvum mitigation in Texas lakes. 


\section{References}

Amsinck, S.L., E. Jeppesen, and F. Landkildehus. 2005. Inference of past changes in zooplankton community structure and planktivorous fish abundance from sedimentary subfossils - a study of a coastal lake subjected to major fish kill incidents during the past century. Archiv für Hydrobiol. 162: 363-382.

Anderson, D.M., and D. L. Garrison.1997. The ecology and oceanography of harmful algal blooms. Limnol Oceanogr 42: 1009-1305.

Baker, J. W., J. P. Grover, B. W. Brooks, F. Ureña-Boeck, D. L. Roelke, R. Errera, and R. L. Kiesling. 2007. Growth and toxicity of Prymnesium parvum (Haptophyta) as a function of salinity, light and temperature. J. Phycol. 43: 219-227.

Baker, J.W., J. P. Grover, R. Ramachandrannair, C. Black, T. W. Valenti Jr., B. W. Brooks, and D. L. Roelke. 2009. Growth at the edge of the niche: An experimental study of the harmful alga Prymnesium parvum. Limnol. Oceanogr.: 54: 1679-1687.

Barreiro, A., C. Guisande, I. Maneiro, T.P. Lien, C. Legrand, T. Tamminen, S. Lehtinen, P. Uronen, and E. Granéli. 2005. Relative importance of the different negative effects of the toxic haptophyte Prymnesium parvum on Rhodomonassalina and Brachionusplicatilis. Aquat. Microb. Ecol. 38:259-267.

Britton, A. J., C. M. Beale, W. Towers, and R. L. Hewison. 2009. Biodiversity gains and losses: Evidence for homogenisation of Scottish alpine vegetation. Biological Conservation 142: 1728-1739.

Brooks, B. W., J. P. Grover, and D. L. Roelke. 2011. Prymnesium parvum, An emerging threat to inland waters. Environmental Toxicology and Chemistry (featured article). 30:1955-1964.

Brooks, B. W., S. V. James, T. W. Valenti, Jr., F. Urena-Boeck, C. Serrano, J. P. Berninger, L. Schwierzke, L. D. Mydlarz, J. P. Grover, and D. L. Roelke. 2010. Comparative toxicity of Prymnesium parvum in inland waters. Journal of American Water Resources Association 46:45-62.

Cottenie, K., E. Michels, N. Nuytten, and L. DeMeester. 2003. Zooplankton metacommunity structure: regional vs. local processes in highly interconnected ponds. Ecology 84:991-1000.

Dierberg, F. E., and T. A. DeBusk. 2005. An evaluation of two tracers in surface-flow wetlands: Rhodamine-wt and lithium. Wetlands 25:8-25.

Edvardsen, B., and E. Paasche. 1998. Bloom dynamics and physiology of Prymnesium and Chrysochromulina. In The physiological ecology of harmful algal blooms, D. M. Anderson, A. D. Cembella, and G. M. Hallegraff, ed., 193-208. Heidelberg: Springer-Verlag.

Fistarol, G. O., C. Legrand, and E. Granéli. 2003. Allelopathic effect of Prymnesium parvum on a natural plankton community. Mar. Ecol. Prog. Ser. 255:115-125. 
Grover, J. P., D. L. Roelke, B. W. Brooks. 2012. Modeling of plankton community dynamics characterized by algal toxicity and allelopathy: A focus on historical Prymnesium parvum blooms in a Texas reservoir. Ecological Modelling 227:147-161.

Grover, J. P., J. W. Baker, D. L. Roelke, and B. W. Brooks. 2010. Mathematical models of population dynamics of Prymnesium parvum in inland waters. J. Am. Water Res. Assoc. 46:92-107.

Grover, J. P., K. W. Crane, J. W. Baker, B. W. Brooks, and D. L. Roelke. 2011. Spatial variation of harmful algae and their toxins in flowing-water habitats: A theoretical exploration. Journal of Plankton Research 33:211-228.

Guo, M., P. J. Harrison, and F. J. R. Taylor. 1996. Fish kills related to Prymnesium parvum N. Carter (Haptophyta) in the Peoples Republic of China. J. Appl. Phycol. 8:111-117.

Hallegraeff, G. M. 1993. A review of harmful algal blooms and their apparent global increase. Phycologia 32:79-99.

Hayden, N. J., D. L. Roelke, B. W. Brooks, J. P. Grover, M. T. Neisch, T. W. Valenti, Jr., K. N. Prosser, G. M. Gable, G. D. Umphres, and N. C. Hewitt. 2012. Beyond hydraulic flushing: Deep water mixing takes the harm out of a haptophyte bloom. Harmful Algae 20:42-57.

Holdway, P. A., R. A. Watson, and B. Moss. 1978. Aspects of the ecology of Prymnesium parvum (Haptophyta) and water chemistry in Norfolk Broads, England. Freshwater Biol. 8:295-311.

Igarashi, T., Y. Oshima, M. Murata, and T. Yasumoto. 1995. Chemical studies on prymnesins isolated from Prymnesium parvum. In Harmful Marine Algal Blooms: Proceedings of the Sixth International Conference on Toxic Marine Phytoplankton, October 1993, Nantes, France, ed. P. Lassus, G. Arzul, E. ErardLe Denn, P. Gentien, and C. Marcaillou Le Baut, 303-308. Paris, France: Lavoisier Publishing.

James, T. L., and A. De La Cruz. 1989. Prymnesium parvum Carter (Chrysophyceae) as a suspect of mass mortalities of fish and shellfish communities in western Texas. Texas J. Sci. 41:429-430.

Johansson, N., and E. Granéli. 1999. Influence of different nutrient conditions on cell density, chemical composition and toxicity of Prymnesium parvum (Haptophyta) in semi-continuous cultures. J. Exp. Mar. Biol. Ecol. 239: 243-258.

Jones, C. G., J. H. Lawton, and M. Shachak. 1994. Organisms as ecosystem engineers. Oikos 69:373-386.

Kaartvedt, S., T. M. Johnsen, D. L. Aksnes, and U. Lie. 1991. Occurrence of the toxic phytoplagellate Prymnesium parvum and associated fish mortality in a Norwegian fjord system. Can. J. Fish. Aquat. Sci. 48:2316-2323.

Keefe, S. H., L. B. Barber, R. L. Runkel, J. N. Ryan, D. M. McKnight, and R. D. Wass. 2004. Conservative and reactive solute transport in constructed wetlands. Water Resources Research 40. DOI: 10.1029/2003WRo02130. 
Krasnotshchek G. P., and L .S. Abramowitsch. 1971. Mass development of Prymnesium parvum Cart. in fish breeding ponds. Hydrobiol. 7:54-55.

Leibold, M. A., and J. Norberg. 2004. Biodiversity in metacommunities: Plankton as complex adaptive systems? Limnol Oceanogr. 49:1278-1289.

Leibold, M. A., M. Holyyoak, N. Mouquet, P. Amarasekare, J. M. Chase, M. F. Hoopes, R. D. Holt,J. B. Shurin, R. Law, D. Tilman,M. Loreau, and A. Gonzalez. 2004. The metacommunity concept: A framework for multi-scale community ecology. Ecol Lett 7:601-613.

MacArthur, R. H., and E. O. Wilson. 1967. The theory of island biogeography. Princeton, NJ: Princeton University Press.

Madden, C. J., and J. W. Day, Jr. 1992. An instrument system for high speed mapping of chlorophyll-a and physico-chemical variables in surface waters. Estuaries 15: 421-427.

Maso, M., and E. Garcés. 2006. Harmful microalgae blooms (HAB), problematic and conditions that induce them. Mar. Pollut. Bull. 53:620-630.

Masseti, M. 2009. Mammals of the Mediterranean islands: Homogenisation and the loss of biodiversity. Mammalia 73: 169-202.

Moestrup, O. 1994. Economic aspects: Blooms, nuisance species, and toxins. In The haptophyte algae. Systematics Association Special, ed. J. C. Green and B. S. C. Leadbeater, 51: 265-285. Oxford, UK: Clarendon Press.

Nygaard, K., and A. Tobiesen. 1993. Bacterivory in algae - A survival strategy during nutrient limitation. Limnol. Oceanogr. 39:273-279.

Remmel, E. J., N. Kohmescher, J. H. Larson, and K. D. Hambright. 2011. An experimental analysis of harmful algae-zooplankton interactions and the ultimate defense. Limnology and Oceanography 56:461-470.

Roelke, D. L. 2000. Copepod food-quality threshold as a mechanism influencing phytoplankton succession and accumulation of biomass, and secondary productivity: A modeling study with management implications. Ecol Mod 134:245-274.

Roelke, D. L., and P. M. Eldridge. 2008. Mixing of supersaturated assemblages and the precipitous loss of species. The American Naturalist 171:162-175.

Roelke, D. L., and P. M. Eldridge. 2010. Losers in the 'Rock-Paper-Scissors' game: The role of non-hierarchical competition and chaos as biodiversity sustaining agents in aquatic systems. Ecological Modelling 221:1017-1027.

Roelke, D. L., and Y. Buyukates. 2001. The diversity of harmful algal bloom-triggering mechanisms and the complexity of bloom initiation. Hum. Ecol. Risk Assess. 7: 1347-1362.

Roelke, D. L., B. W. Brooks, J. P. Grover, D. M. Kalisek, and B. L. Harris. $2012 \mathrm{a}$. Approaches to Golden Algae control: In-lake mesocosm experiments. ERDC/EL CR-12-1. Vicksburg, MS: U.S. Army Engineer Research and Development Center. 
Roelke, D. L., B. W. Brooks, J. P. Grover, G. M. Gable, L. Schwierzke-Wade, and N. C. Hewitt. 2012b. Anticipated human population and climate change effects on algal blooms of a toxic haptophyte in the southcentral USA. Can. J. Fish. Aquat. Sci. 69(8): 1389-1404.

Roelke, D. L., G. M. Gable, T. W. Valenti, J. P. Grover, B. W. Brooks, and J. L. Pinckney. 2010. Hydraulic flushing as a Prymnesium parvum bloom-terminating mechanism in a subtropical lake. Harmful Algae 9:323-332.

Roelke, D. L., J. P. Grover, B. W. Brooks, J. Glass, D. Buzan, G. M. Southard, L. Fries, G. M. Gable, L. Schwierzke-Wade, M. Byrd, and J. Nelson. 2011. A decade of fishkilling Prymnesium parvum blooms in Texas: Roles of inflow and salinity. Journal of Plankton Research 33:243-254.

Roelke, D. L., R. Errera, R. Kiesling, B. W. Brooks, J. P. Grover, L. Schwierzke, F. UreñaBoeck, J. Baker, and J. L. Pinckney. 2007. Effects of nutrient enrichment on Prymnesium parvum population dynamics and toxicity: Results from field experiments, Lake Possum Kingdom, USA. Aquat. Microb. Ecol. 46:125-140.

Rosetta, C. H., and G. B. McManus. 2003. Feeding by ciliates on two harmful algal bloom species, Prymnesium parvum and Prorocentrum minimum. Harmful Algae 2:109-126.

Sager, D. R., A. Barkoh, D. L. Buzan, L. Fries, J. Glass, G. Kurten, J. Ralph, L. Singhurst, G. Southard, and L. Riley. 2008. Toxic Prymnesium parvum: A potential threat to U.S. Reservoirs. In Balancing Fisheries Management and Water Uses for Impounded River Systems, ed. M. S. Allen, S. Sammons, and M. J. Maccina, 261273. Bethesda, MD: American Fisheries Society.

Schwierzke-Wade, L., D. L. Roelke, B. W. Brooks, J. P. Grover, and T. W. Valenti, Jr. 2011. Prymnesium parvum bloom termination: Role of hydraulic dilution. Journal of Plankton Research 33: 309-318.

Skingel, T. R., S. E. Spencer, C. Q. Le, C. A. Serrano, L. D. Mydlarz, B. J. Scarbrough, K. A. Schug, B. W. Brooks, J. P. Grover. 2010. Hemolytic toxicity and nutritional status of Prymnesium parvum during population growth. Aquat. Micro. Ecol. 61: 141-148.

Smayda, T. J. 1990. Novel and nuisance phytoplankton blooms in the sea: Evidence for a global epidemicIn Toxic Marine Phytoplankton, ed. E. Granéli, 29-40. New York: Elsevier.

Sopanen, S., M. Koski, P. Kuuppo, P. Uronen, C. Legrand, and T. Tamminen. 2006. Toxic haptophyte Prymnesium parvum affects grazing, survival, egestion and egg production of the calanoid copepods Eurytemora affinis and Acartia bifilosa. Mar. Ecol. Prog. Ser. 327:223-232.

Southard, G. M., L. T. Fries, and A. Barkoh. 2010. Prymnesium parvum: The Texas experience. J. Am. Water Res. Assoc. 46:14-23.

Suijlen, J. M., and J. J. Buyse. 1994. Potentials of photolytic rhodamine WT as a largescale water tracer assessed in a long-term experiment in the Loosdrecht lakes. Limnol. Oceanogr. 39:1411-1423. 
Tai, D. Y., and R. E. Rathbun. 1988. Photolysts of rhodamine-WT dye. Chemosphere 17:559-573.

Texas Parks and Wildlife Deparment (TPWD). 2003. Prymnesium parvum Workshop Report. Austin, TX. (http://www.tpwd.state.tx.us/landwater/water/environconcerns/hab/).

Thrush, S. F., J. S. Gray, J. E. Hewitt, and K. I. Ugland. 2006. Predicting the effects of habitat homogenization on marine biodiversity. Ecological Applications 16:16361642.

Tillmann, U. 2003. Kill and eat your predator: A winning strategy of the planktonic flagellate Prymnesium parvum. Aquat. Microbial. Ecol. 32:73-84.

Ulitzur, S., and M. Shilo. 1964. A sensitive assay system for determination of the ichthyotoxicity of Prymnesium parvum. J. Gen. Microbiol. 36:161-169.

Upstill-Goddard, R. C., J. M. Suijlen, G. Malin, and P. D. Nightingale. 2001. The use of photolytic rhodamines WT and sulpho $\mathrm{G}$ as conservative tracers of dispersion in surface waters. Limnol. Oceanogr. 46:927-934.

Van Dolah, F. M., D. L. Roelke, and R. Greene. 2001. Health and ecological impacts of harmful algal blooms: Risk assessment needs. Hum Ecol. Risk Assess. 7:13291345 .

van Rijn, J., and M. Shilo. 1989. Environmental factors in fish culture systems. In Fish culture in warm water systems: Problems and trends, ed. M. Shilo and S. Sarig, 163-177. Boca Raton, FL: CRC Press, Inc.

Xu, Y., Q. Cai, M. Shao, and X. Han. 2012. Patterns of asynchrony for phytoplankton fluctuations from reservoir mainstream to a tributary bay in a giant dendritic reservoir (Three Gorges Reservoir, China). Aquatic Science 74:287-300. 


\section{Appendix A: High-resolution Spatial Mapping of Rhodamine WT}

This appendix shows the high-resolution spatial mapping of Rhodamine

WT in the three coves of focus for the tracer studies: Ranger's Slough, Bee Creek, and Thorp's Spring. Also shown are the transects the boat followed while generating the data for the high-resolution maps, and the fixed position stations where the vertical profiling was performed. 


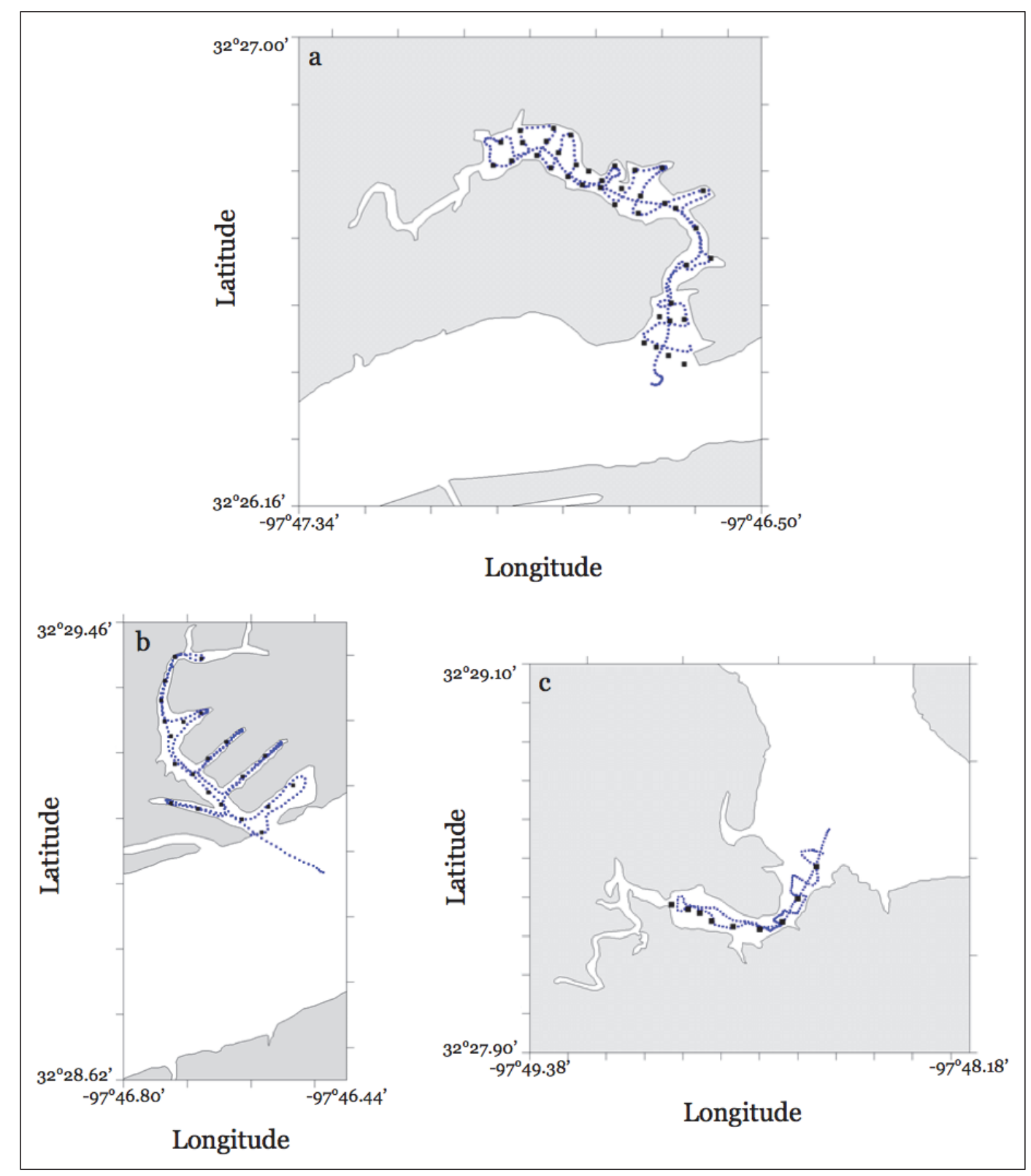

Figure A1. Rhodamine WT dissipation experiments were conducted in Ranger's Slough (a), Bee Creek (b), and Thorp's Spring (c), Lake Granbury (USA). Experiments consisted of surface water horizontal mapping based on a boat following closely spaced transects (dotted lined) and vertical profiling at fixed location stations (filled circles). 

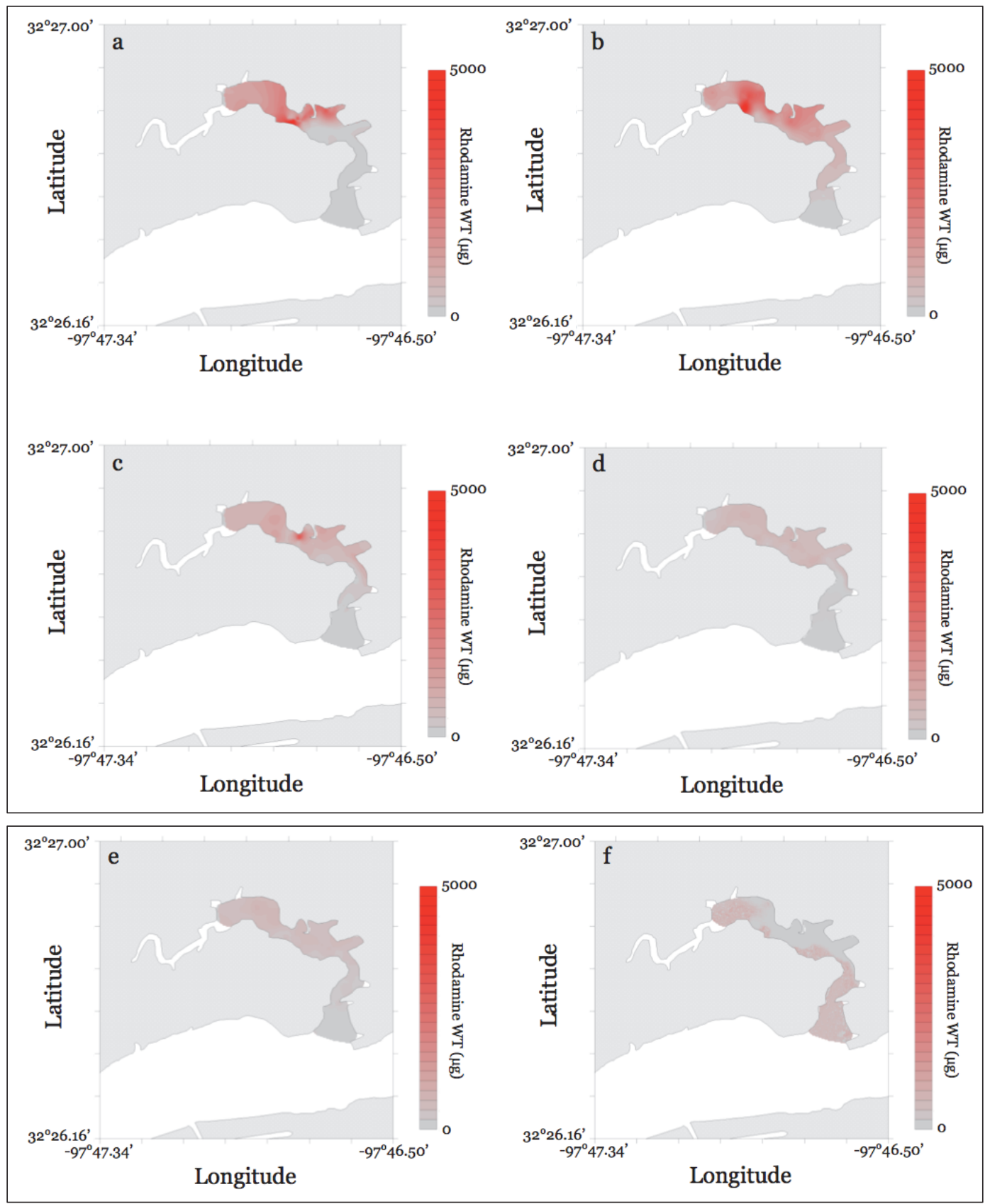

Figure A2. Rhodamine WT distribution in Ranger's Slough during the first experiment (February) on days one (a), two (b), three (c), four (d), five (e), and six (f). 


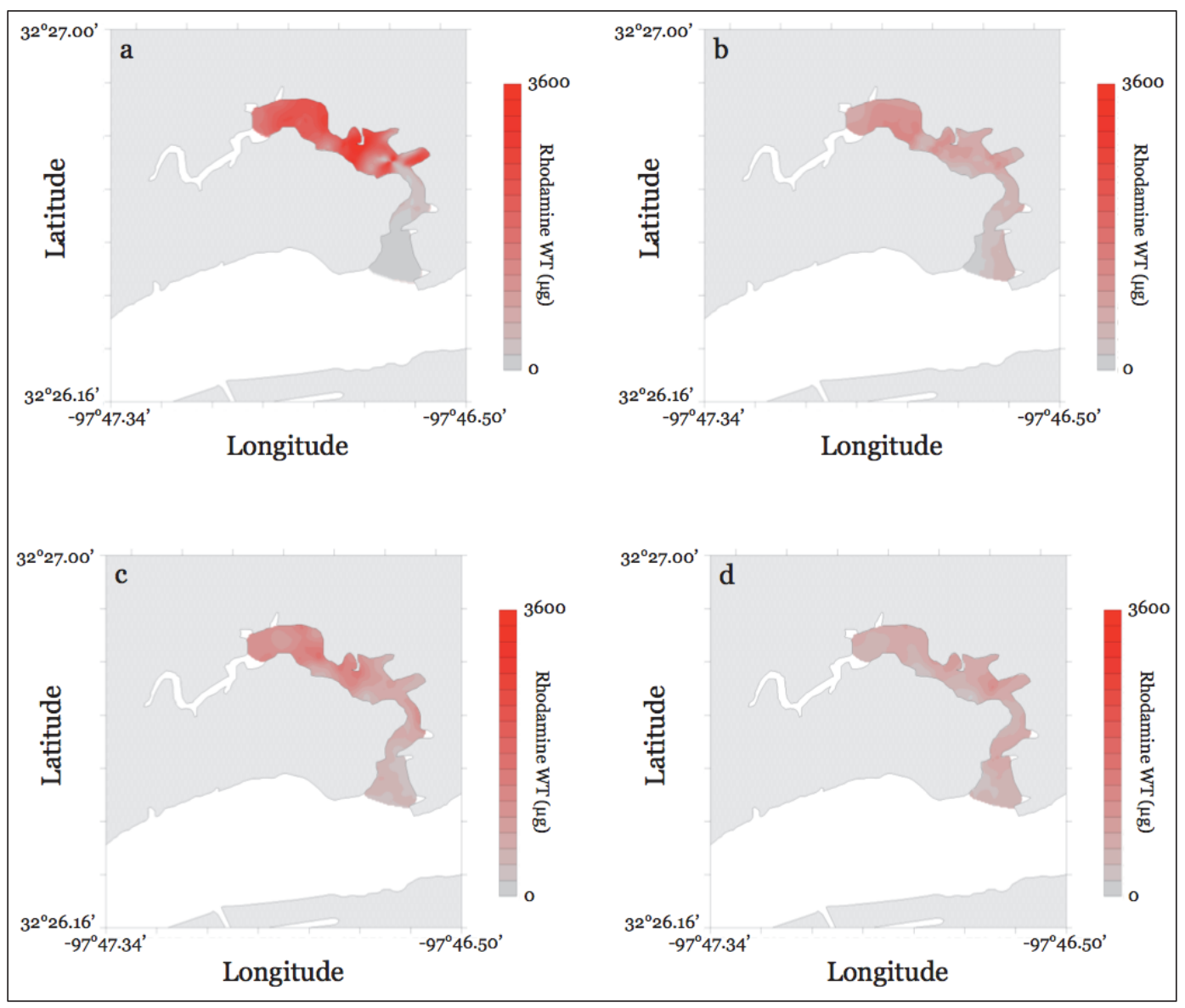

Figure A3. Rhodamine WT distribution in Ranger's Slough during the second experiment (April) on days one (a), two (b), three (c), and four (d). 


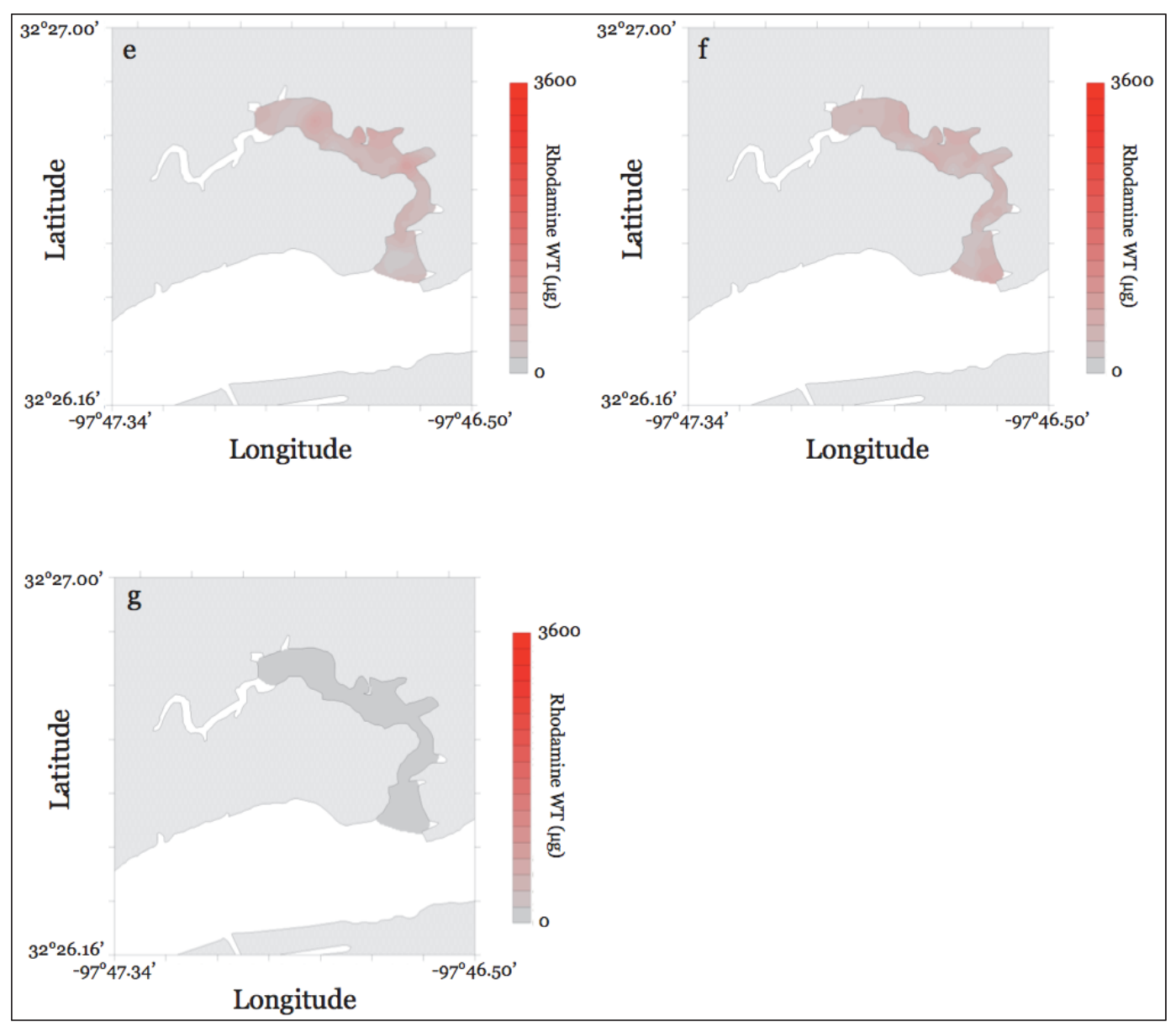

Figure A4. Rhodamine WT distribution in Ranger's Slough during the second experiment (April) on days five (e), six (f) and seven (g). 


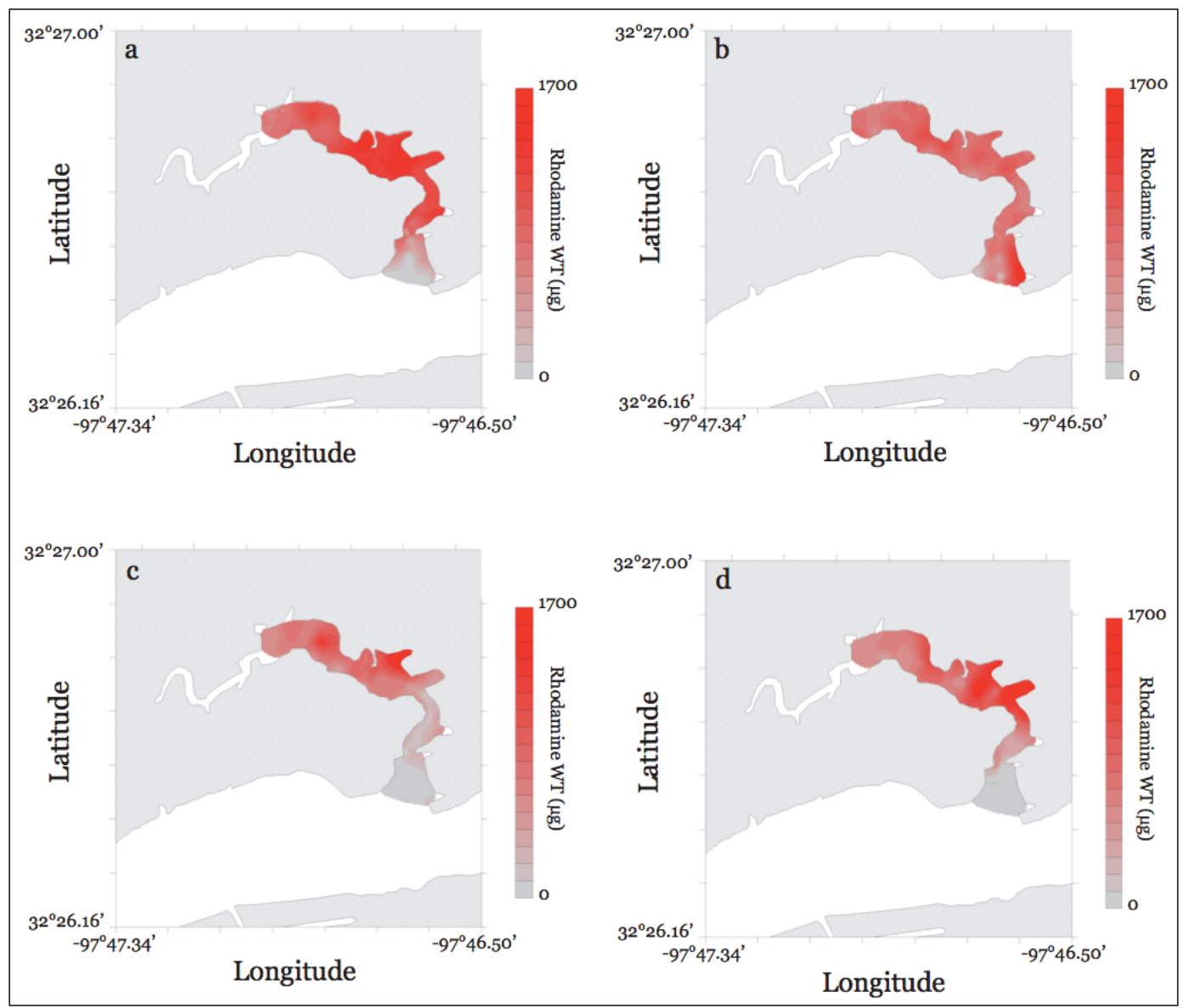

Figure A5. Rhodamine WT distribution in Ranger's Slough during the third experiment (June) on days one (a), two (b), three (c), and four (d). 


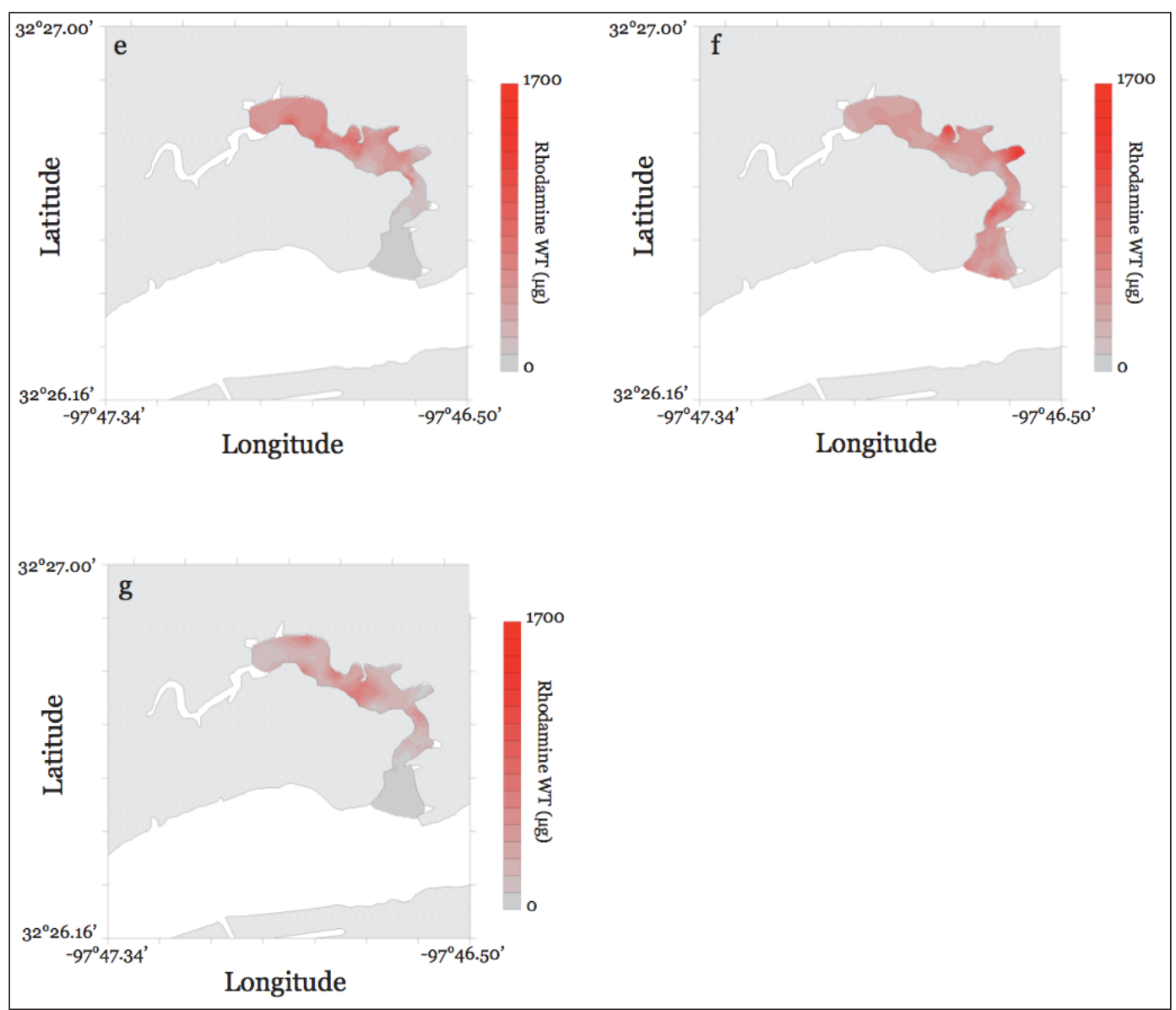

Figure A6. Rhodamine WT distribution in Ranger's Slough during the third experiment (June) on days five (e), six (f), and seven (g). 


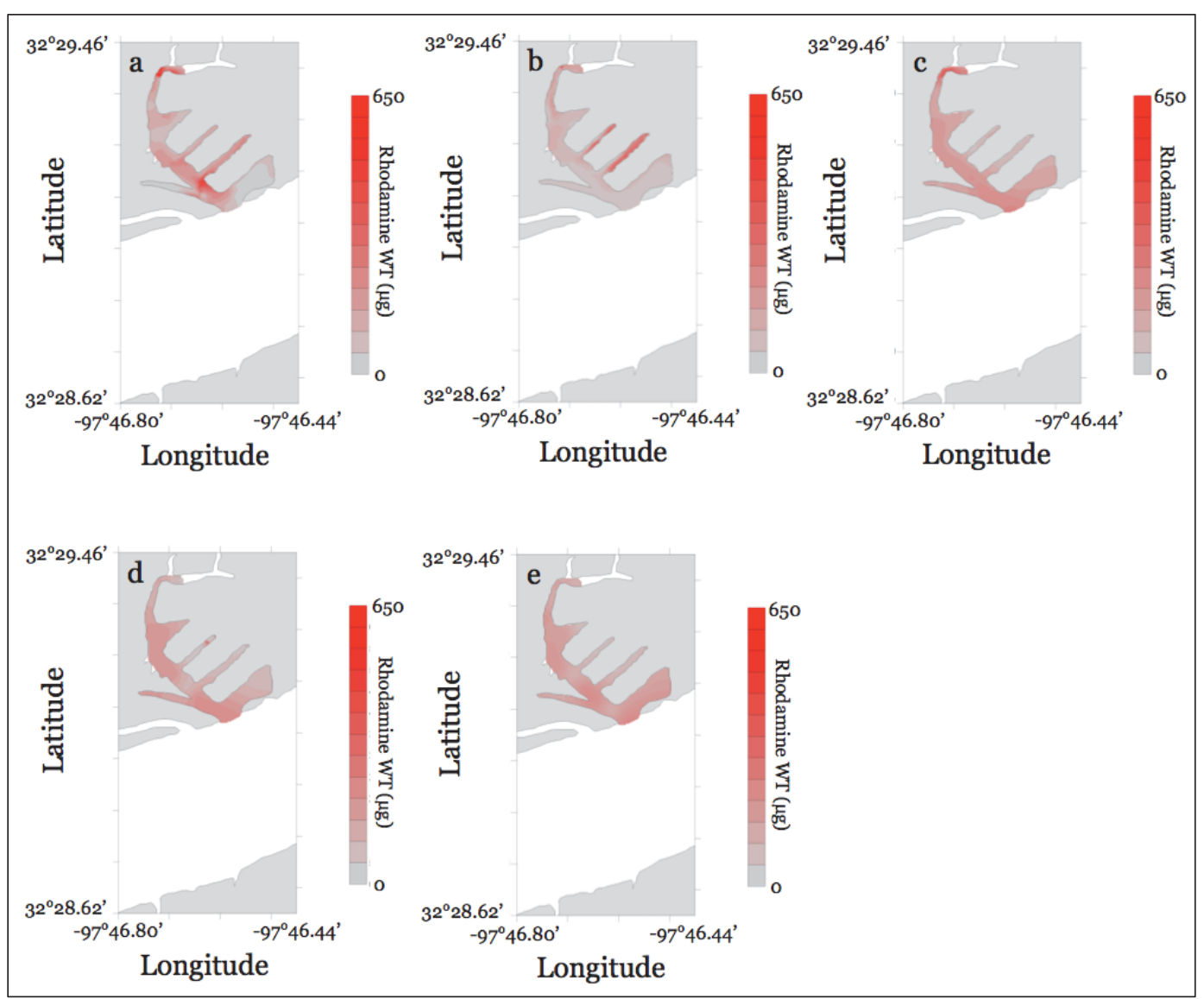

Figure A7. Rhodamine WT distribution in Bee Creek during the first experiment (February) on days one (a), two (b), three (c), four (d), and five (e). 


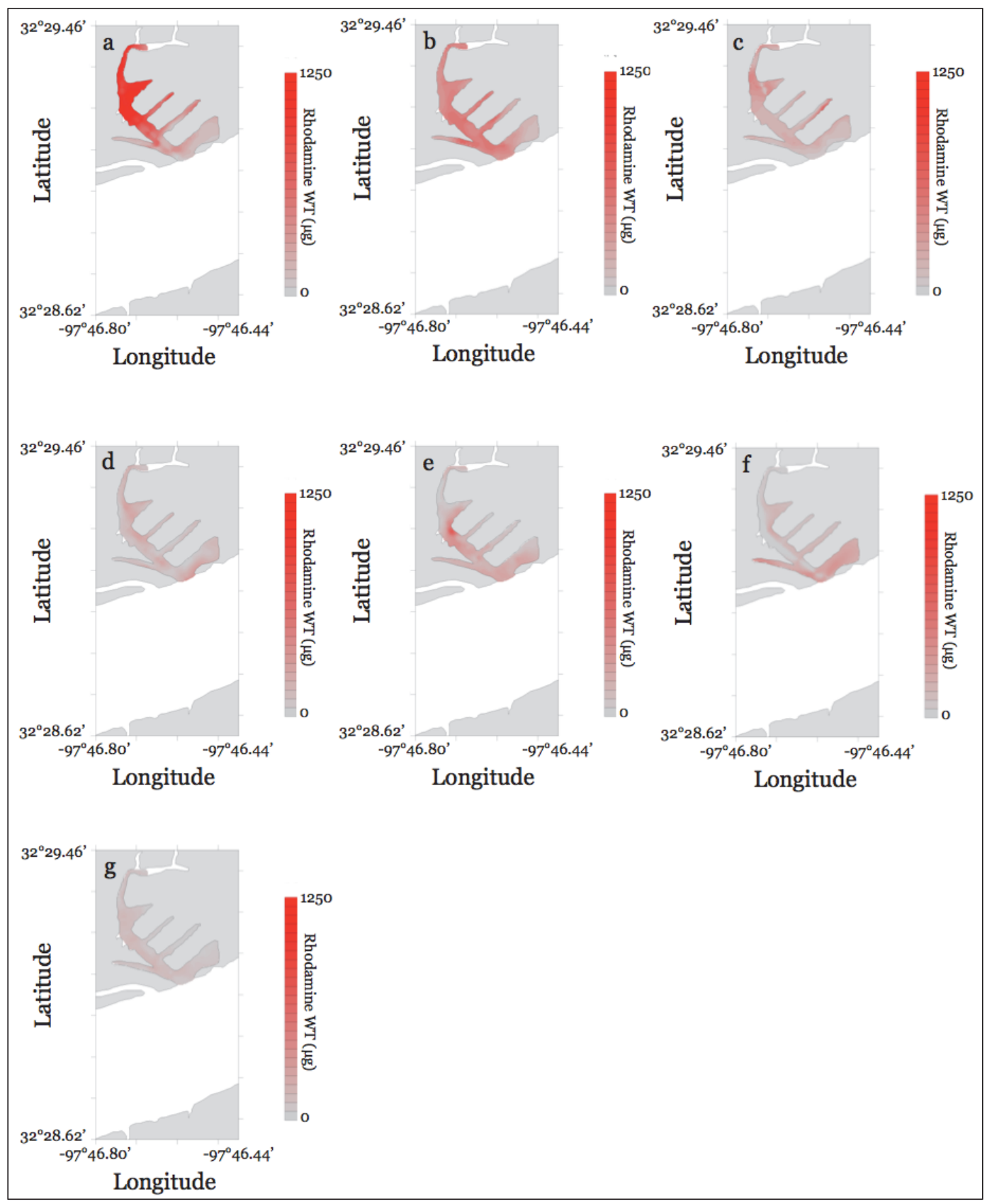

Figure A8. Rhodamine WT distribution in Bee Creek during the second experiment (April) on days one (a), two (b), three (c), four (d), five (e), six (f), and seven (f). 


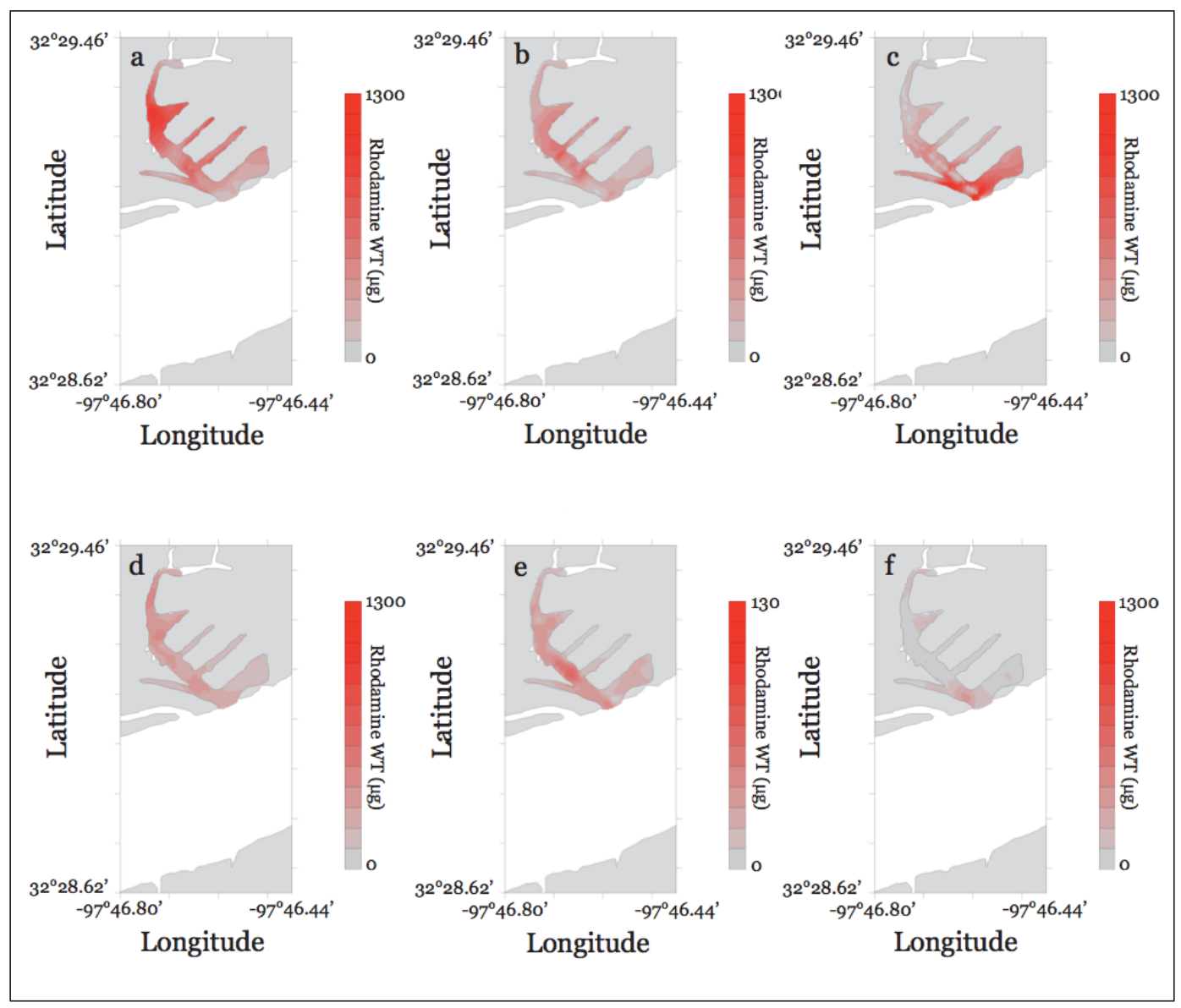

Figure A9. Rhodamine WT distribution in Bee Creek during the third experiment (June) on days one (a), two (b), three (c), four (d), five (e), and six (f). 


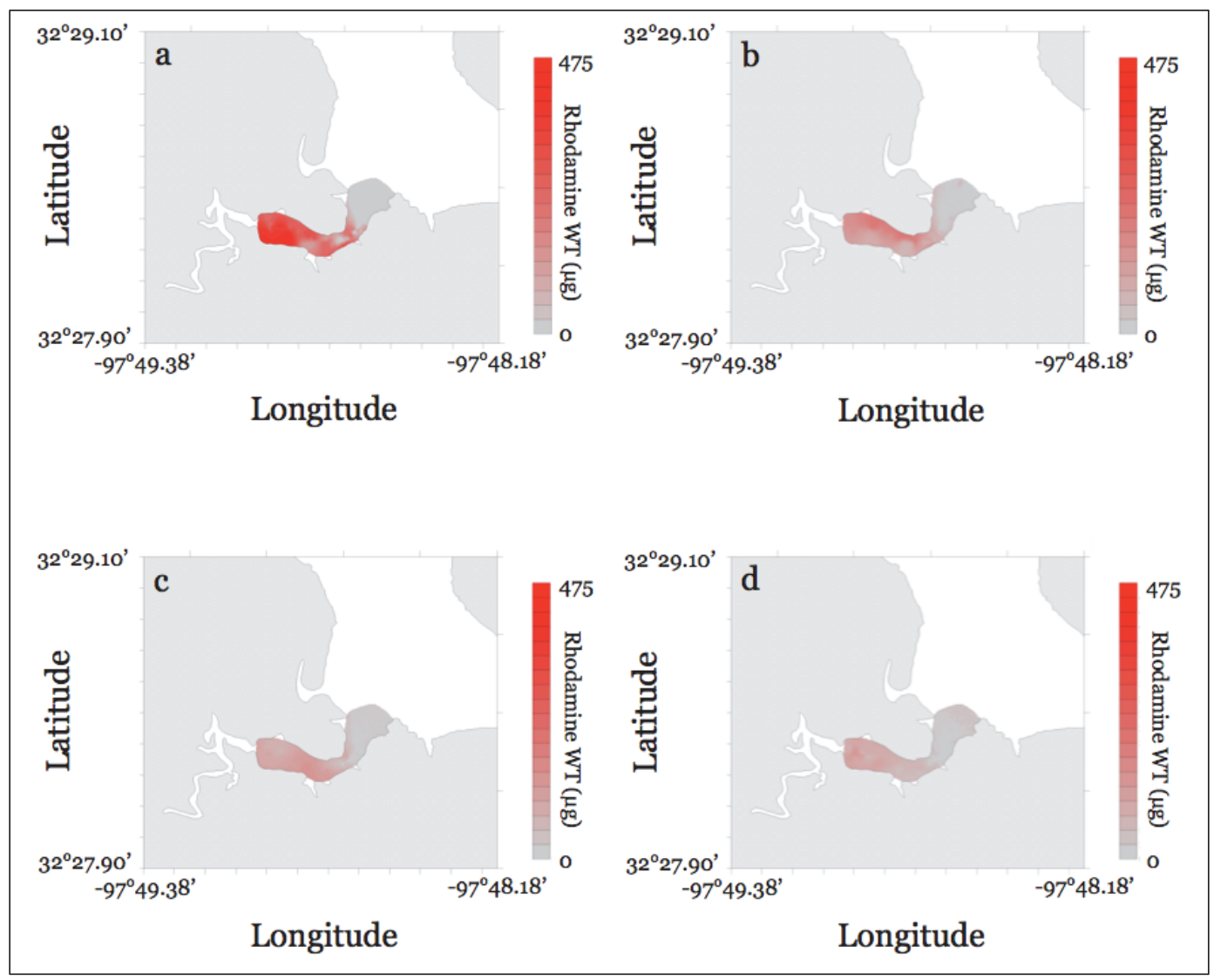

Figure A10. Rhodamine WT distribution in Thorp's Spring during the first experiment (February) on days one (a), two (b), three (c), and four (d). 


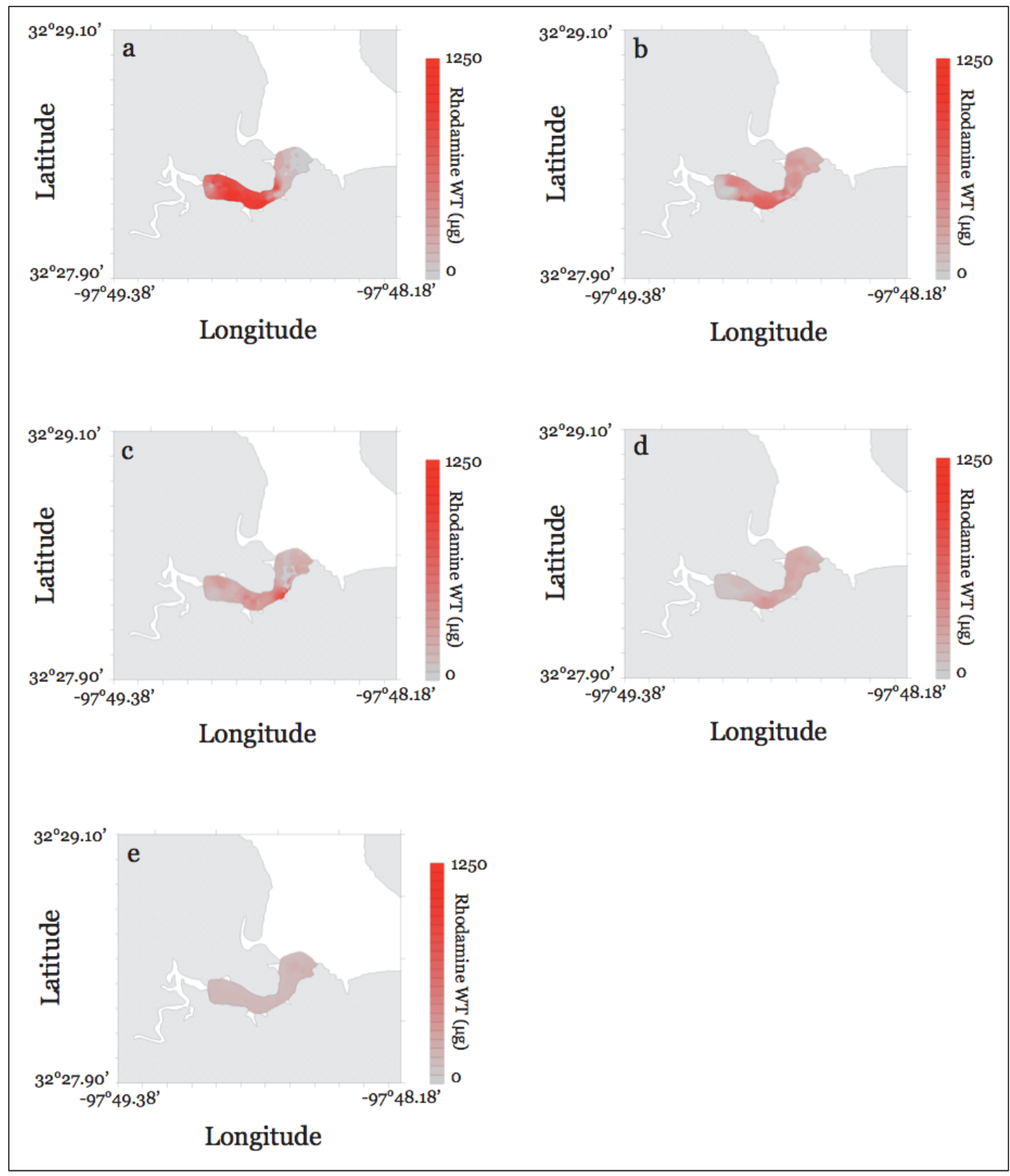

Figure A11. Rhodamine WT distribution in Thorp's Spring during the second experiment (April) on days one (a), two (b), three (c), four (d), and five (e). 


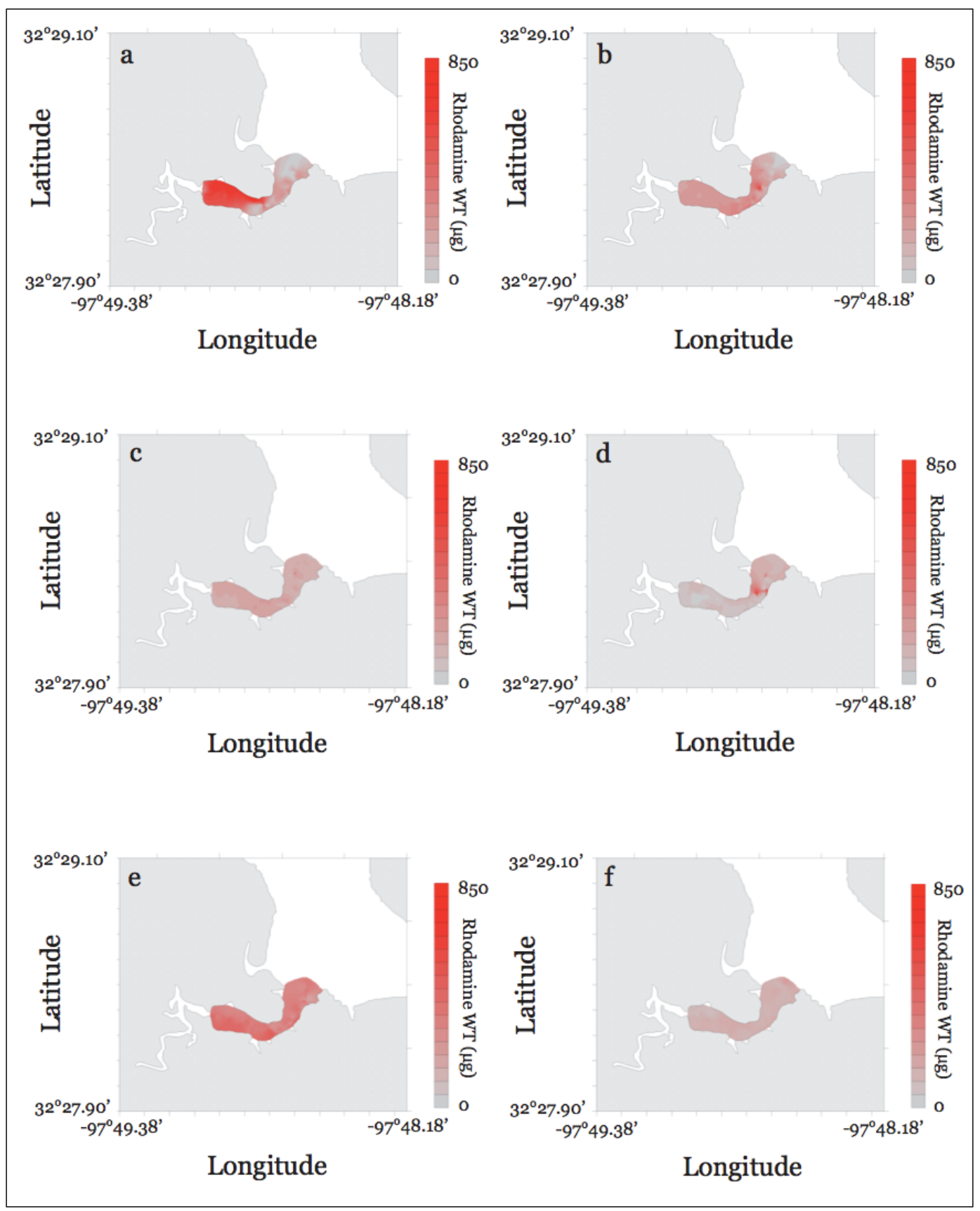

Figure A12. Rhodamine WT distribution in Thorp's Spring during the third experiment (June) on days one (a), two (b), three (c), four (d), five (e), and six (f). 


\section{Appendix B: Numerical Modeling Details}

This appendix presents governing equations, variable and parameter definitions, parameter values, forcing parameters, and other technical details for the coupled biological-physical model used for numerical simulations of $P$. parvum bloom dynamics.

Equations for the biological reactions in the model are:

$$
\begin{gathered}
R_{Z}=\mu_{Z} Z-m_{Z} Z \\
R_{i}=\mu_{i} N_{i}-Z \frac{f_{i}}{V_{i}}, \quad i=p, c \\
R_{R}=-\sum_{i} \mu_{i} N_{i} q_{R, i}+Z \sum_{i}\left(\frac{f_{i} q_{R, i}}{V_{i}}-\mu_{Z} q_{R, Z}\right), i=p, c \\
R_{S}=-\sum_{i} \mu_{i} N_{i} q_{S, i}+Z \sum_{i}\left(\frac{f_{i} q_{S, i}}{V_{i}}-\mu_{Z} q_{S, Z}\right), i=p, c \\
R_{C}=\mu_{C} N_{C} \varepsilon_{C}-k_{C} C \\
R_{P}=\left(\mu_{p}^{\mathrm{opt}}-\mu_{p}\right) N_{p} \varepsilon_{P}-k_{P} P
\end{gathered}
$$

where

$$
\begin{aligned}
Z & =\text { population density of zooplankton } \\
N_{p} & =\text { population density of } P \text {. parvum } \\
N_{c} & =\text { population density of other algae } \\
R & =\text { concentration of phosphate } \\
N & =\text { concentration of nitrate } \\
C & =\text { concentration of toxin produced by cyanobacteria } \\
P & =\text { concentration of toxin produced by } P . \text { parvum }
\end{aligned}
$$

$R_{Z}, R_{p}, R_{c}, R_{R}, R_{S}, R_{C}$ and $R_{P=\text { respective reaction rates for the above }}$ variables. Table $\mathrm{B} 1$ lists the definitions of all notation, units, and parameter values used in the model. The equation system (B.1) is the same set of 
biological reactions and interactions used in a previous one-compartment, chemostat model for Lake Granbury (Grover et al. 2012). Further explanation of the assumptions underlying the governing equations is available in this publication.

Table B1. Notation, units, and parameter values

\begin{tabular}{|c|c|c|c|}
\hline Quantity & Meaning & Units & Value \\
\hline \multicolumn{4}{|c|}{ State Variables } \\
\hline$Z_{k}$ & $\begin{array}{l}\text { Zooplankton volume density in compartment } \\
k ; k=1 \text { for main lake, } k=2 \text { for cove }\end{array}$ & $\mu \mathrm{m}^{3}$ liter $^{-1}$ & Variable \\
\hline$N_{i, k}$ & $\begin{array}{l}\text { Population density for algal type } i \text { in } \\
\text { compartment } k ; i=p \text { for } P \text {. parvum, } i=c \text { for } \\
\text { cyanobacteria }\end{array}$ & Cells liter-1 & Variable \\
\hline$R_{k}$ & $\begin{array}{l}\text { Dissolved phosphate concentration in } \\
\text { compartment } k\end{array}$ & $\mu \mathrm{mol}$ liter-1 $^{-1}$ & Variable \\
\hline$S_{k}$ & $\begin{array}{l}\text { Dissolved nitrate concentration in } \\
\text { compartment } k\end{array}$ & $\mu \mathrm{mol}$ liter-1 & Variable \\
\hline$C_{k}$ & $\begin{array}{l}\text { Dissolved cyanotoxin concentration in } \\
\text { compartment } k\end{array}$ & $\mu \mathrm{g}$ liter $^{-1}$ & Variable \\
\hline$P_{k}$ & $\begin{array}{l}\text { Dissolved } P \text {. parvum toxin concentration in } \\
\text { compartment } k\end{array}$ & $\mu \mathrm{g}$ liter $^{-1}$ & Variable \\
\hline \multicolumn{4}{|c|}{ Ecophysiological Functions } \\
\hline$\mu_{Z}, \mu_{Z}^{C}, \mu_{Z}^{R}, \mu_{Z}^{S}$ & $\begin{array}{l}\text { Zooplankton population growth rate, and } \\
\text { potential carbon-, nitrogen-, and phosphorus- } \\
\text { limited growth rates, respectively }\end{array}$ & $d^{-1}$ & Variable \\
\hline$f_{i}$ & Zooplankton ingestion rate on algal type $i$ & $d^{-1}$ & Variable \\
\hline$m_{z}$ & Zooplankton mortality rate & $\mathrm{d}^{-1}$ & Variable \\
\hline$\mu_{i}$ & Population growth rate of algal type $i$ & $\mathrm{~d}^{-1}$ & Variable \\
\hline$\mu_{\max , i}$ & $\begin{array}{l}\text { Nutrient-saturated population growth rate of } \\
\text { algal type } i\end{array}$ & $\mathrm{~d}^{-1}$ & Variable \\
\hline$f_{\max }$ & Maximal zooplankton ingestion rate & $\mathrm{d}^{-1}$ & Variable \\
\hline \multicolumn{4}{|c|}{ Constant Parameters } \\
\hline$e_{z}$ & $\begin{array}{l}\text { Zooplankton assimilation efficiency for } \\
\text { volume (carbon) }\end{array}$ & None & 0.3 \\
\hline$Q_{R}, Q_{S}$ & $\begin{array}{l}\text { Phosphorus and nitrogen quotas per unit } \\
\text { zooplankton volume, respectively }\end{array}$ & $\mu \mathrm{mol} / \mu \mathrm{m}^{3}$ & $\begin{array}{l}0.061 \times 10^{-9} \\
1.2 \times 10^{-9}\end{array}$ \\
\hline$q_{R, i}, q_{S, i}$ & $\begin{array}{l}\text { Phosphorus and nitrogen quotas per cell for } \\
\text { algal type } i\end{array}$ & $\mu \mathrm{mol} / \mathrm{cell}$ & $\begin{array}{l}1.39 \times 10^{-9}, 32.0 \times \\
10^{-9} \text { for } P . \text { parvum; } \\
2.86 \times 10^{-9}, 32.5 \times \\
10^{-9} \text { for } \\
\text { cyanobacteria }\end{array}$ \\
\hline$V_{i}$ & Cell volume for algal type i & $\mu \mathrm{m}^{3} /$ cell & $\begin{array}{l}300 \text { for P. parvum; } \\
35 \text { for cyanobacteria }\end{array}$ \\
\hline
\end{tabular}




\begin{tabular}{|c|c|c|c|}
\hline Quantity & Meaning & Units & Value \\
\hline$m_{z}(20)$ & Zooplankton mortality rate at $20^{\circ} \mathrm{C}$ & $d^{-1}$ & 0.14 \\
\hline$Q_{10}$ & $\begin{array}{l}\text { Factor by which zooplankton mortality and } \\
\text { ingestion rates increase for a } 10^{\circ} \mathrm{C} \text { increase } \\
\text { in temperature }\end{array}$ & None & 2.8 \\
\hline$K_{R, i}, K_{s, i}$ & $\begin{array}{l}\text { Half-saturation constants for phosphorus- } \\
\text { and nitrogen-limited growth of algal type } i \text {, } \\
\text { respectively }\end{array}$ & $\mu \mathrm{mol}$ liter-1 $^{-1}$ & $\begin{array}{l}0.009,0.01 \text { for } P . \\
\text { parvum; } 0.166 \\
3.686 \text { for } \\
\text { cyanobacteria }\end{array}$ \\
\hline$K_{c}$ & $\begin{array}{l}\text { Half-inhibition constant for growth of } P . \\
\text { parvum in response to cyanotoxin } \\
\text { concentration }\end{array}$ & $\mu g$ liter-1 & 0.1 \\
\hline$\xi$ & $\begin{array}{l}\text { Exponent controlling nonlinearity of inhibition } \\
\text { of } P \text {. parvum growth in response to cyanotoxin } \\
\text { concentration }\end{array}$ & None & 1.0 \\
\hline$w_{i}$ & $\begin{array}{l}\text { Preference for zooplankton ingestion of algal } \\
\text { type } i\end{array}$ & None & $\begin{array}{l}0.5 \text { for } P \text {. parvum; } \\
0.49 \text { for } \\
\text { cyanobacteria }\end{array}$ \\
\hline Kz & $\begin{array}{l}\text { Half-saturation constant for zooplankton } \\
\text { ingestion }\end{array}$ & $\mu \mathrm{m}^{3}$ liter $^{-1}$ & $5.97 \times 10^{9}$ \\
\hline$K_{P}$ & $\begin{array}{l}\text { Half-inhibition constant for zooplankton } \\
\text { ingestion in response to concentration of } P \text {. } \\
\text { parvum toxin }\end{array}$ & $\mu g$ liter-1 & 0.5 \\
\hline$\eta$ & $\begin{array}{l}\text { Exponent controlling nonlinearity of inhibition } \\
\text { of zooplankton ingestion in response to } \\
\text { concentration of } P \text {. parvum toxin }\end{array}$ & none & 2 \\
\hline$f_{\max }(20)$ & Maximal zooplankton ingestion rate at $20^{\circ} \mathrm{C}$ & $d^{-1}$ & 2.4 \\
\hline$\varepsilon \subset, \varepsilon P$ & $\begin{array}{l}\text { Production coefficients for cyanotoxin and } P \text {. } \\
\text { parvum toxin, respectively }\end{array}$ & $\mu \mathrm{g}$ cell-1 $^{-1}$ & $\begin{array}{l}10.0 \times 10^{-9} \text { for } P \\
\text { parvum; } \\
12.5 \times 10^{-9} \text { for } \\
\text { cyanobacteria }\end{array}$ \\
\hline$k_{c}, k_{P}$ & $\begin{array}{l}\text { First-order degradation coefficients for } \\
\text { cyanotoxin and } P \text {. parvum toxin, respectively }\end{array}$ & $d^{-1}$ & 0.5 for both toxins \\
\hline$\mu_{p}^{\mathrm{opt}}$ & Optimal growth rate of $P$. parvum & $\mathrm{d}^{-1}$ & 0.94 \\
\hline$\phi$ & $\begin{array}{l}\text { Ratio of cove volume to total system volume } \\
\text { (cove plus main lake) }\end{array}$ & none & Varies for cove \\
\hline$\psi$ & Ratio of flow through cove to total system flow & none & Set equal to $\phi$ \\
\hline$E$ & Exchange rate between cove and main lake & $\mathrm{d}^{-1}$ & $\begin{array}{l}\text { Varies through } \\
\text { range bounding } \\
\text { observed values }\end{array}$ \\
\hline$F$ & $\begin{array}{l}\text { Flushing imposed to treat blooms of } P \text {. } \\
\text { parvum }\end{array}$ & $\mathrm{d}^{-1}$ & $\begin{array}{l}\text { Varies according to } \\
\text { treatment scenario }\end{array}$ \\
\hline$Z_{1}^{i n}, \quad Z_{2}^{i n}$ & Inflowing zooplankton density & $\mu \mathrm{m}^{3}$ liter $^{-1}$ & $\begin{array}{l}Z_{1}^{i n}=1 \times 10^{6} \\
Z_{2}^{i n}=0\end{array}$ \\
\hline
\end{tabular}




\begin{tabular}{|c|c|c|c|}
\hline Quantity & Meaning & Units & Value \\
\hline$N_{i, 1}^{i n}, \quad N_{i, 2}^{i n}$ & Inflowing algal density & Cells liter-1 & $\begin{array}{l}N_{i, 1}^{i n}=0.1 \times 10^{6} \\
N_{i, 2}^{i n}=0\end{array}$ \\
\hline$R_{1}^{i n}, \quad R_{2}^{i n}$ & Inflowing phosphate concentration & $\mu \mathrm{mol}$ liter-1 $^{-1}$ & $R_{1}^{i n}=R_{2}^{i n}=$ forced \\
\hline$S_{1}^{\text {in }}, \quad S_{2}^{\text {in }}$ & Inflowing nitrate concentration & $\mu \mathrm{mol}$ liter-1 $^{-1}$ & $S_{1}^{\text {in }}=S_{2}^{\text {in }}=$ forced \\
\hline$C_{1}^{i n}, \quad C_{2}^{i n}$ & Inflowing cyanotoxin concentration & $\mu \mathrm{g}$ liter $^{-1}$ & $C_{1}^{i n}=C_{2}^{i n}=0$ \\
\hline$P_{1}^{i n}, \quad P_{2}^{i n}$ & Inflowing P. parvum toxin concentration & $\mu g$ liter $^{-1}$ & $P_{1}^{i n}=P_{2}^{i n}=0$ \\
\hline \multicolumn{4}{|c|}{ Forced Parameters } \\
\hline$D$ & Dilution rate & $d^{-1}$ & Forced \\
\hline$T$ & Temperature & ${ }^{\circ} \mathrm{C}$ & Forced \\
\hline I & Light & $\mu \mathrm{mol} \mathrm{m} \mathrm{m}^{-2} \mathrm{~s}^{-1}$ & Forced \\
\hline$\sigma$ & Salinity & g liter-1 & Forced \\
\hline$R_{k}^{i n}, \quad S_{k}^{i n}$ & $\begin{array}{l}\text { Inflowing phosphate and nitrate } \\
\text { concentrations }\end{array}$ & $\mu \mathrm{mol}$ liter $^{-1}$ & Forced \\
\hline
\end{tabular}

The first term of equation B.1a represents growth of the zooplankton population, which is potentially limited by the rates at which carbon, nitrogen, or phosphorus are acquired by consuming algae. The per capita growth rate $\mu_{Z}$ is the minimum of the potential growth rates limited by these elements:

$$
\mu_{Z}=\min \left\{\mu_{Z}^{C}, \mu_{z}^{N}, \mu_{Z}^{P}\right\}
$$

where the potential growth rates based on carbon (C), nitrogen (N), and phosphorus $(\mathrm{P})$ consumption rates are respectively defined as

$$
\begin{gathered}
\mu_{Z}^{C}=e_{Z} \sum_{i} f_{i} \\
\mu_{Z}^{R}=\frac{1}{Q_{R}} \sum_{i} \frac{f_{i} q_{R, i}}{V_{i}} \text {, and } \mu_{Z}^{S}=\frac{1}{Q_{S}} \sum_{i} \frac{f_{i} q_{S, i}}{V_{i}}
\end{gathered}
$$

In these expressions, $i$ indexes the two algal types represented in the model: $i=p$ for $P$. parvum and $i=c$ for cyanobacteria. The parameter $e_{Z}$ is the efficiency of carbon assimilation by zooplankton; $Q_{R}$ and $Q_{S}$ are the phosphorus and nitrogen quotas per unit zooplankton volume, $q_{R, i}$ and $q_{S, i}$ are the phosphorus and nitrogen quotas per cell for algal type $i$, and $V_{i}$ is 
the cell volume of algal type $i$. The function $f_{i}$ is the ingestion rate of algal type $i$, defined in detail below (Equation B.7 and following text).

The second term of equation B.1a represents temperature-dependent mortality of zooplankton with per capita rate $m_{Z}$ :

$$
m_{Z}(T)=m_{Z}(20) Q_{10}^{\left(\frac{T-20}{10}\right)}
$$

where

$$
\begin{aligned}
T= & \text { temperature } \\
m_{Z}(20)= & \text { mortality rate at } 20^{\circ} \mathrm{C} \\
\mathrm{Q}_{10}= & \text { factor by which zooplankton mortality increases for } \mathrm{a} 10^{\circ} \mathrm{C} \\
& \text { increase in temperature. }
\end{aligned}
$$

The first term of Equation B.1b represents growth of an algal population, either $P$. parvum $(i=p)$ or cyanobacteria $(i=c)$. Algal growth rates are potentially limited by the rates at which nitrogen or phosphorus are acquired from consuming dissolved nutrients. The per capita growth rate $\mu_{i}$ is the minimum of the potential growth rates limited by these elements, but it is also temperature- and light-dependent for both algal types, and salinity-dependent for $P$. parvum. These complex growth dependencies are represented by maximal rates of algal growth that depend on temperature, light, and salinity, multiplied by the minimum of Monod saturation terms that depend on nutrient concentrations. For P. parvum, an additional factor represents inhibition of growth by the dissolved toxin produced by cyanobacteria. Altogether, the per capita growth rates for the two algal types are:

$$
\begin{gathered}
\mu_{p}=\mu_{\text {max }, p}(I, T, \sigma) \min \left\{\frac{R}{K_{R, p}+R}, \frac{S}{K_{S, p}+S}\right\} \frac{K_{C}^{\xi}}{K_{C}^{\xi}+C^{\xi}} \\
\mu_{c}=\mu_{\text {max }, c}(I, T) \min \left\{\frac{R}{K_{R, c}+R}, \frac{S}{K_{S, c}+S}\right\}
\end{gathered}
$$

where

$$
\begin{aligned}
\mu_{\mathrm{max}, I} & =\text { maximal growth rate of type } i \\
I & =\text { irradiance }
\end{aligned}
$$




$$
\sigma=\text { s alinity }
$$

$K_{R, i}$ and $K_{S, I}=$ half-saturation constants for growth limitation by phosphorus and nitrogen, respectively

$K_{C}=$ half-inhibition constant for the effects of cyanotoxin on $P$. parvum

$\xi=$ shape parameter controlling the shape of the inhibition function.

The maximal growth rates for $P$. parvum and cyanobacteria are:

$$
\begin{aligned}
& \mu_{\text {max }, p}(\sigma, I, T)= \\
& \max \left\{0,-3.531+0.02534(\sigma-1.833)+7.468 e^{\left[0.7\left(\frac{T-20}{20}\right)\right]}+0.000611(I-222)\right. \\
& -0.06311(\sigma-1.833)^{2}-3.414 e^{\left[1.4\left(\frac{T-20}{20}\right)\right]}-0.00000573(I-222)^{2} \\
& \left.+0.1697(\sigma-1.833) e^{\left[0.7\left(\frac{T-20}{20}\right)\right]}\right\} \\
& \mu_{\text {max }, c}(I, T)=\max \left\{0, \frac{1.683 I}{33.33+I+I^{2} / 300}-0.01\right\} \frac{T-5}{35}
\end{aligned}
$$

Equation B.6a represents a unimodal response to light, temperature, and salinity for $P$. parvum based on an empirical model fitted to laboratory experiments (Baker et al. 2009). Equation B.6b represents a unimodal function of light and an increasing linear function of temperature for cyanobacteria (Chapra 1997).

The second term of Equation B.1b represents mortality for both algal types due to zooplankton grazing. This mortality rate depends on the function $f_{i}$ for the consumption rate of algal type $i$ by zooplankton:

$$
f_{i}\left(N_{p}, N_{c} ; T\right)=f_{\max }(T)\left(\frac{w_{i} V_{i}^{2} N_{i}^{2}}{K_{Z}^{2}+\sum_{j} w_{j} V_{j}^{2} N_{j}^{2}}\right)\left(\frac{K_{P}^{\eta}}{K_{P}^{\eta}+P^{\eta}}\right), i, j=p, c
$$

The consumption rate depends on algal cell densities and volumes according to a sigmoid functional response (Litchman et al. 2006), with a maximal ingestion rate on a biovolume basis $f_{\max }$ that depends on temperature. The parameter $K_{Z}$ is a half-saturation constant for consumption on a 
biovolume basis, and the parameters $w_{i}$ are preferences for algal type $i$. The consumption of algae by zooplankton is also inhibited by toxin produced by $P$. parvum, through a factor with half-inhibition constant $K_{P}$ and shape parameter $\eta$. The temperature-dependence of zooplankton consumption follows the function

$$
f_{\max }(T)=f_{\max }(20) Q_{10}^{\left(\frac{T-20}{10}\right)}
$$

where

$$
\begin{aligned}
f_{\max }(20)= & \text { maximal ingestion rate at } 20^{\circ} \mathrm{C} \\
\mathrm{Q}_{10}= & \text { factor by which consumption rate increases for } \mathrm{a}^{\circ} \mathrm{0}^{\circ} \mathrm{C} \\
& \text { increase in temperature. }
\end{aligned}
$$

Both algal types suffer additional losses to hydraulic outflow, which are specified by the transport terms in the physical component of the model. Other loss and mortality processes are neglected.

The first terms of Equations B.1c and B.1d for nutrient dynamics represent consumption of dissolved nutrients coupled to algal growth through the cell quotas for nutrients. The second terms of Equations B.1c and B.1d represent recycling of nutrients by zooplankton when excess nutrient is acquired through ingestion of algae.

The first term of Equation B.1e represents toxin production by cyanobacteria, proportional to their productivity through a coefficient $\varepsilon_{C}$. The second term of Equation B.1e represents first-order decay of this toxin with rate constant $k_{C}$. The first term of Equation B.1f represents toxin production by $P$. parvum, which is proportional to the reduction of growth rate below its value under optimal conditions, with coefficient $\varepsilon_{P}$. The second term of Equation B.1f represents first-order decay of this toxin with rate constant $k_{P}$.

The reaction rates represented by equation system B.1 are placed in the physical context of the transport equations for the cove-main lake system. In all cases the reaction rates depend only on the values of variables in the respective local compartment, cove or main lake. The full equation system for the model is then: 


$$
\begin{aligned}
& \frac{d Z_{1}}{d t}=\frac{(1-\phi) D}{1-\psi} Z_{1}^{i n}-\frac{D+E}{1-\psi} Z_{1}+\frac{\phi D+E+F}{1-\psi} Z_{2}+R_{Z} \\
& \frac{d Z_{2}}{d t}=\frac{\phi D}{\psi} Z_{2}^{i n}+\frac{E}{\psi} Z_{1}-\frac{\phi D+E+F}{\psi} Z_{2}+R_{Z} \\
& \frac{d N_{i, 1}}{d t}=\frac{(1-\phi) D}{1-\psi} N_{i, 1}^{i n}-\frac{D+E}{1-\psi} N_{i, 1}+\frac{\phi D+E+F}{1-\psi} N_{i, 2}+R_{i}, \quad i=p, c \\
& \frac{d N_{i, 2}}{d t}=\frac{\phi D}{\psi} N_{i, 2}^{i n}+\frac{E}{\psi} N_{i, 1}-\frac{\phi D+E+F}{\psi} N_{i, 2}+R_{i}, \quad i=p, c \\
& \frac{d R_{1}}{d t}=\frac{(1-\phi) D}{1-\psi} R_{1}^{i n}-\frac{D+E}{1-\psi} R_{1}+\frac{\phi D+E+F}{1-\psi} R_{2}+R_{R} \\
& \frac{d R_{2}}{d t}=\frac{\phi D}{\psi} R_{2}^{i n}+\frac{E}{\psi} R_{1}-\frac{\phi D+E+F}{\psi} R_{2}+R_{R} \\
& \frac{d S_{1}}{d t}=\frac{(1-\phi) D}{1-\psi} S_{1}^{i n}-\frac{D+E}{1-\psi} S_{1}+\frac{\phi D+E+F}{1-\psi} S_{2}+R_{S} \\
& \frac{d S_{2}}{d t}=\frac{\phi D}{\psi} S_{2}^{i n}+\frac{E}{\psi} S_{1}-\frac{\phi D+E+F}{\psi} S_{2}+R_{S} \\
& \frac{d C_{1}}{d t}=\frac{(1-\phi) D}{1-\psi} C_{1}^{i n}-\frac{D+E}{1-\psi} C_{1}+\frac{\phi D+E+F}{1-\psi} C_{2}+R_{C} \\
& \frac{d C_{2}}{d t}=\frac{\phi D}{\psi} C_{2}^{i n}+\frac{E}{\psi} C_{1}-\frac{\phi D+E+F}{\psi} C_{2}+R_{C} \\
& \frac{d P_{1}}{d t}=\frac{(1-\phi) D}{1-\psi} P_{1}^{i n}-\frac{D+E}{1-\psi} P_{1}+\frac{\phi D+E+F}{1-\psi} P_{2}+R_{P} \\
& \frac{d P_{2}}{d t}=\frac{\phi D}{\psi} P_{2}^{i n}+\frac{E}{\psi} P_{1}-\frac{\phi D+E+F}{\psi} P_{2}+R_{P}
\end{aligned}
$$

For the physical model, subscript 1 indicates quantities pertaining to the main lake, and subscript 2 to those pertaining to the cove. The parameter $\phi$ is the ratio of cove volume to total system volume (cove plus main lake), 
and $\psi$ is the ratio of flow through the cove to total flow through the system. The parameter $D$ is the dilution rate resulting from flow through the whole system (cove plus main lake), $E$ is the exchange rate between cove and main lake, and $F$ is the additional flushing through the cove imposed by bloom treatments. The parameters with superscript "in" are inflowing concentrations of the respective constituents into the cove and main lake compartments. Further explanation of the transport parameters of the physical model and the values adopted in this study are provided in Chapter 1 of the main text of this report.

Six of the parameters in the model are time-variable: dilution rate $(D)$, salinity $(\sigma)$, irradiance $(I)$, temperature $(T)$, and the inflowing concentrations of phosphate and nitrate $\left(R_{k}^{i n}, S_{k}^{i n}\right)$. These parameters were changed daily according to observational data as compiled in Grover et al. (2010). Daily values of dilution rate were obtained by estimating Brazos River discharge as the mean of two USGS gauges: 08090800 , about $40 \mathrm{~km}$ upstream of the headwaters of Lake Granbury, and 08091000, about $60 \mathrm{~km}$ downstream of the dam. Discharge was then divided by the volume of the lake. The parameter $\psi$ in the physical model partitions this flow between cove and main lake compartments and was assumed to equal the volume ratio $\phi$. Other data were obtained from approximately monthly sampling of 10 stations at Lake Granbury from 1 August 2006 to 31 August 2007, which were then averaged over stations, and daily values were calculated by linear interpolation. These daily values were assumed to apply equally to cove and main lake compartments. Nutrient input concentrations were assumed to be equal to measured total nutrient concentrations in the lake. Average daily irradiance in the water column was estimated assuming exponential attenuation of surface irradiance, with an attenuation coefficient estimated from Secchi depth, for an average depth in the lake of $5 \mathrm{~m}$ (as described in detail in Grover et al. 2010).

All other parameters were assigned constant values (Table B1).

Numerical simulations of the model equation system (B.9) were computed with an adaptive step-size, fourth/fifth order Runge-Kutta algorithm (Press et al. 1986). This algorithm was run for one day at a time, using the daily values of the six time-variable parameters. The model was coded in Fortran 77 and compiled and built with Absoft Fortran, version 1.0.4. 


\section{Appendix B References}

Baker, J. W., J. P. Grover, R. Ramachandrannair, C. Black, T. W. Valenti, Jr., B. W. Brooks, and D. L. Roelke. 2009. Growth at the edge of the niche: An experimental study of the harmful alga Prymnesium parvum. Limnology and Oceanography 54:1679-1687.

Chapra, S. C. 1997. Surface water quality modeling. New York: McGraw-Hill.

Grover, J. P., D. L. Roelke, and B. W. Brooks. 2012. Modeling of plankton community dynamics characterized by algal toxicity and allelopathy: A focus on historical Prymnesium parvum blooms in a Texas reservoir. Ecological Modelling 227: 147-161.

Grover, J. P., J. W. Baker, D. L. Roelke, and B. W. Brooks. 2010. Mathematical models of population dynamics of Prymnesium parvum in inland waters. Journal of the American Water Resources Association 46:92-107.

Litchman, E., C. A. Klausmeier, J. R. Miller, O. M. Schofield, and P. G. Falkowski. 2006. Multinutrient, multi-group model of present and future oceanic phytoplankton communities. Biogeoscience 3:585-606.

Press, W. H., B. P. Flannery, S. A. Teukolsky, and W. T. Vetterling. 1986. Numerical recipes: The art of scientific computing. Cambridge, MA: Cambridge University Press. 


\section{Appendix C: Dendrograms and Time-series Euclidean Distances}

This appendix presents dendrograms and time-series Euclidean distances for the cove-open lake station comparisons using the historical data.

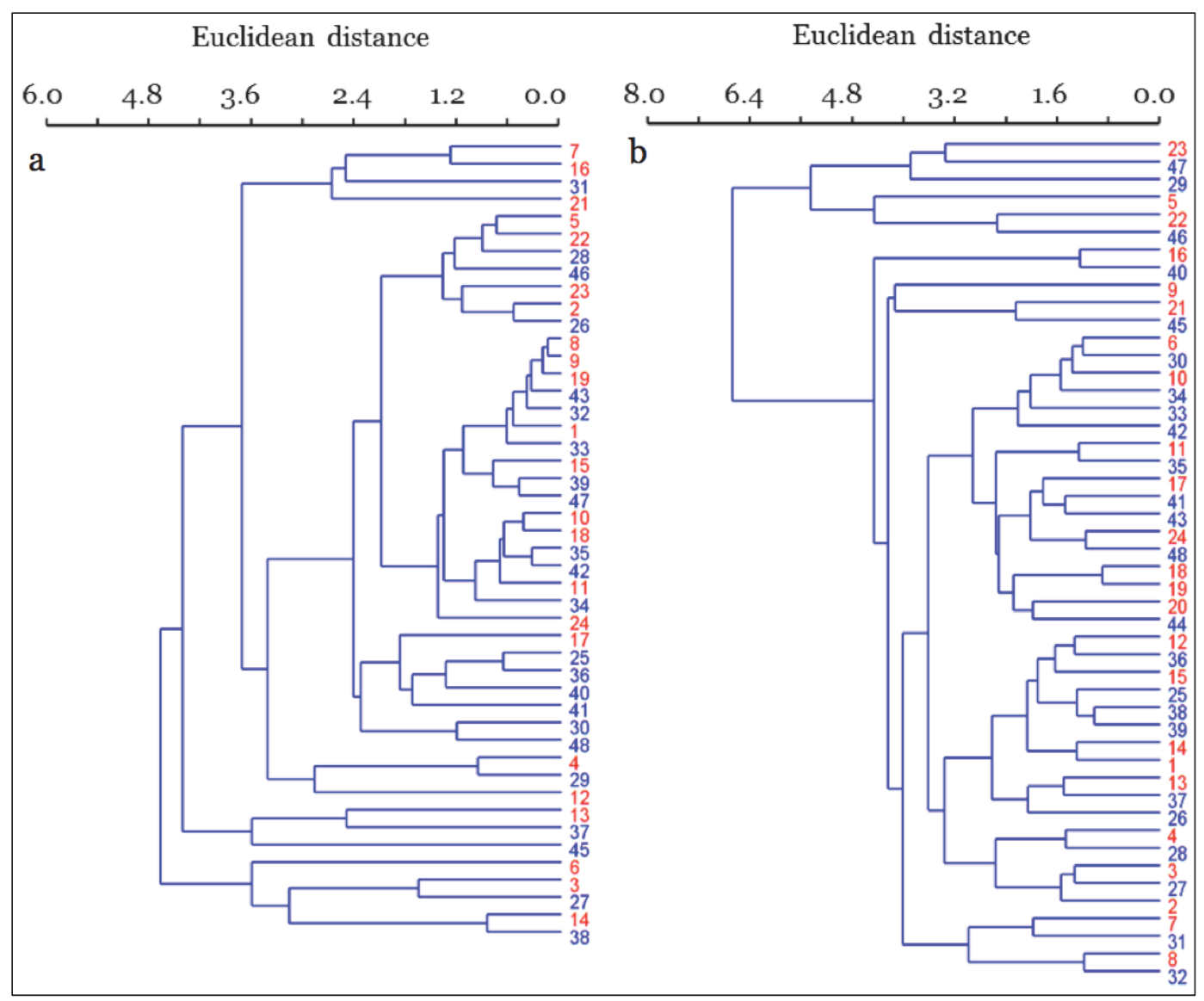

Figure $\mathrm{C}$. Dendrograms comparing biotic (a) and abiotic (b) parameters from cove A and the averaged data from stations 2 and 3 . Here, red numbers reflect observations from the cove and blue numbers reflect observation averages from the open lake. The numbers are paired based on sampling month and year. For example, $[1,25]$ represents the first cove and open lake sampling during December $2007 ;[2,26]$ represents the second cove and open lake sampling during January 2008; and so forth, with $[24,48]$ representing the final cove and open lake sampling during April 2010. 


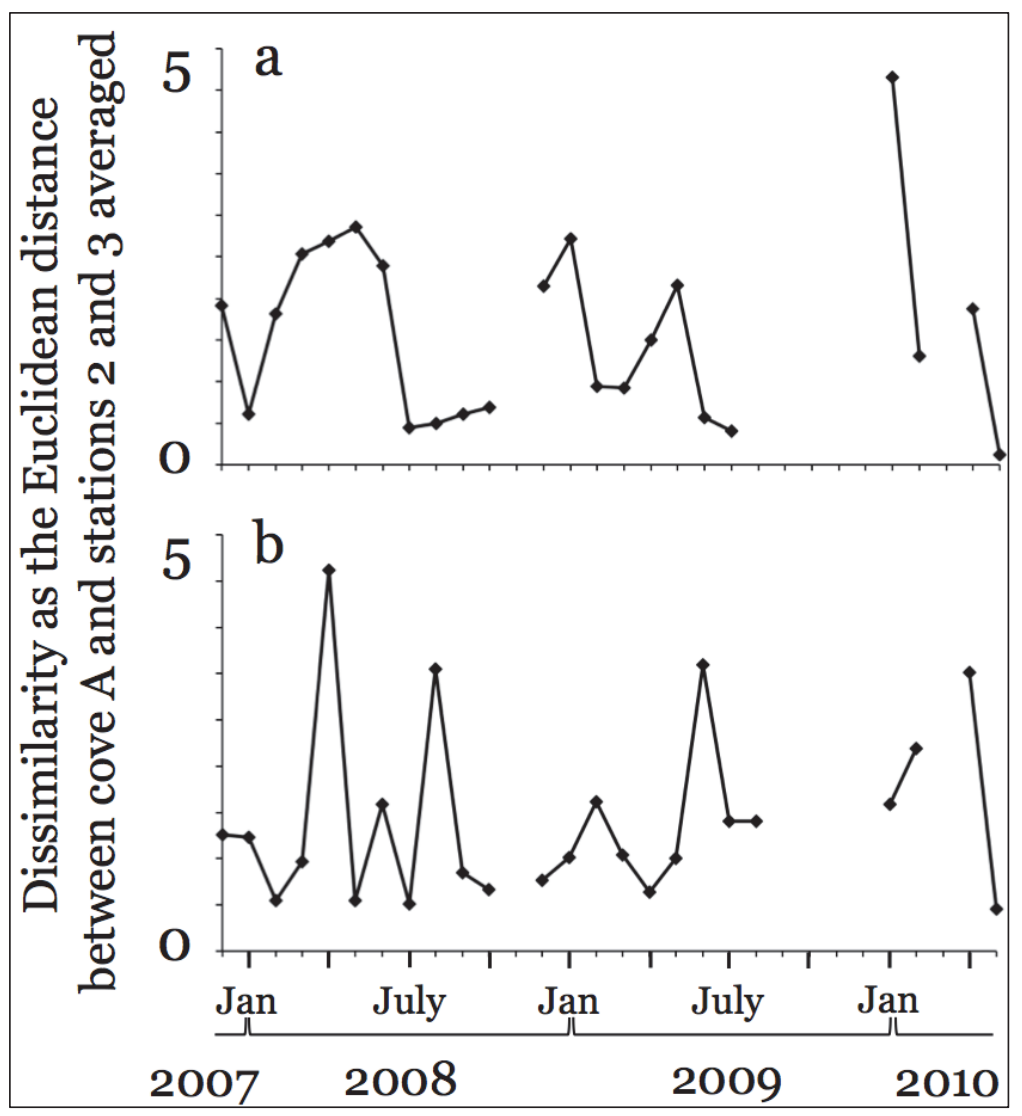

Figure C2. Time-series dissimilarity between biotic (a) and abiotic (b) parameters as estimated by the Euclidean distance for comparison of the average values for cove $A$ and stations 2 and 3 . 


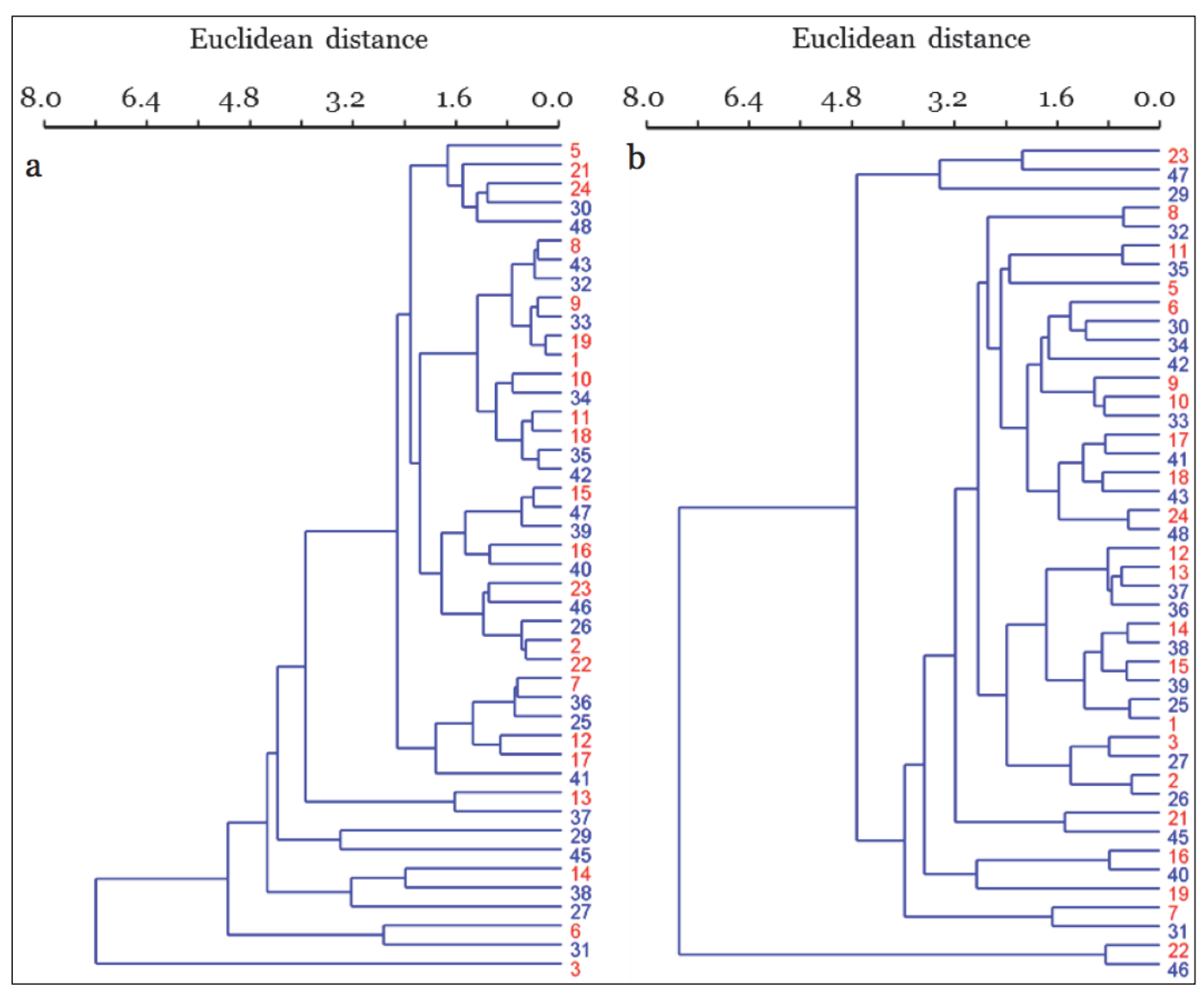

Figure C3. Dendrograms comparing biotic (a) and abiotic (b) parameters from cove $B$ and the averaged data from stations 2 and 3 . Here, red numbers reflect observations from the cove and blue numbers reflect observation averages from the open lake. The numbers are paired based on sampling month and year. For example, $[1,25]$ represents the first cove and open lake sampling during December 2007; [2,26] represents the second cove and open lake sampling during January 2008; and so forth, with $[24,48]$ representing the final cove and open lake sampling during April 2010. 


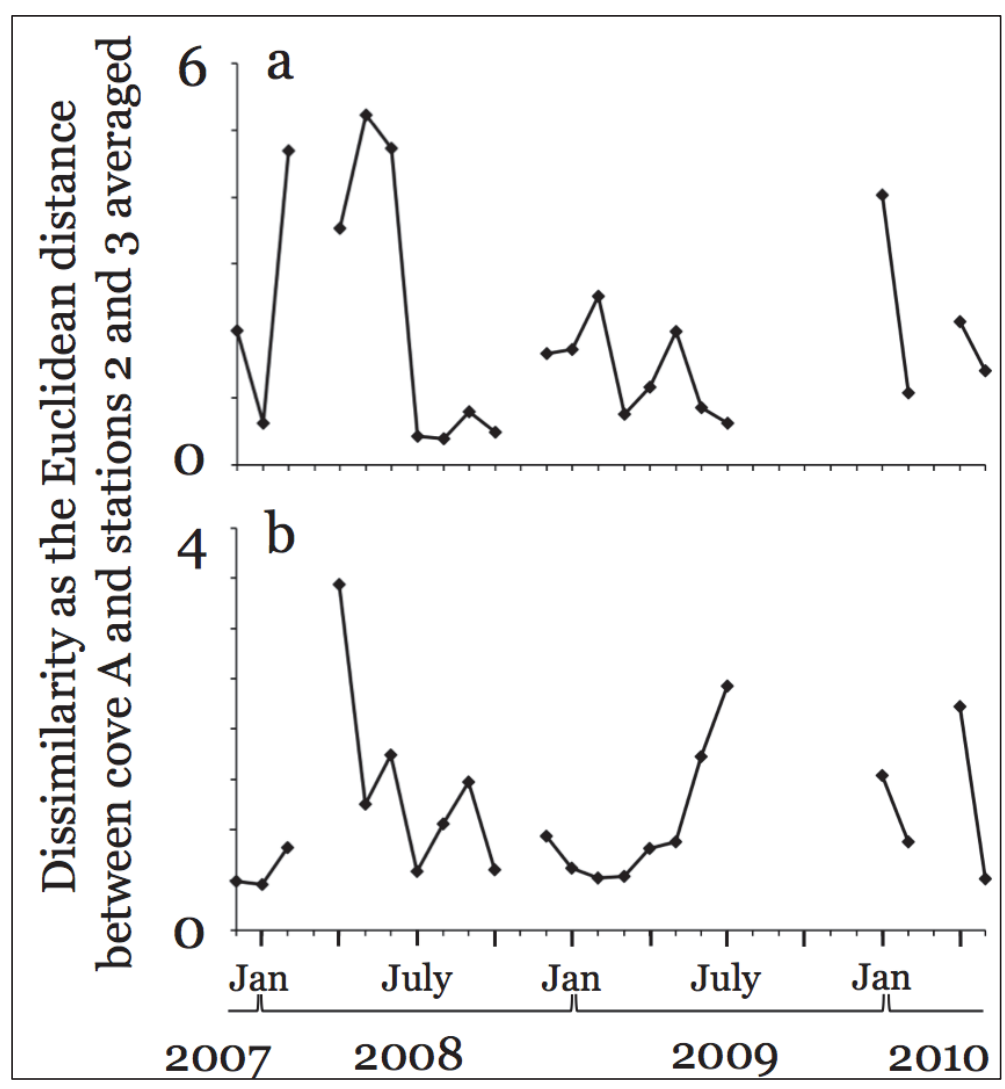

Figure C4. Time-series dissimilarity between biotic (a) and abiotic (b) parameters as estimated by the Euclidean distance for the comparison of average values for cove B and stations 2 and 3 . 


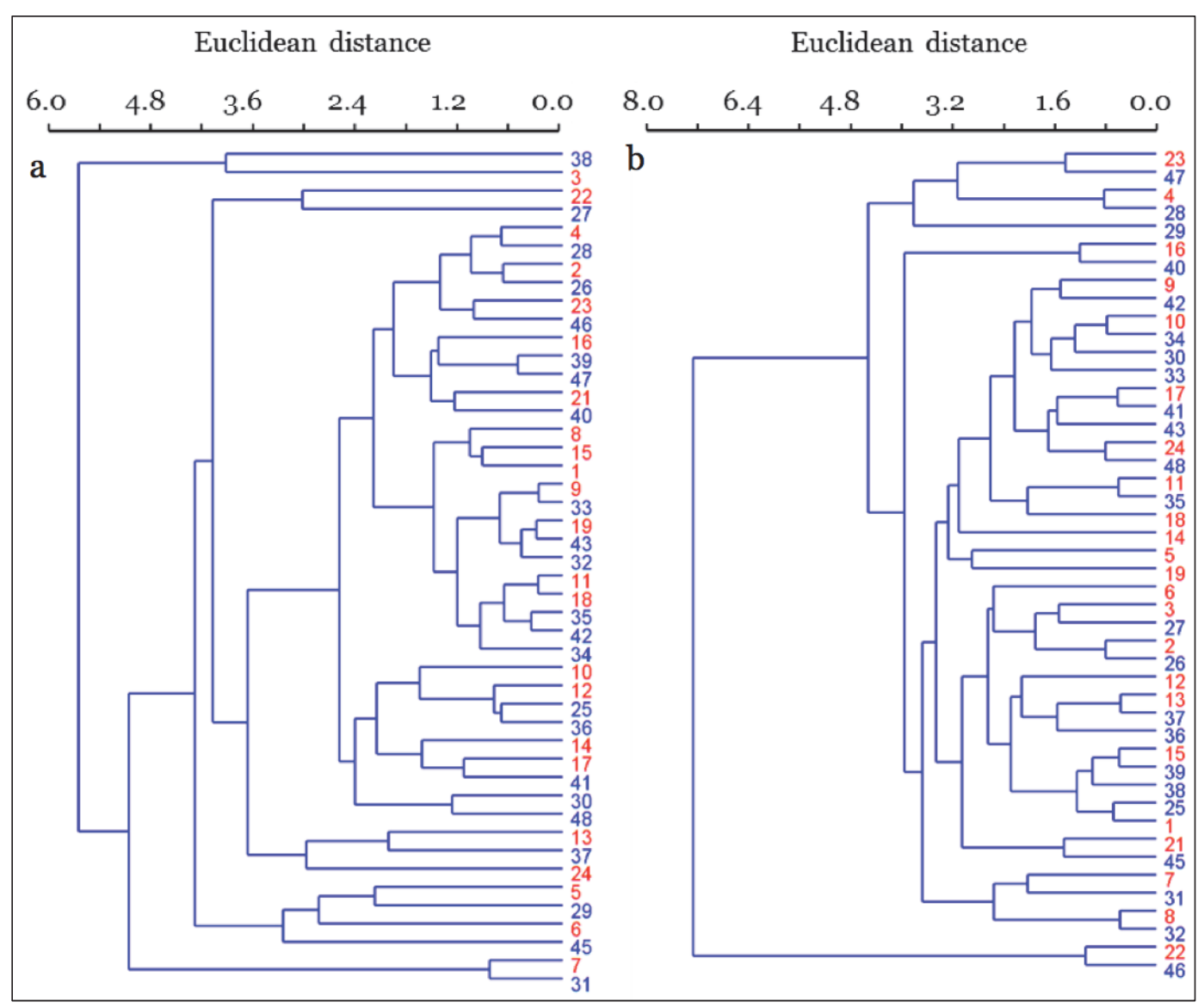

Figure C5. Dendrograms comparing biotic (a) and abiotic (b) parameters from cove $\mathrm{C}$ and the averaged data from stations 2 and 3 . Here, red numbers reflect observations from the cove and blue numbers reflect observation averages from the open lake. The numbers are paired based on sampling month and year. For example, $[1,25]$ represents the first cove and open lake sampling during December 2007; [2,26] represents the second cove and open lake sampling during January 2008 ; and so forth, with $[24,48]$ representing the final cove and open lake sampling during April 2010. 


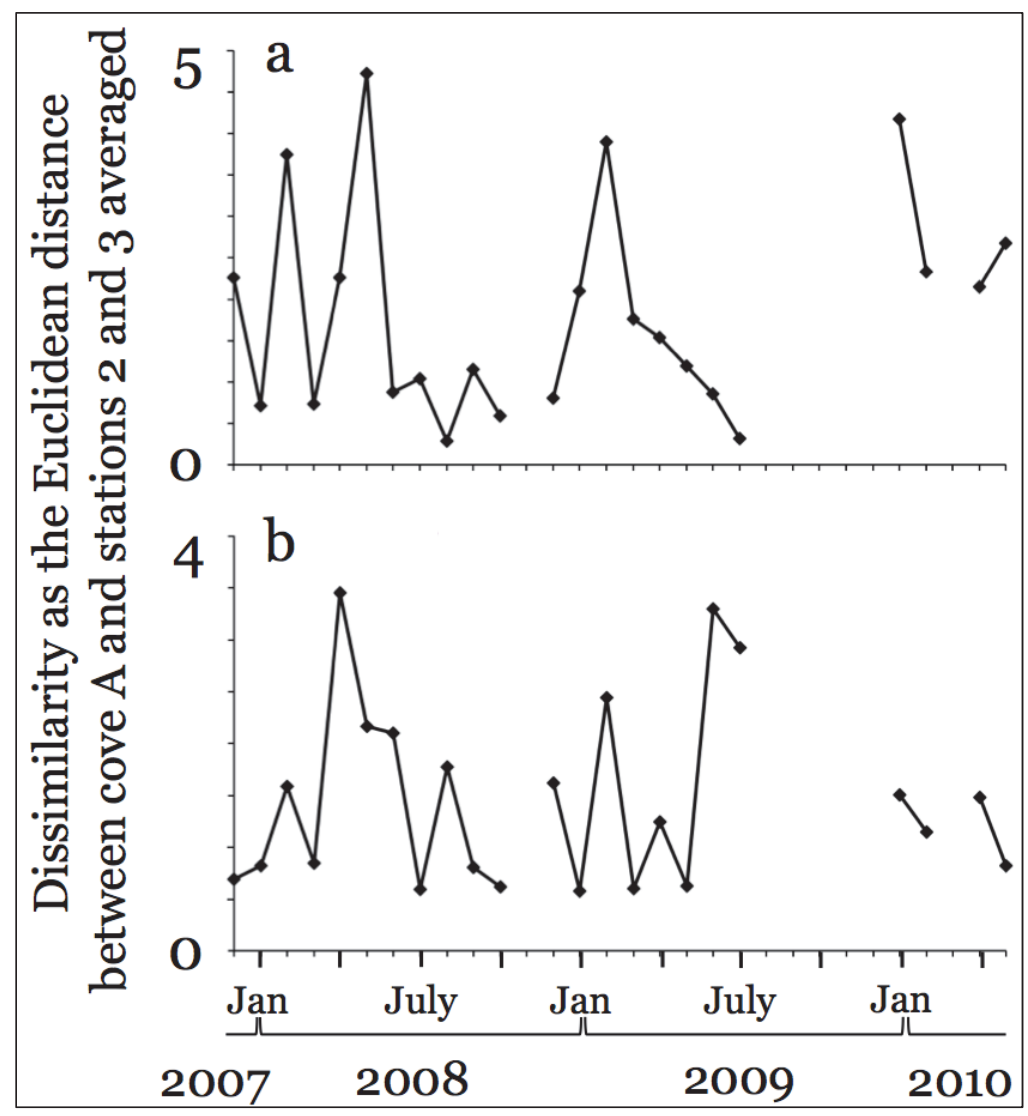

Figure C6. Time-series dissimilarity between biotic (a) and abiotic (b) parameters as estimated by the Euclidean distance for the comparison between average values for cove $C$ and stations 2 and 3 . 


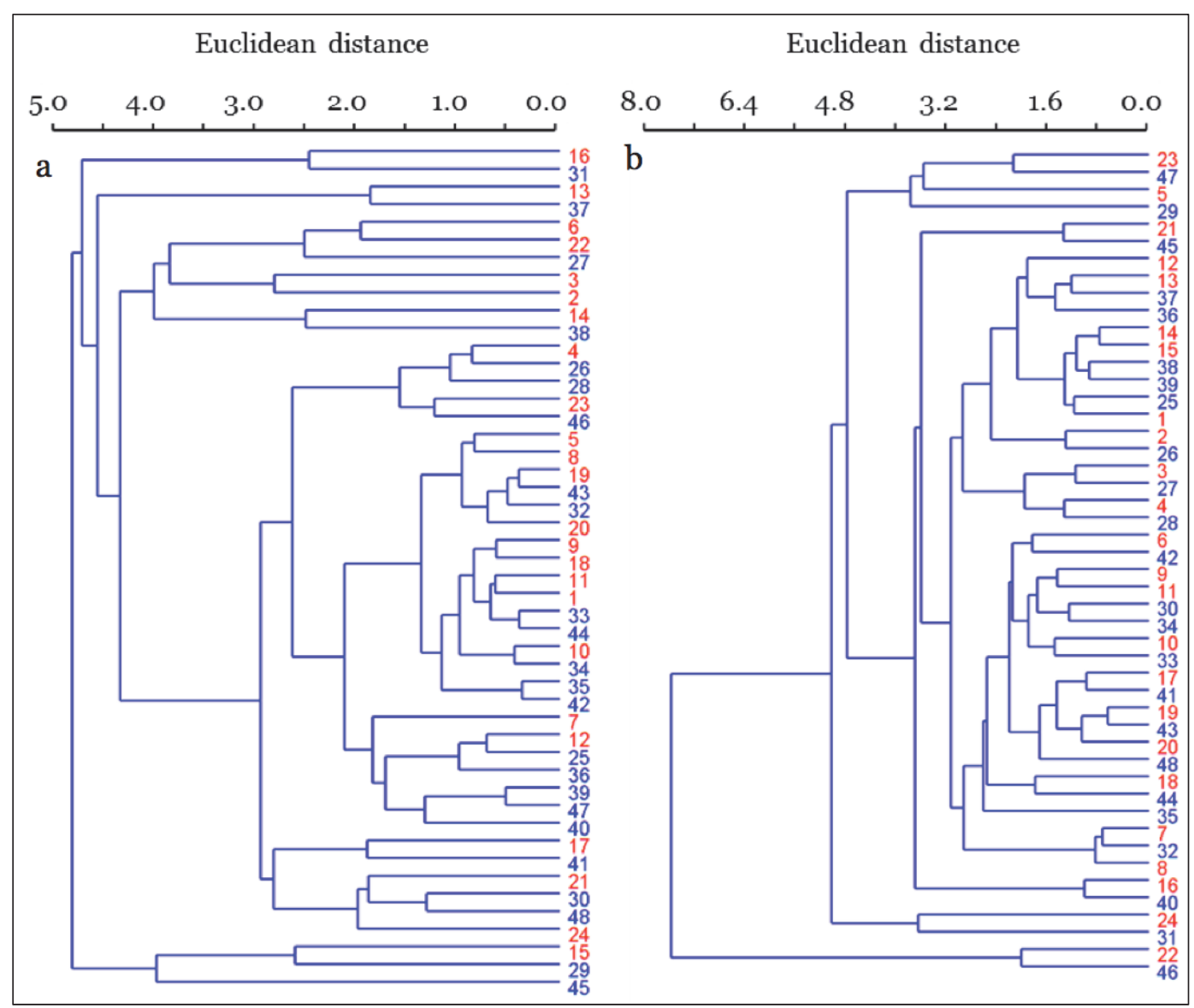

Figure C7. Dendrograms comparing biotic (a) and abiotic (b) parameters from cove $D$ and the averaged data from stations 2 and 3 . Here, red numbers reflect observations from the cove and blue numbers reflect observation averages from the open lake. The numbers are paired based on sampling month and year. For example, $[1,25]$ represents the first cove and open lake sampling during December 2007; $[2,26]$ represents the second cove and open lake sampling during January 2008 ; and so forth, with $[24,48]$ representing the final cove and open lake sampling during April 2010. 


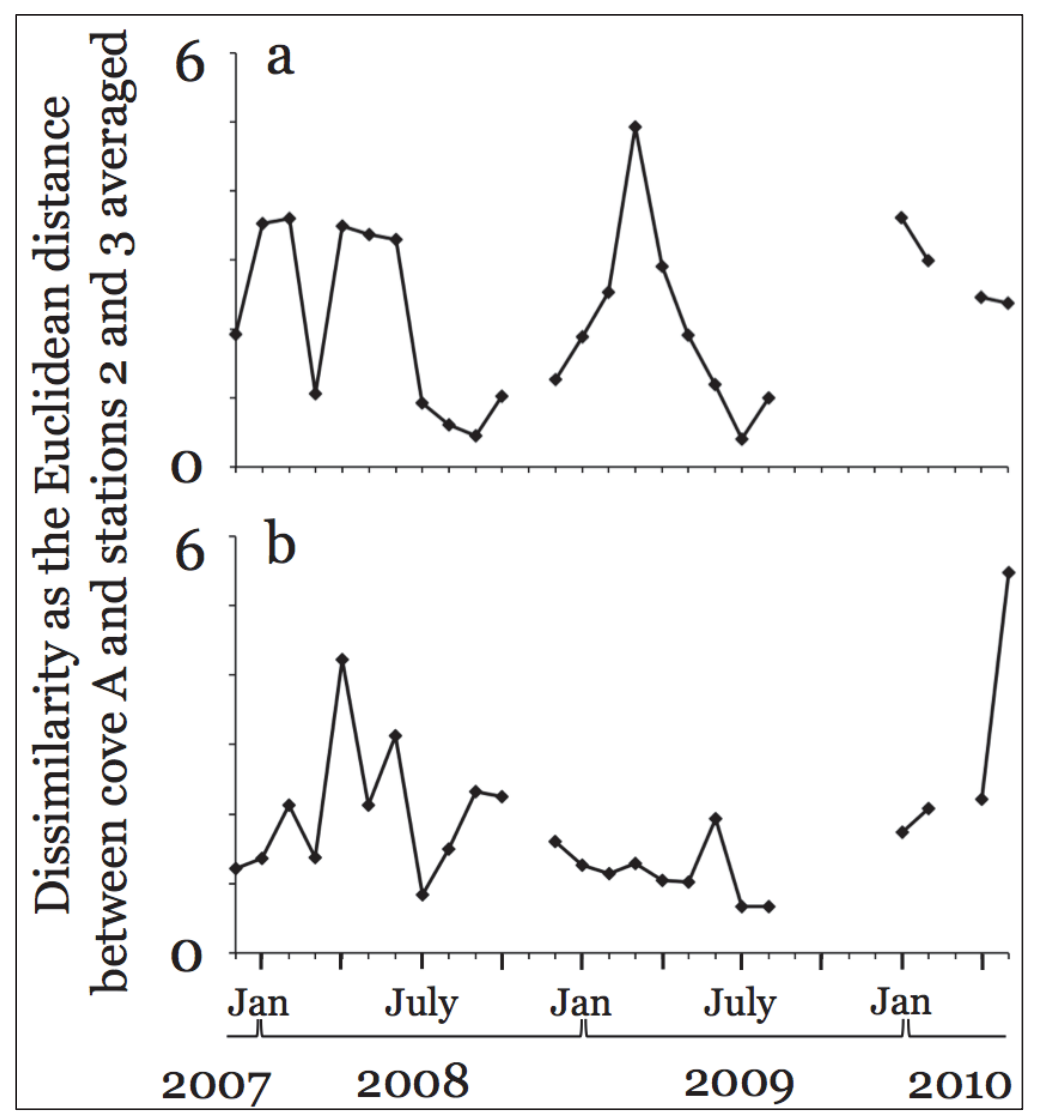

Figure C8. Time-series dissimilarity between biotic (a) and abiotic (b) parameters as estimated by the Euclidean distance for the comparison between average values for cove $D$ and stations 2 and 3 . 


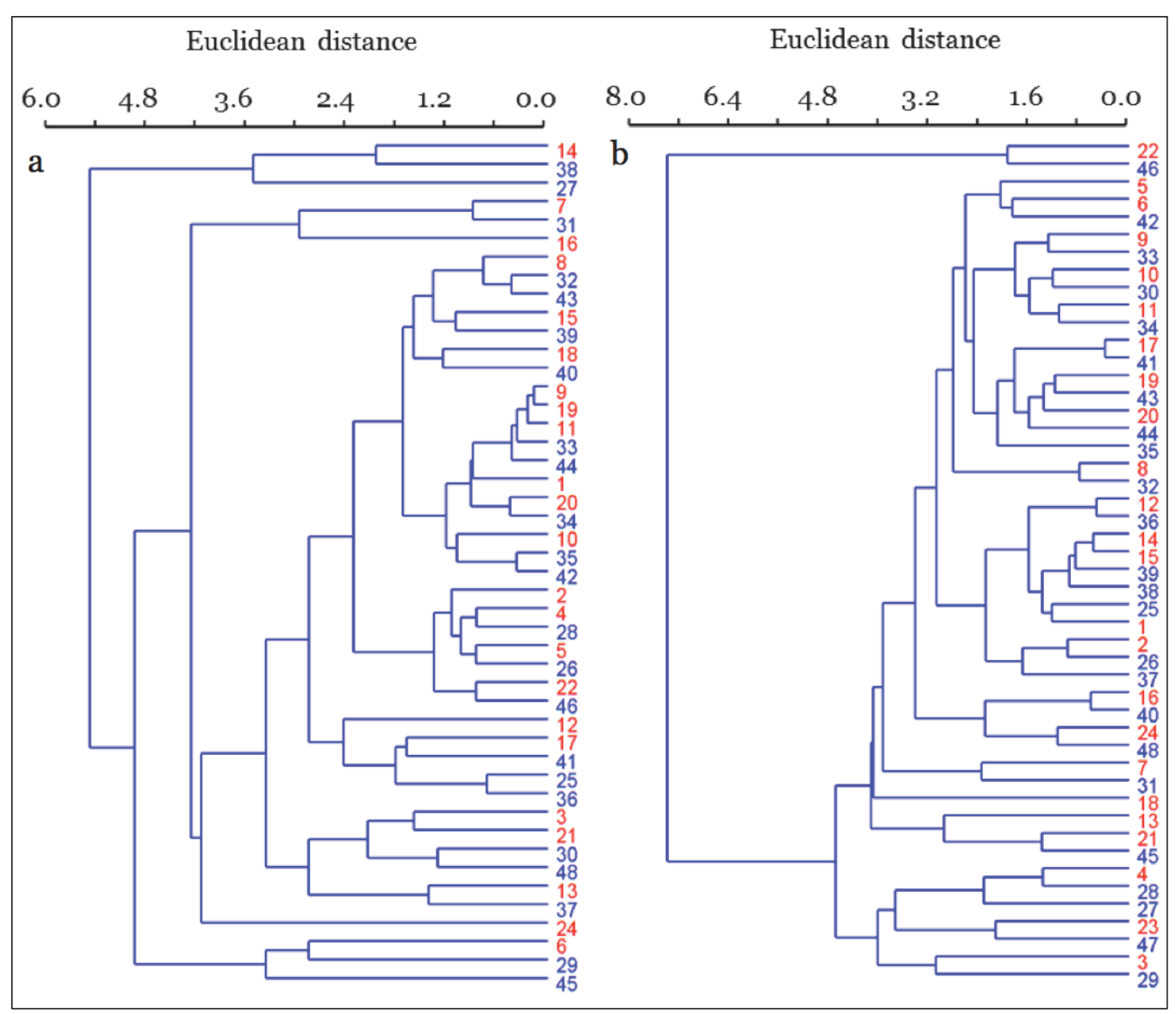

Figure C9. Dendrograms comparing biotic (a) and abiotic (b) parameters from cove $E$ and the averaged data from stations 2 and 3 . Here, red numbers reflect observations from the cove and blue numbers reflect observation averages from the open lake. The numbers are paired based on sampling month and year. For example, $[1,25]$ represents the first cove and open lake sampling during December 2007; $[2,26]$ represents the second cove and open lake sampling during January 2008 ; and so forth, with $[24,48]$ representing the final cove and open lake sampling during April 2010. 


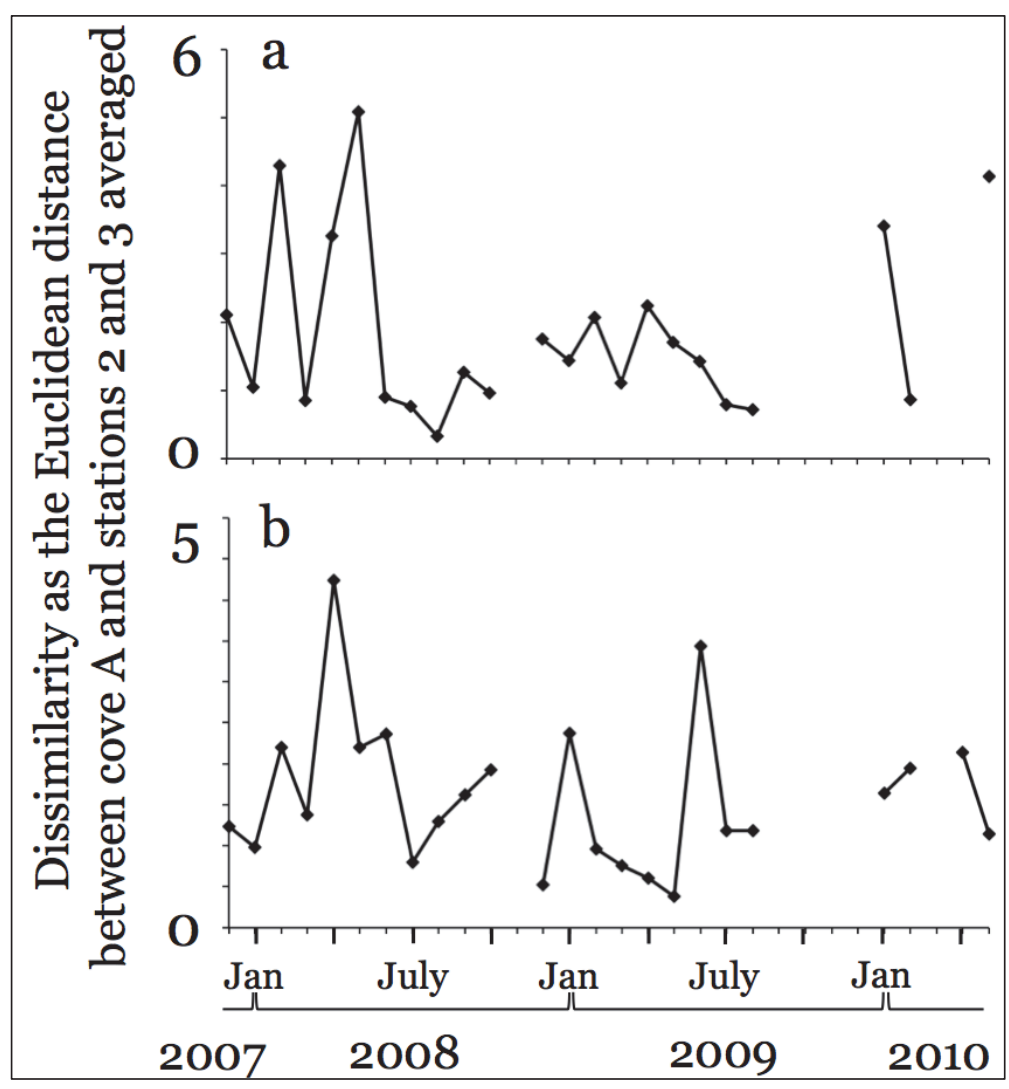

Figure C10. Time-series dissimilarity between biotic (a) and abiotic (b) parameters as estimated by the Euclidean distance for the comparison between average values for cove $\mathrm{E}$ and stations 2 and 3 . 


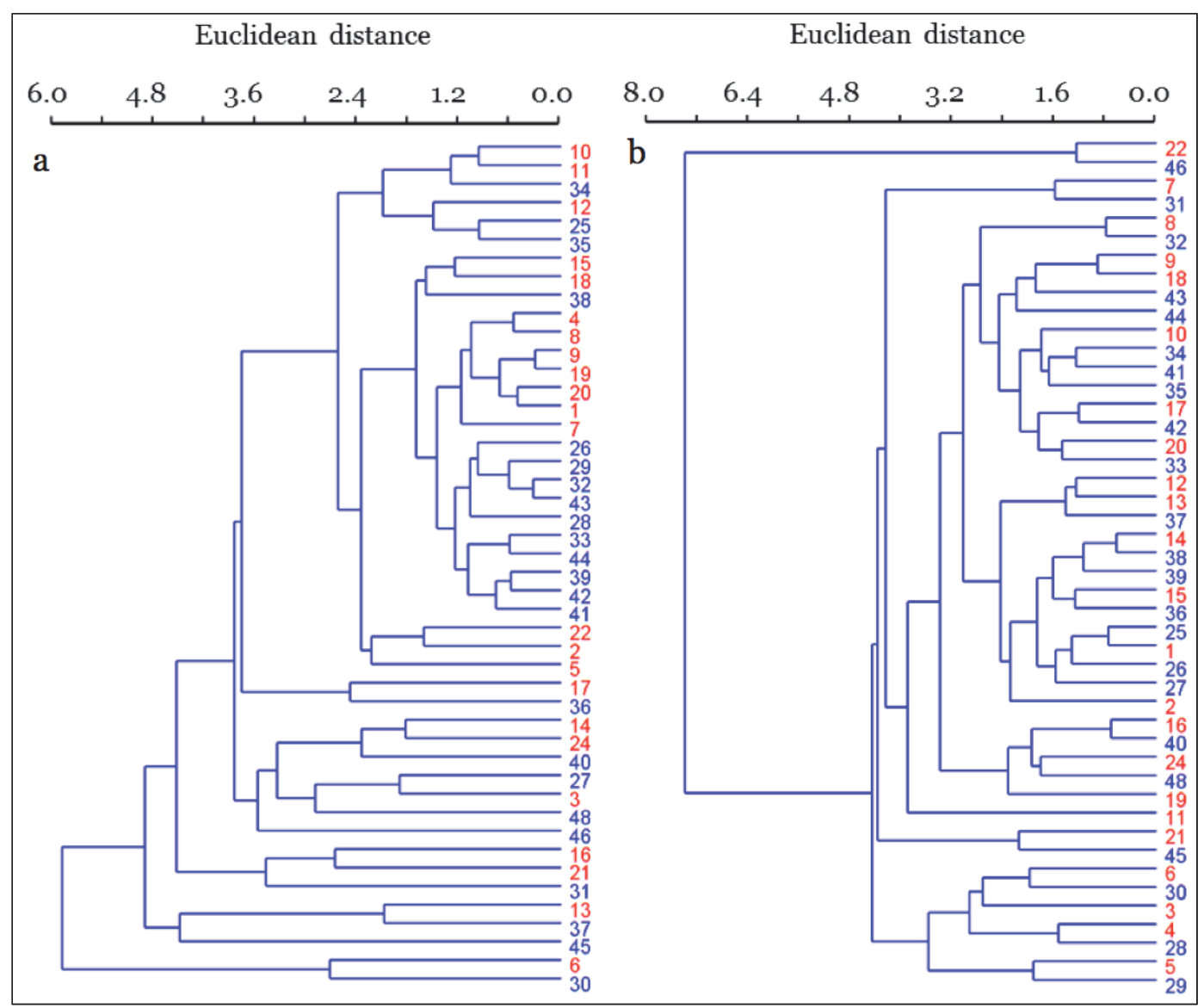

Figure $\mathrm{C} 11$. Dendrograms comparing biotic (a) and abiotic (b) parameters from cove $\mathrm{F}$ and the averaged data from stations 4 and 5 . Here, red numbers reflect observations from the cove and blue numbers reflect observation averages from the open lake. The numbers are paired based on sampling month and year. For example, $[1,25]$ represents the first cove and open lake sampling during December 2007; $[2,26]$ represents the second cove and open lake sampling during January 2008; and so forth, with $[24,48]$ representing the final cove and open lake sampling during April 2010. 


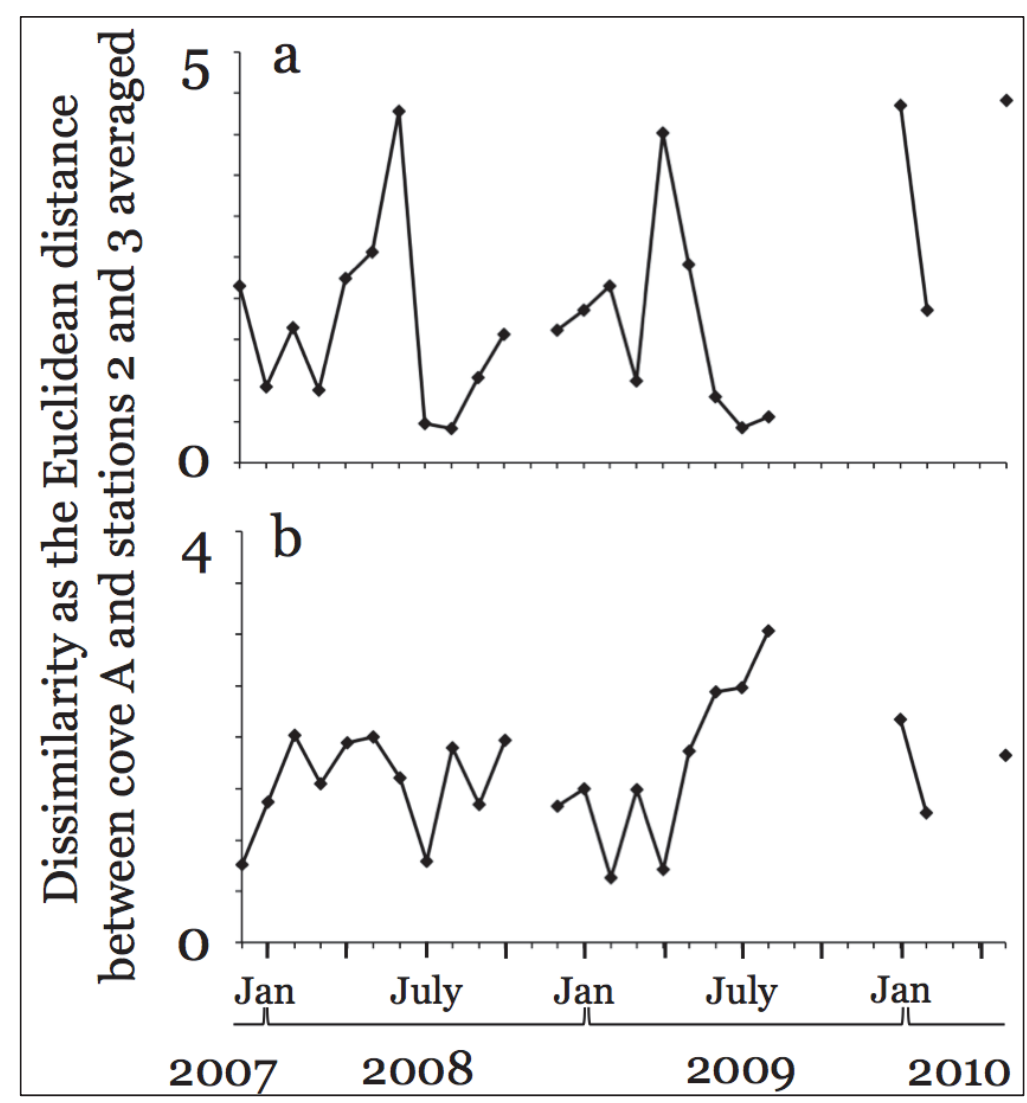

Figure $\mathrm{C} 12$. Time-series dissimilarity between biotic (a) and abiotic (b) parameters as estimated by the Euclidean distance for the comparison between average values for cove $\mathrm{F}$ and stations 4 and 5 . 


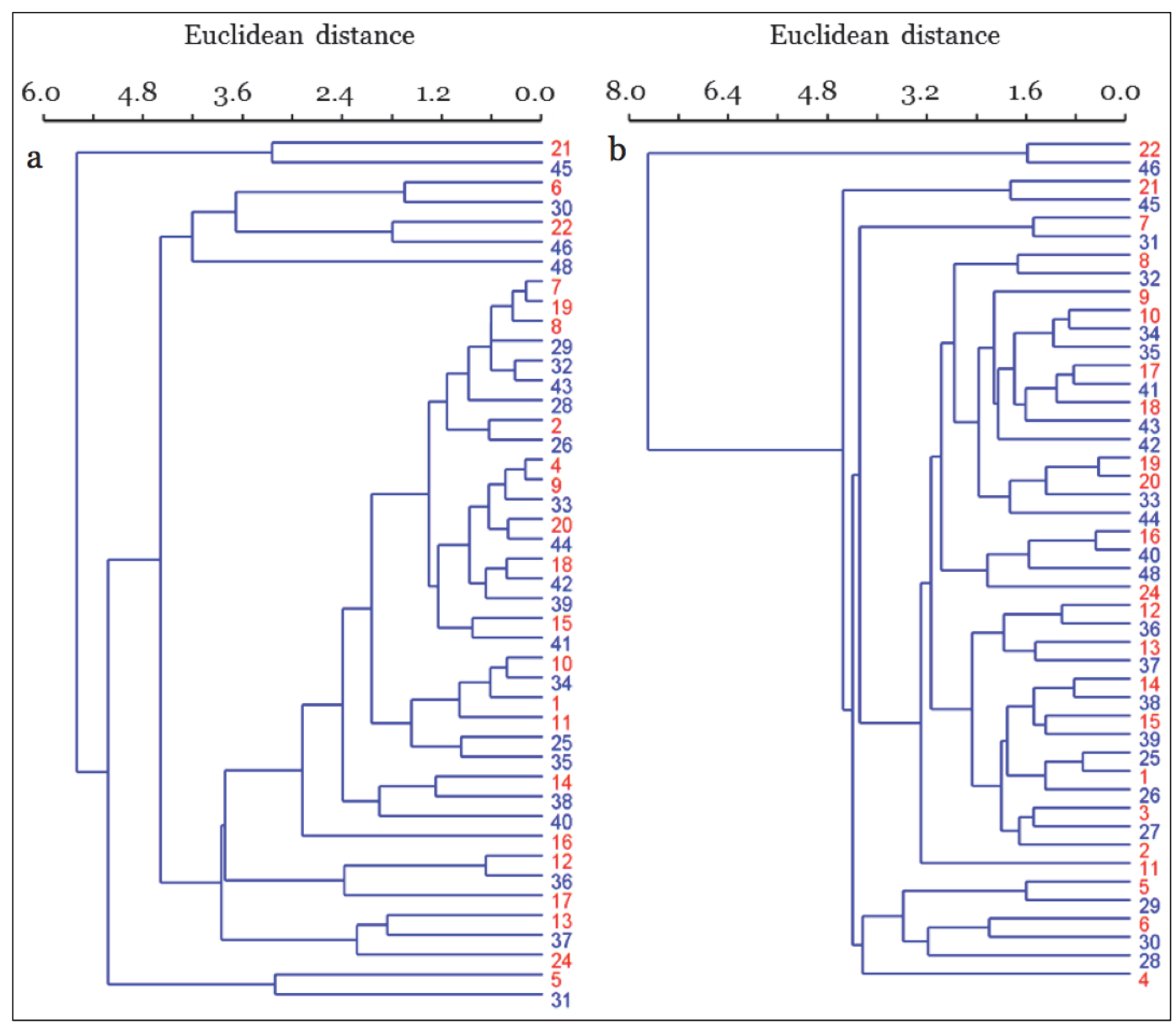

Figure $\mathrm{C} 13$. Dendrograms comparing biotic (a) and abiotic (b) parameters from cove $\mathrm{G}$ and the averaged data from stations 4 and 5 . Here, red numbers reflect observations from the cove and blue numbers reflect observation averages from the open lake. The numbers are paired based on sampling month and year. For example, [1,25] represents the first cove and open lake sampling during December 2007; $[2,26]$ represents the second cove and open lake sampling during January 2008; and so forth, with $[24,48]$ representing the final cove and open lake sampling during April 2010. 


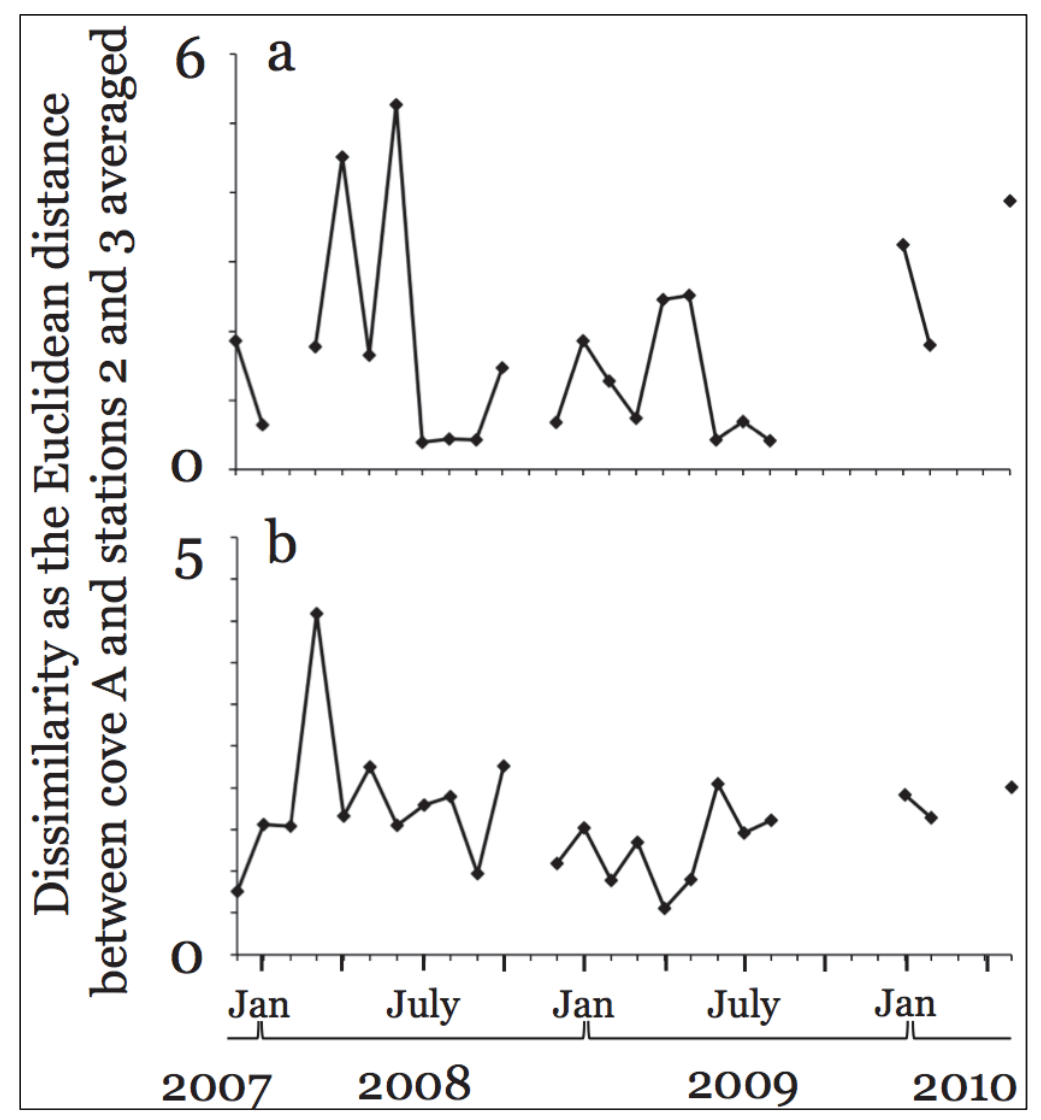

Figure $\mathrm{C} 14$. Time-series dissimilarity between biotic (a) and abiotic (b) parameters as estimated by the Euclidean distance for the comparison between average values for cove $\mathrm{G}$ and stations 4 and 5 . 


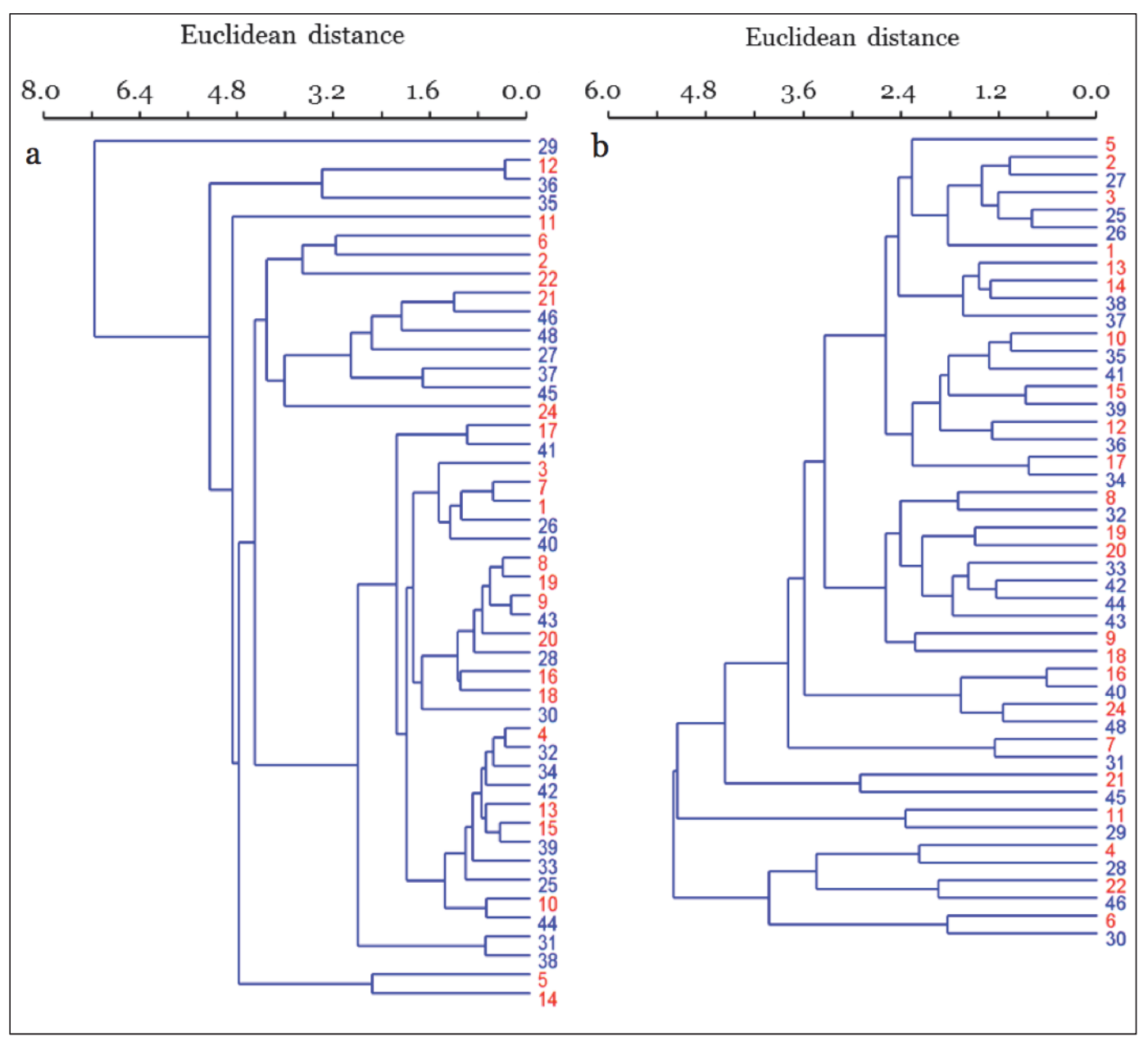

Figure C15. Dendrograms comparing biotic (a) and abiotic (b) parameters from cove $\mathrm{H}$ and the averaged data from stations 6 and 7 . Here, red numbers reflect observations from the cove and blue numbers reflect observation averages from the open lake. The numbers are paired based on sampling month and year. For example, [1,25] represents the first cove and open lake sampling during December 2007; $[2,26]$ represents the second cove and open lake sampling during January 2008 ; and so forth, with $[24,48]$ representing the final cove and open lake sampling during April 2010. 


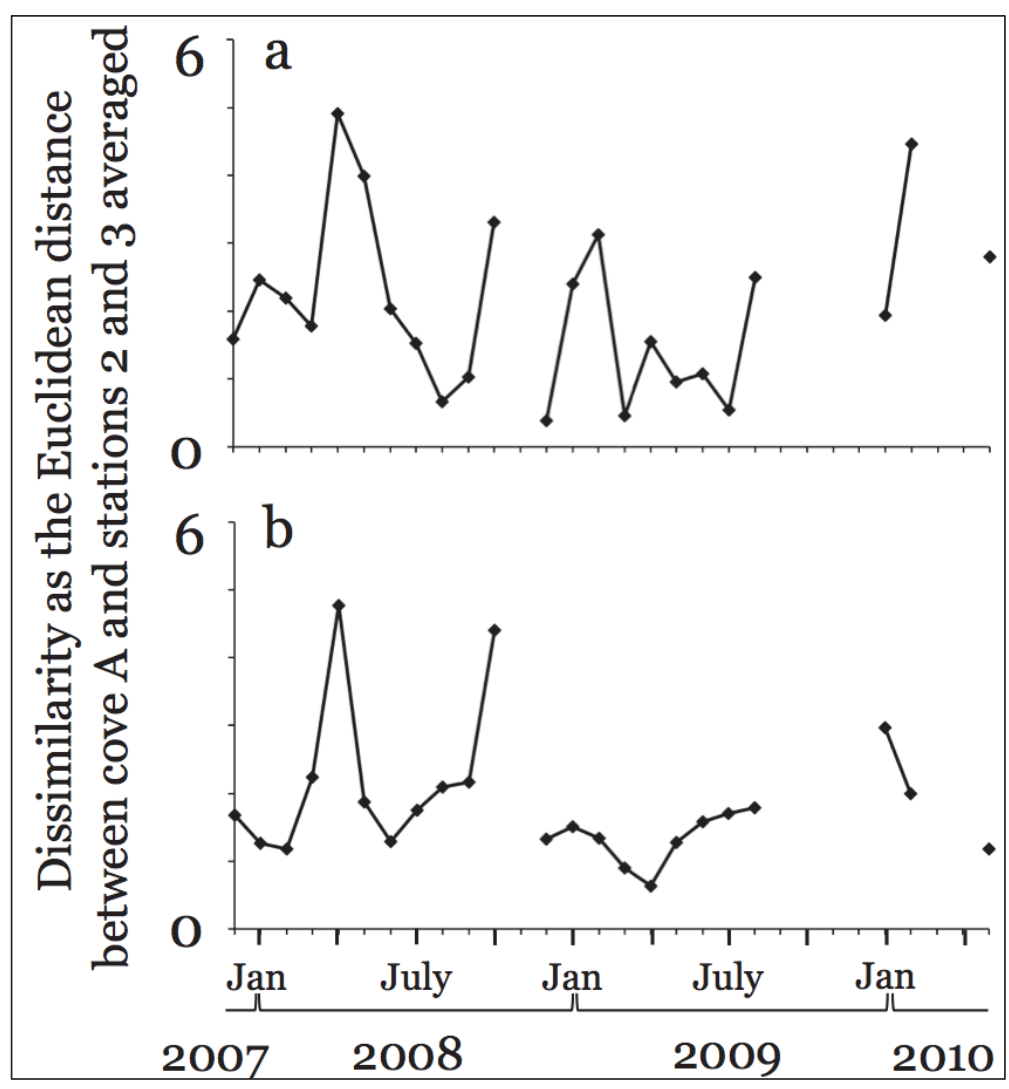

Figure C16. Time-series dissimilarity between biotic (a) and abiotic

(b) parameters as estimated by the Euclidean distance for the comparison between average values for cove $\mathrm{H}$ and stations 6 and 7 . 


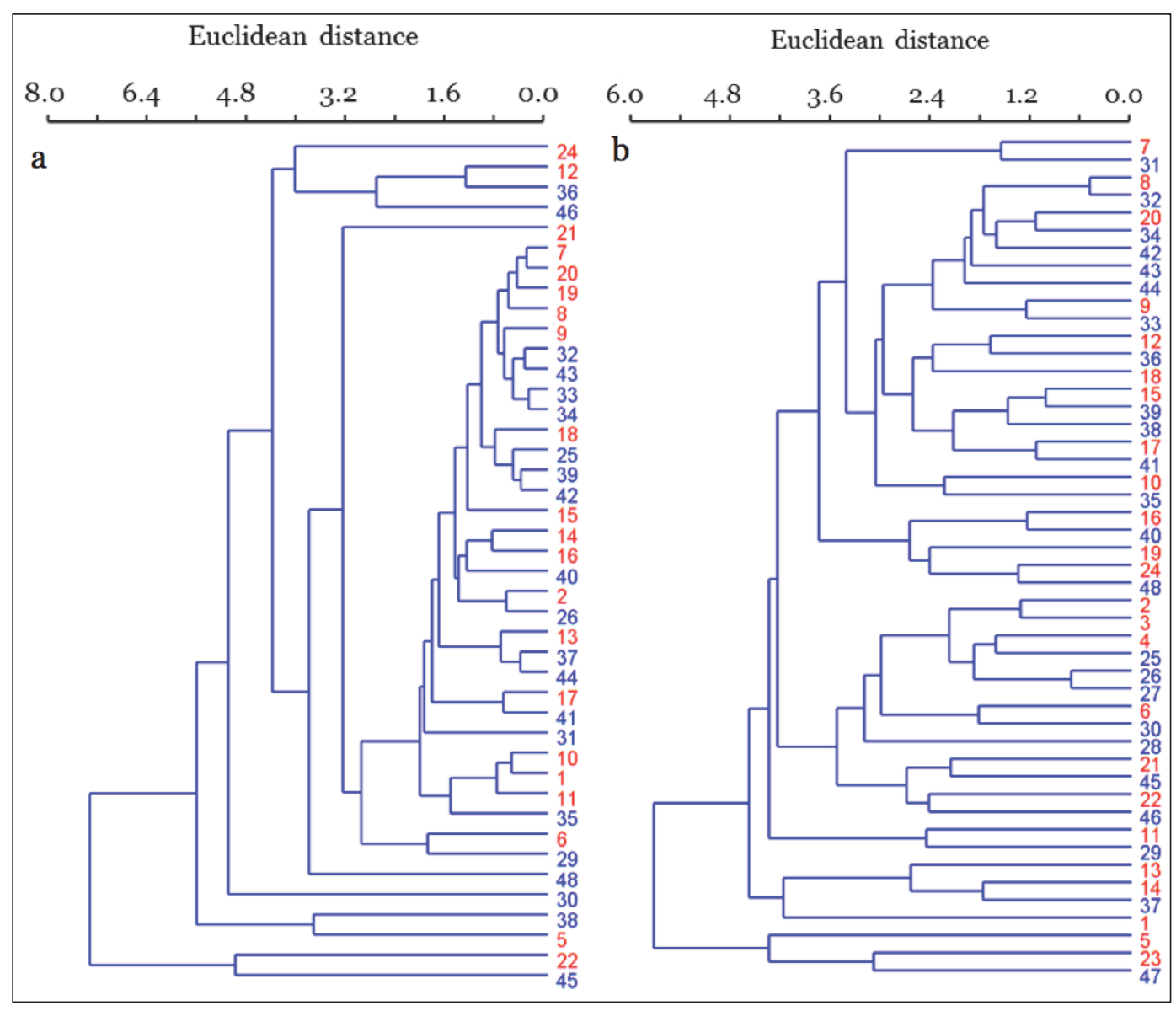

Figure C17. Dendrograms comparing biotic (a) and abiotic (b) parameters from cove I and the averaged data from stations 8 and 9 . Here, red numbers reflect observations from the cove and blue numbers reflect observation averages from the open lake. The numbers are paired based on sampling month and year. For example, $[1,25]$ represents the first cove and open lake sampling during December 2007; $[2,26]$ represents the second cove and open lake sampling during January 2008; and so forth, with $[24,48]$ representing the final cove and open lake sampling during April 2010. 


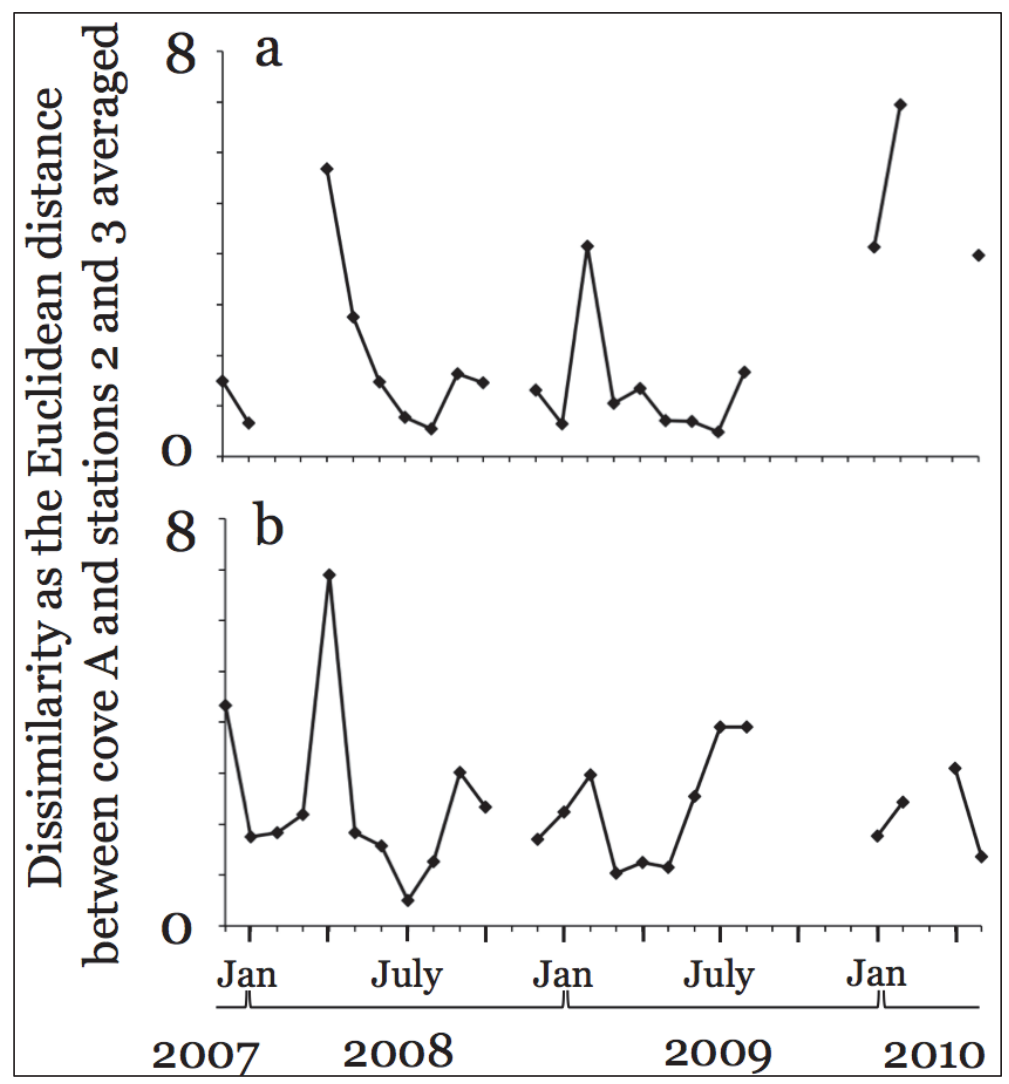

Figure C18. Time-series dissimilarity between biotic (a) and abiotic (b) parameters as estimated by the Euclidean distance for the comparison between average values for cove $\mathrm{I}$ and stations 8 and 9 . 


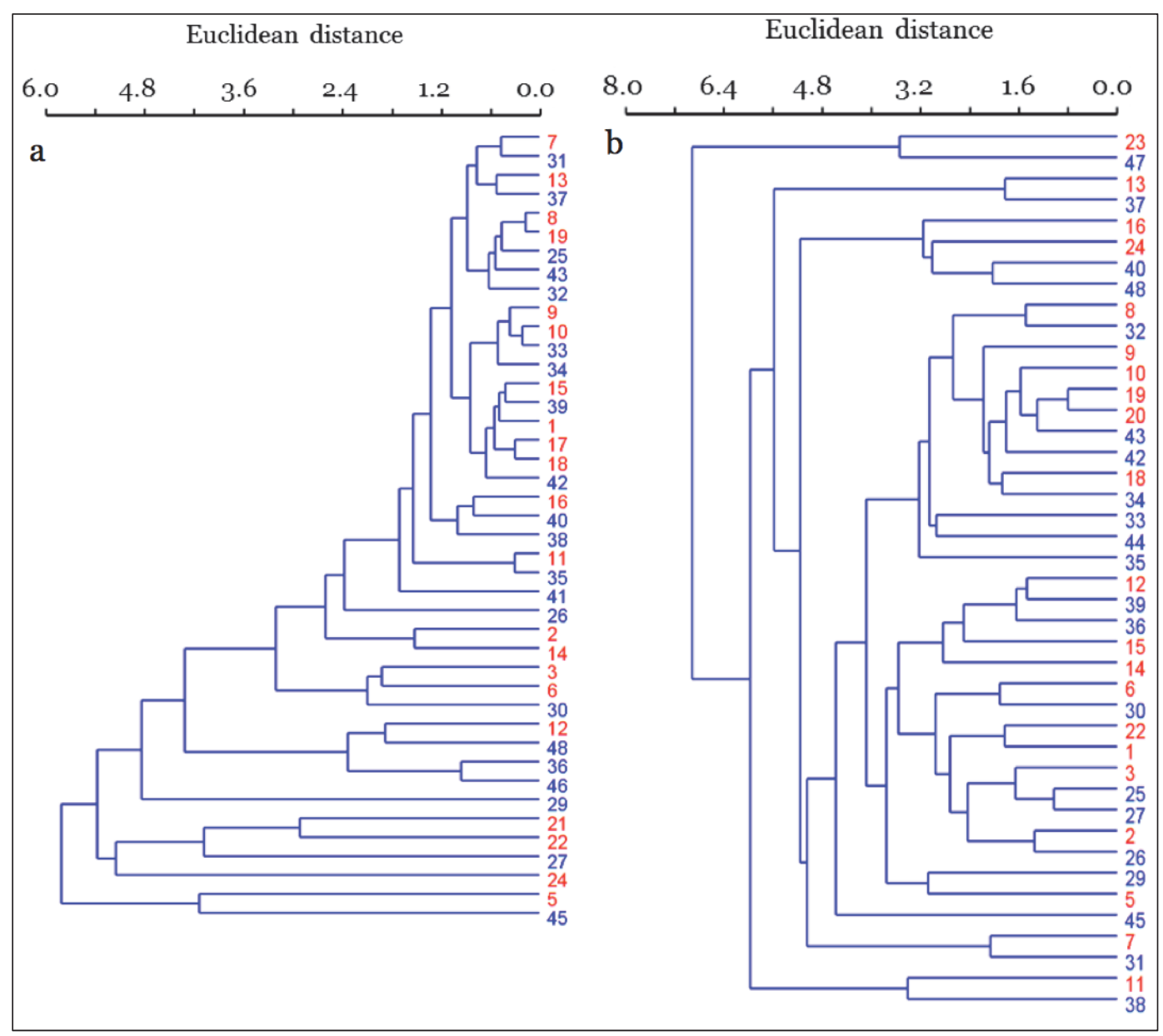

Figure C19. Dendrograms comparing biotic (a) and abiotic (b) parameters from cove $J$ and the data from station 10. Here, red numbers reflect observations from the cove and blue numbers reflect observation averages from the open lake. The numbers are paired based on sampling month and year. For example, $[1,25]$ represents the first cove and open lake sampling during December 2007; $[2,26]$ represents the second cove and open lake sampling during January 2008; and so forth, with $[24,48]$ representing the final cove and open lake sampling during April 2010. 


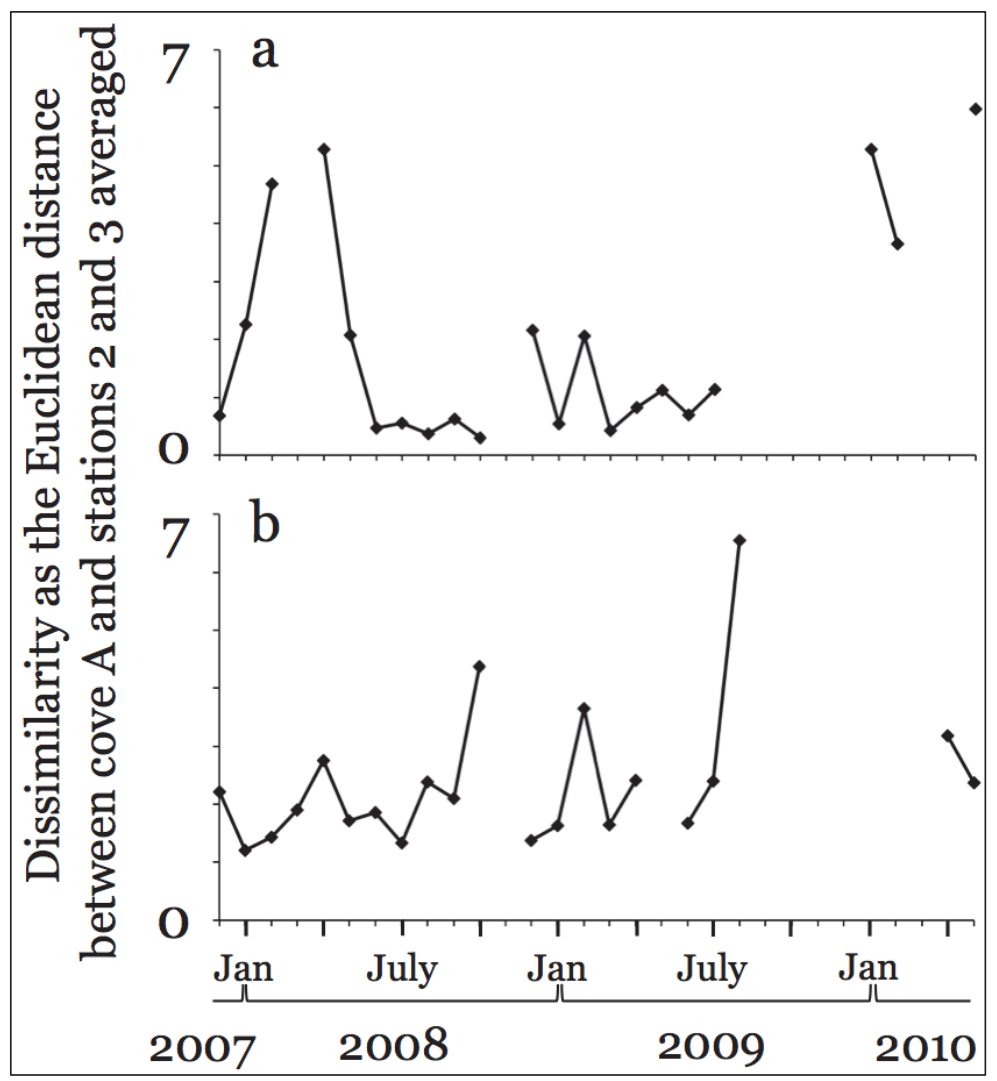

Figure C20. Time-series dissimilarity between biotic (a) and abiotic (b) parameters as estimated by the Euclidean distance for the comparison between cove J and station 10 . 


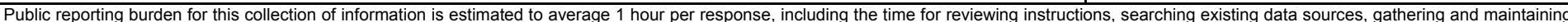

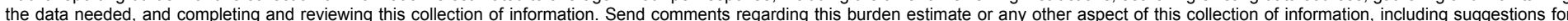

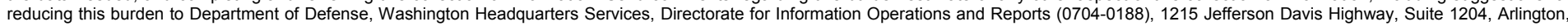

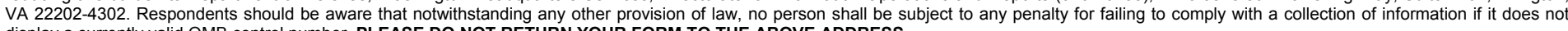
display a currently valid OMB control number. PLEASE DO NOT RETURN YOUR FORM TO THE ABOVE ADDRESS.
1. REPORT DATE (DD-MM-YYYY) 2. REPORT TYPE
3. DATES COVERED (From - To) April 2013 Final report

\section{TITLE AND SUBTITLE}

Golden Algae Control: Efficacy of Hydraulic Manipulations in Coves of Lake Granbury

5a. CONTRACT NUMBER

Golden Algae Control: Efficacy of Hydraulic Manipulations in Coves of Lake Granbury

\section{5b. GRANT NUMBER}

5c. PROGRAM ELEMENT NUMBER

\section{AUTHOR(S)}

Daniel L. Roelke, Bryan W. Brooks, James P. Grover, and Veronica M. Lundgren

5d. PROJECT NUMBER

5e. TASK NUMBER

5f. WORK UNIT NUMBER

\section{PERFORMING ORGANIZATION NAME(S) AND ADDRESS(ES)}

8. PERFORMING ORGANIZATION REPORT NUMBER

Texas A\&M University, Texas AgriLife Research, Department of Wildlife and Fisheries

Sciences, 2258 TAMUS, College Station, TX 77843

ERDC/EL CR-13-1

Baylor University, Center for Reservoir and Aquatic Systems Research, One Bear Place \#97266, Waco, TX 76798-7266

University of Texas at Arlington, Department of Biology, Box 19498, Arlington, TX 760190001

9. SPONSORING / MONITORING AGENCY NAME(S) AND ADDRESS(ES)

10. SPONSOR/MONITOR'S ACRONYM(S)

Headquarters, U.S. Army Corps of Engineers

Washington, DC 20314-1000

11. SPONSOR/MONITOR'S REPORT NUMBER(S)

\section{DISTRIBUTION / AVAILABILITY STATEMENT}

Approved for public release; distribution unlimited.

\section{SUPPLEMENTARY NOTES}

\section{ABSTRACT}

Bloom mitigation approaches employing deepwater flushing show great promise when targeting coves of Lake Granbury, USA. They may be limited, however, based on the natural water exchange rate between targeted coves and the surface waters of the open lake. This potential limitation was investigated by conducting dye-tracer studies that enabled direct measurement of water exchange rates. Historical data were also analyzed to explore the dissimilarity between coves and the open lake. Finally, a numerical model was built to estimate $P$. parvum bloom reduction levels under various deepwater flushing scenarios. Dye tracer studies involved time-series, high-resolution spatial mapping of Rhodamine WT in three target coves. To complement spatial mapping, vertical profiling was performed at fixed-location stations throughout these coves. These combined processes allowed researchers to calculate the total amount of Rhodamine WT over time in these coves.

(see reverse)

15. SUBJECT TERMS

Aquatic plant control

Bloom mitigation

16. SECURITY CLASSIFICATION OF:

\begin{tabular}{|l|l|l|}
\hline a. REPORT & b. ABSTRACT & c. THIS PAGE \\
UNCLASSIFIED & UNCLASSIFIED & UNCLASSIFIED \\
\hline
\end{tabular}

Deepwater flushing

Euclidean distance measures

Golden algae

Harmful algal blooms (HABs)

18. NUMBER
OF PAGES
108

Lake Granbury, Texas

Rhodamine WT

Water exchange rates OF ABSTRACT 19a. NAME OF RESPONSIBLE PERSON

19b. TELEPHONE NUMBER (include area code) 


\section{ABSTRACT (concluded)}

From this information, natural water exchange rates between coves and surface waters of the open lake could be determined, and were typically found to be in the range of $\sim 0.25-0.30 \mathrm{~d}^{-1}$. Analysis of historical data utilized an extensive data set comprised of biotic and abiotic parameters from 10 coves and 10 open lake stations. The data record spanned multiple years with a once-per-month sampling frequency. Dissimilarity relationships (estimated from Euclidean distance measures) between coves and the open lake with changes in winds and inflows to the lake were examined. It was found that water exchanges with coves located lower in the lake were linked to winds and inflows. Mechanisms driving water exchanges with coves higher in the lake, however, are still not clear. Proposed management scenarios were depicted with deepwaters being pumped from the open lake to the upper regions of coves. Results suggest that P. parvum blooms can effectively be mitigated in cove habitats of Lake Granbury through managed deepwater hydraulic flushing. In some scenarios, blooms were reduced by $>70 \%$. The next steps in research aimed at further developing this mitigation approach should be a coupled study involving model refinement and a valuation study. 